Article

\title{
Expression of the Reverse Transcriptase Domain of Telomerase Reverse Transcriptase Induces Lytic Cellular Response in DNA-Immunized Mice and Limits Tumorigenic and Metastatic Potential of Murine Adenocarcinoma 4T1 Cells
}

\author{
Juris Jansons ${ }^{1,2,+}$, Ekaterina Bayurova ${ }^{3,4,+}+\mathbb{C}_{\text {, Dace Skrastina }}^{2}$, Alisa Kurlanda ${ }^{1}$, \\ Ilze Fridrihsone ${ }^{1}$, Dmitry Kostyushev ${ }^{5}{ }^{\circ}$, Anastasia Kostyusheva ${ }^{5}$, Alexander Artyuhov ${ }^{6}$, \\ Erdem Dashinimaev ${ }^{6,7}$, Darya Avdoshina ${ }^{4} \mathbb{D}$, Alla Kondrashova ${ }^{4} \mathbb{C}^{\mathbb{O}}$, Vladimir Valuev-Elliston ${ }^{8}$, \\ Oleg Latyshev ${ }^{3}$, Olesja Eliseeva ${ }^{3}\left(\mathbb{D}\right.$, Stefan Petkov ${ }^{9}$, Maxim Abakumov ${ }^{3,10,11}\left(\mathbb{D}\right.$, Laura Hippe ${ }^{1}(\mathbb{D}$, \\ Irina Kholodnyuk ${ }^{1}{ }^{\mathbb{D}}$, Elizaveta Starodubova ${ }^{8}$, Tatiana Gorodnicheva ${ }^{12}$, Alexander Ivanov ${ }^{3,8} \mathbb{D}^{\mathbb{B}}$, \\ Ilya Gordeychuk ${ }^{3,4,13}$ (D) and Maria Isaguliants $1,3,4,9, *$ (D) \\ 1 Department of Research, and Department of Pathology, Pathology, Rīga Stradinš University, LV-1007 Riga, \\ Latvia; juris.jansons@rsu.lv (J.J.); alisa.kurlanda@rsu.lv (A.K.); ilze.fridrihsone@rsu.lv (I.F.); \\ laura.hippe@rsu.lv (L.H.); irina.holodnuka@rsu.lv (I.K.) \\ 2 Latvian Biomedical Research and Study Centre, LV-1067 Riga, Latvia; daceskr@biomed.lu.lv \\ 3 N.F. Gamaleya National Research Center for Epidemiology and Microbiology, Moscow 127994, Russia; \\ 79153645941@ya.ru (E.B.); oleglat80@mail.ru (O.L.); olesenka80@mail.ru (O.E.); \\ abakumov1988@gmail.com (M.A.); aivanov@yandex.ru (A.I.); lab.gord@gmail.com (I.G.) \\ 4 Chumakov Federal Scientific Center for Research and Development of Immune-and-Biological Products of \\ Russian Academy of Sciences, Moscow 127994, Russia; darya_avdoshina@mail.ru (D.A.); \\ varyaw96@gmail.com (A.K.) \\ 5 National Medical Research Center of Tuberculosis and Infectious Diseases, Ministry of Health, \\ Moscow 127994, Russia; dkostushev@gmail.com (D.K.); kostyusheva_ap@mail.ru (A.K.) \\ 6 Center for Precision Genome Editing and Genetic Technologies, Pirogov Russian National Research Medical \\ University, Moscow 127994, Russia; alexanderartyuhov@gmail.com (A.A.); dashinimaev@gmail.com (E.D.) \\ 7 Koltzov Institute of Developmental Biology of Russian Academy of Sciences, Moscow 127994, Russia \\ 8 Engelhardt Institute of Molecular Biology, Russian Academy of Sciences, Moscow 127994, Russia; \\ gansfaust@mail.ru (V.V.-E.); estarodubova@yandex.ru (E.S.) \\ 9 Department of Microbiology, Tumor and Cell Biology, Karolinska Institutet, 17177 Stockholm, Sweden; \\ Stefan.petkov@ki.se \\ 10 Laboratory of Biomedical Nanomaterials, National University of Science and Technology MISIS, \\ Moscow 127994, Russia \\ 11 Department of Medical Nanobiotechnologies, Pirogov Russian National Research Medical University, \\ Moscow 127994, Russia \\ 12 Evrogen, Moscow 127994, Russia; tatiana.gorod@evrogen.ru \\ 13 Institute for Translational Medicine and Biotechnology, Sechenov First Moscow State Medical University, \\ Moscow 127994, Russia \\ * Correspondence: maria.issagouliantis@rsu.lv \\ + These authors contributed equally to this work.
}

Received: 27 May 2020; Accepted: 15 June 2020; Published: 18 June 2020

check for updates

\begin{abstract}
Telomerase reverse transcriptase (TERT) is a classic tumor-associated antigen overexpressed in majority of tumors. Several TERT-based cancer vaccines are currently in clinical trials, but immune correlates of their antitumor activity remain largely unknown. Here, we characterized fine specificity and lytic potential of immune response against rat TERT in mice. BALB/c mice were primed with plasmids encoding expression-optimized hemagglutinin-tagged or nontagged TERT or empty vector and boosted with same DNA mixed with plasmid encoding firefly luciferase (Luc DNA).
\end{abstract}


Injections were followed by electroporation. Photon emission from booster sites was assessed by in vivo bioluminescent imaging. Two weeks post boost, mice were sacrificed and assessed for IFN- $\gamma$, interleukin-2 (IL-2), and tumor necrosis factor alpha (TNF- $\alpha$ ) production by T-cells upon their stimulation with TERT peptides and for anti-TERT antibodies. All TERT DNA-immunized mice developed cellular and antibody response against epitopes at the N-terminus and reverse transcriptase domain (rtTERT) of TERT. Photon emission from mice boosted with TERT/TERT-HA+Luc DNA was 100 times lower than from vector+Luc DNA-boosted controls. Bioluminescence loss correlated with percent of IFN- $\gamma / \mathrm{IL}-2 / \mathrm{TNF}-\alpha$ producing CD8+ and CD4+ T-cells specific to rtTERT, indicating immune clearance of TERT/Luc-coexpressing cells. We made murine adenocarcinoma 4T1luc2 cells to express rtTERT by lentiviral transduction. Expression of rtTERT significantly reduced the capacity of 4T1luc2 to form tumors and metastasize in mice, while not affecting in vitro growth. Mice which rejected the tumors developed T-cell response against rtTERT and low/no response to the autoepitope of TERT. This advances rtTERT as key component of TERT-based therapeutic vaccines against cancer.

Keywords: therapeutic cancer vaccines; telomerase reverse transcriptase (TERT); reverse transcriptase domain; intradermal DNA immunization; electroporation; epitopes; CD4+ and CD8+ lytic T cell response; antibodies; murine adenocarcinoma cells; lentiviral transduction; tumor growth; suppression; rejection; metastasis

\section{Introduction}

Cancer immunotherapies fall in two major categories: passive that includes blockade of immune checkpoints and adoptive immunotherapy and active that includes therapeutic vaccination and immuno/chemotherapy combinations [1]. Multiple tumor-associated antigens (TAAs) expressed by cancer cells have been identified as targets of functional anticancer T-cell response and tested as immunogens for active cancer immunotherapy [2,3]. Active immunotherapies based on TAAs presented by the patient autologous tumor cells or dendritic cells (DCs) as well as chimeric antigen receptor $\mathrm{T}$ cell immunotherapy (CAR-T) are effective, specifically if combined with surgery and radioand/or chemotherapy [4-6]. However, design and preparation of such vaccines as well as treatments are individualized, which implies extra time and extra costs. Straightforward active tumor immunotherapy implying immunization with TAA-based vaccines is still underdeveloped. Classic vaccination with recombinant antigens or peptides as monotherapy gives little clinical benefit [1,7]. Genetic vaccines show better clinical efficacy [8,9], also in veterinary [10,11] and translational oncology [12]. Potency of DNA immunization was demonstrated in a variety of clinical applications $[13,14]$. The first successful therapeutic DNA vaccine reported to cause recession of cervical neoplasia based on the consensus tumor antigens of HPV16 [15] is currently in two Phase III clinical trials (NCT03185013 and NCT03721978). Development of other candidate cancer DNA vaccines based on endogenous and viral antigens is in progress [16].

Telomerase reverse transcriptase (TERT) is a classic TAA overexpressed in majority of tumors [17]. The telomerase enzyme catalyzes de novo synthesis of telomere repeats, maintaining telomere length required for unlimited cell proliferation. Human telomere synthesis occurs early in development $[18,19]$. The majority of adult somatic cells do not have appreciable telomerase activity and telomeres gradually shorten, limiting cell division capacity [20]. In the majority of human cancers, however, telomerase is reactivated and supports the sustained proliferative capacity of these cells [21]. This reactivation could be induced by DNA damage [22] and/or deregulated expression of the MYC oncoprotein [23]. Catalytic component of telomerase-telomerase reverse transcriptase (TERT) is the rate-limiting factor for telomerase activity; it is expressed in virtually all tumors [17]. Degraded fragments of TERT expressed on the surface of tumor cells are recognized by the immune system and induce cellular immune response resulting in a partial control of tumor growth [24]. Overexpressed in tumors and immunogenic in 
subjects controlling tumor growth, TERT presents as an attractive target of therapeutic cancer vaccines. In addition, TERT is highly conserved, also in tumors, with cancer-associated mutations occurring mainly in the promoter region [25], which opens a possibility to make this vaccine basically universal. In vivo studies have revealed both safety and curative potential of TERT-based immunotherapy, which does not harm healthy cells [26,27]. First clinical trials of DNA vaccine based on TERT applied in cancer patients reported it to be safe, well tolerated, and immunogenic [28,29], immunization resulting in disease stabilization in $58 \%$ of patients with relapsed or refractory cancers [28]. Despite this promising progress, the panel of TERT-based vaccine candidates is still limited, and clinical trials are few (NCT04280848; NCT00510133; NCT00753415, NCT00961844, NCT01153113, NCT01935154, NCT02293707, NCT02960594, NCT03265717, and NCT03502785; and NCT03491683 and NCT03946358). This motivates intensive efforts to create a wider panel of efficacious TERT-based tumor vaccines as well as delineate the immune mechanism(s) underlying their efficacy.

Here, we have designed a new variant of cancer vaccine against TERT, an expression-optimized DNA encoding rat TERT. Our experiments demonstrated that intradermal injection of TERT DNA into mice followed by electroporation induces an effector response of CD8+ and CD4+ T cells against multiple epitopes, specifically in the reverse transcriptase (RT) domain of TERT (rtTERT). Expression of this domain by murine adenocarcinoma cells drastically reduced their capacity to form tumors and generate metastasis. Mice with restricted growth of rtTERT-expressing tumor cells exhibited CD4+ and CD8+ T cell response against epitopes of rtTERT that are recognized by DNA-immunized mice. We also mapped autoepitopes of TERT lying outside rtTERT and demonstrated that T-helper cell response against such epitopes promotes tumor growth. This points at RT domain as the necessary and sufficient as well as safe component of therapeutic cancer vaccines based on TERT.

\section{Materials and Methods}

\subsection{Plasmids}

The amino acid sequence of rat TERT was taken from UniProtKB database (accession number Q673L6). Two variants of rat TERT gene were used in the study, one-encoding the native protein (TERT) and second-recombinant construct with hemagglutinin (HA) tag at the C-terminus (TERT-HA). TERT and TERT-HA proteins were encoded by synthetic genes optimized for expression in mammalian cells (GenBank submissions MK749423 and MK749424). To increase protein expression, coding sequences were supplied with the Kozak sequence AAT-ATG-GGA at the $5^{\prime}$-end resulting in Met-Gly at the protein $\mathrm{N}$-terminus. TERT-encoding sequences were cloned into the eukaryotic expression vector pVAX1 (Invitrogen, Waltham, MA, USA) generating two plasmids-pVax-TERT and pVax-TERT-HA. Nucleotide sequence encoding RT domain of rat TERT (rtTERT) was amplified using primers 5'-AGGAATAACATATGGGAGTGAA-3' and 5'-AATGGATCCTTACAAGCCACACCAGGGAAAC-3' and cloned into prokaryotic expression vector $\mathrm{pET} 15 \mathrm{~b}$ using NdeI and BamHI sites, generating plasmid pET15rtTERT. To follow gene expression after DNA immunization, we used the plasmid encoding firefly luciferase pVaxLuc2 (kind gift of A.K. Roos, Karolinska Institutet, Stockholm, Sweden). Plasmids were produced in E. coli and purified using Plasmid EndoFree Kits (Qiagen, Hilden, Germany) as recommended by the manufacturer.

\subsection{Peptides and Recombinant Proteins Used for Immunoassays}

TERT-derived peptides used in the assays of cellular and antibody immunogenicity are listed in Table 1. Peptides (SynPep Ltd., Shanghai, China) were purified by HPLC to 70\% purity; their structure was confirmed by mass spectrometry. 
Table 1. Synthetic peptides used in assays of cellular and antibody responses induced by DNA immunization with rat telomerase reverse transcriptase (TERT).

\begin{tabular}{|c|c|c|c|c|c|c|c|c|}
\hline Name & Amino Acid (aa) Sequence & $\begin{array}{l}\text { Position in Rat } \\
\text { TERT, 1st and } \\
\text { Last aa Residue }\end{array}$ & $\begin{array}{l}\text { Identity to Mouse } \\
\text { TERT, Common } \\
\text { aa/Total aa }(\%)\end{array}$ & $\begin{array}{l}\text { Identity to Human } \\
\text { TERT, Unique } \\
\text { aa/Total aa (\%) }\end{array}$ & $\begin{array}{l}\text { Class I Score } \\
\text { for H2 Db Mice } \\
\text { (IEDB) }\end{array}$ & $\begin{array}{l}\text { Class I Score } \\
\text { for H2 Dd Mice } \\
\text { (IEDB) }\end{array}$ & $\begin{array}{l}\text { The Highest } \\
\text { Class II Scores } \\
\text { (IEDB) }\end{array}$ & $\begin{array}{l}\text { T Cell Epitopes } \\
\text { Localized in } \\
\text { the Region }\end{array}$ \\
\hline TERT 1 & PPSLTGARRLVEIIFLGSRPRTSGPFC & $356-382$ & $24 / 27(89)$ & $19 / 27(70)$ & 0.47 & 0.58 & $1.28-1.33$ & {$[30,31]$} \\
\hline TERT 2 & ILAMFLFWLMDTYVVQLLRSFFYITETT & $530-558$ & $26 / 28(93)$ & $22 / 28(79)$ & 0.3727 & 0.349 & $6.48-9.01$ & {$[30,32-36]$} \\
\hline TERT 3 & QKNRLFFYRKSVWSKLQSIGIRQQL & $559-584$ & $24 / 25(96)$ & $24 / 25(96)$ & -0.185 & -0.268 & $2.65-7.13$ & {$[30,34-38]$} \\
\hline TERT 4 & DTWLAMPICRLRFIPK & $600-616$ & $16 / 16(100)$ & $7 / 16(44)$ & 0.31 & 0.19 & 9.44 & {$[32,39]$} \\
\hline TERT 5 & SLLHFFLRFVRHSVVKIDGRFYVQ & $791-815$ & $16 / 24(67)$ & $12 / 24(50)$ & 0.379 & 0.4973 & 9.4 & {$[30,36]$} \\
\hline TERT 6 & QQDGLLLRFVDDFLLVTPHL & $845-865$ & $19 / 20(95)$ & $17 / 20(85)$ & 0.32 & 0.438 & $>10$ & [33-35] \\
\hline TERT 7 & KTVVNFPVETGALGGAAPHQLPAHCLFPW & $888-917$ & $26 / 29(90)$ & $22 / 29(76)$ & 0.2196 & 0.5080 & $7.75-10.73$ & {$[30,31,37]$} \\
\hline TERT 8 & LGGAAPHQLPAHCLFPWCGLLLDTRTLE & $901-929$ & $26 / 28(93)$ & $23 / 28(82)$ & 0.355 & 0.333 & 11.25 & {$[30,31,33,37]$} \\
\hline TERT 9 & FLDLQVNSLQTVCINIYKIFLLQAYRFHACVI & 973-1001 & $32 / 32(100)$ & $29 / 32(90)$ & 0.176 & 0.1579 & $7.81-10.77$ & {$[30,31,33-36,38]$} \\
\hline
\end{tabular}


Anti-TERT antibody ELISA was performed using recombinant His-tagged rtTERT produced in E. coli. For this, E. coli Rosetta (DE3) strain (Novagen, Darmstadt, Germany) harboring extra copies of tRNAs, rarely used in E coli, were transformed with pET15rtTERT. Recombinant rtTERT was expressed as described previously for hepatitis C virus NS5A [40]. Protein purification was performed in the denaturing conditions by affinity chromatography on Ni-NTA-agarose (Novagen); buffers were supplemented with Protease Inhibitor Cocktail for use in purification of His-tagged proteins as recommended by the manufacturer (Sigma, Darmstadt, Germany). Fraction containing the protein with molecular mass corresponding to rtTERT was identified after analysis of fractions on $12 \%$ SDS-PAGE followed by Coomassie R250 staining. The protein was renatured by dialysis in three steps: initially, against buffer A (20 mM Tris- $\mathrm{HCl}, \mathrm{pH} 7.5,500 \mathrm{mM} \mathrm{NaCl}, 4 \mathrm{M}$ urea, and 10\% glycerol), then against buffer A $(100 \mathrm{~mL})$ to which $500 \mathrm{~mL}$ buffer B $(20 \mathrm{mM}$ Tris-HCl, pH 7.5, $1 \mathrm{M} \mathrm{NaCl}$ and $10 \%$ glycerol) was slowly added, and finally, against buffer C (20 mM Tris- $\mathrm{HCl}, \mathrm{pH} 7.5,500 \mathrm{mM} \mathrm{NaCl}$, and $50 \%$ glycerol). Purified rtTERT was aliquoted and stored at $-20{ }^{\circ} \mathrm{C}$.

\subsection{Transient Expression of TERT in Mammalian Cells}

Briefly, 293T cells were cultivated in high-glucose DMEM (PanEco, Moscow, Russia) supplemented with 10\% fetal bovine serum (FBS)(HyClone, GE Healthcare, Chicago, IL, USA) and penicillin/streptomycin (both from HyClone). Cells were transfected with plasmids pVAX1, pVax-TERT, or pVax-TERT-HA using Lipofectamine LTX (Invitrogen, Waltham, MA, USA) according to the manufacturer's instructions. Two days later, cells were harvested, lysed, and subjected to electrophoreses in 10\% PAAG followed by Western blot using protocols described previously [41]. Blots were stained with polyclonal rabbit antibodies against synthetic peptide derived from TERT (Ab191523, Abcam, Cambridge, UK) diluted 1:1000, stripped, and then, re-stained with monoclonal anti-actin antibodies (Sigma-Aldrich, St. Louis, MO, USA) diluted 1:5000.

\subsection{Generation of 4T1luc2 Derivatives Expressing rtTERT by Lentiviral Transduction}

Derivatives of murine mammary gland adenocarcinoma cells expressing firefly luciferase 4T1luc2 ("Bioware Ultra Cell Line 4T1luc2," Caliper, Hopkinton, MA, USA; http://www.caliperls.com/assets/ 014/7158.pdf) were generated as described previously [42]. In brief, coding sequence for rtTERT was recloned from pET15rtTERT into lentiviral vector pRRLSIN.cPPT.PGK (Addgene plasmid \#12252; a gift from D. Trono) under the control of the human phosphoglycerate kinase (PGK) promoter, generating lentiviral vector pLVrtTERT (Supplementary Figure S1). Lentiviral particles were produced by transient transfection of 293T cells as described elsewhere [43] and concentrated 10-fold with Amicon Ultra-15 $100 \mathrm{~K}$ centrifuge concentrators (Merck-Millipore, Darmstadt, Germany). Infectious titers of the lentiviral particles were determined in HT1080 cells by quantitative real-time PCR [43] using standard samples of HT-1080 DNA with a known number of viral genome copies. Transduction of 4T1luc2 cells was performed with the multiplicity of lentiviral infection of 5 and 180 transducing units per cell. Monoclonal populations of 4T1luc2 derivative clones were generated by limiting dilution in 96-well plates. Resulting 4T1luc2 derivatives were cultured in the full RPMI-1640 medium with $10 \% \mathrm{FBS}$ and $100 \mathrm{mg} / \mathrm{mL}$ penicillin/streptomycin mix at $37{ }^{\circ} \mathrm{C}$ with $5 \% \mathrm{CO}_{2}$ and split every $2-3$ days. Doubling time of derivative clones was estimated as described previously [42]. Presence of inserts of rtTERT DNA was confirmed by PCR and sequencing. Clones were characterized by the number of inserts of rtTERT DNA in the genome of 4 Tluc2 cells determined by ddPCR (see below).

\subsection{Extraction of Nucleic Acids and Analysis of Genomic rtTERT Inserts in 4T1luc2 Daughter Clones}

Cell culture medium was discarded and cells were detached using 0.25\% trypsin with EDTA before purification with MagNA Pure Compact Nucleic Acid Isolation Kit I-Large Volume (Roche, Basel, Switzerland) using MagNA Pure Compact Instrument (Roche, Basel, Switzerland) according to the manufacturer's instructions. DNA concentration was determined using Quant-IT ${ }^{\mathrm{TM}}$ PicoGreen $^{\mathrm{TM}}$

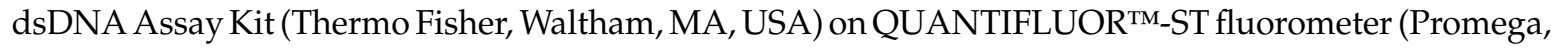


Madison, WI, USA). Presence of inserts encoding rtTERT in the genome of derivative clones was verified by PCR with specific primers (Supplementary Table S1). Analysis was performed directly after DNA purification.

Copy number of $r t T E R T$ loci with respect to invariant reference loci Mstn and Actb was estimated using digital droplet PCR (ddPCR). Copy number of $r t T E R T$ inserts was calculated as the number of detected $r t T E R T$ loci in DNA sample, divided by the number of Mstn and Actb loci and multiplied by 2 (number of Mstn and Actb copies). Reaction mixes were prepared using ddPCR EvaGreen Supermix (Bio-Rad, Hercules, CA, USA) using $10 \mathrm{ng}$ of genomic DNA and $250 \mathrm{nM}$ of primers (Supplementary Table S1) per reaction. Droplets were generated using automated Droplet Generator (Bio-Rad). Thermocycling was performed on C1000 Touch Thermal Cycler (Bio-Rad), thermal cycling protocol is presented in Supplementary Table S2. Data were collected using QX200 Droplet Reader (Bio-Rad) and analyzed using QuantaSoft software version 1.7.4.0917 (Bio-Rad). Results of primer validation are presented in Supplementary Figure S2A-C. Two clearly distinguishable clusters of positive and negative droplets were observed for $A c t b, M s t n$, and $r t T E R T$ (Supplementary Figure S2A-C, respectively). No significant amplification was observed for any primer pair in the absence of the template (Supplementary Figure S2A-C).

\subsection{Reverse Transcription and Analysis of rtTERT mRNA Expression by Semiquantitative PCR}

Nucleic acids extracted and purified as described above were reverse transcribed using MMLV reverse transcription kit (Evrogen, Moscow, Russia). Gene-specific PCRs were performed on Applied Biosystems QuantStudio 5 cycler (Thermo Fisher) with SYBR Green Kit (Evrogen) using primers specific to $r$ TERT and presented relative to levels of mRNA of HPRT1. Respective primer sequences are presented in Supplementary Table S1. Relative gene expression levels were calculated using ddCt method [44].

\subsection{Analysis of Expression of Endogenous TERT in 4 T1luc2 Clones by Immunofluorescent Microscopy}

Parental 4T1luc2 cells and daughter clones were assessed for expression of endogenous TERT by immunofluorescence using commercial rabbit anti-TERT antibodies Ab191523 (Abcam). Peptide used to generate Ab191523 localizes outside of rtTERT, hence the antibodies do not recognize the rtTERT domain of rat TERT. Staining was performed as follows. Briefly, 4T1luc2 and derivate clones were seeded on glass coverslips and fixed in $4 \%$ paraformaldehyde for $10 \mathrm{~min}$. Next, coverslips were washed 3 times in Tris- $\mathrm{HCl}(50 \mathrm{mM}, \mathrm{pH} 7.8)$, incubated for $30 \mathrm{~min}$ with blocking buffer ( $50 \mathrm{mM}$ Tris-HCl, $\mathrm{pH} 7.8$, $0.02 \%$ of Triton $\mathrm{X}-100,10 \%$ horse sera, and $150 \mathrm{mM} \mathrm{NaCl}$ ), and incubated with primary antibodies (1:50) for $1 \mathrm{~h}$ at $20^{\circ} \mathrm{C}$. Cells were washed 3 times for $5 \mathrm{~min}$ in washing buffer ( $50 \mathrm{mM}$ Tris-HCl, $\mathrm{pH} 7.8$, $0.02 \%$ of Triton X-100 and $200 \mathrm{mM} \mathrm{NaCl}$ ) and then, incubated with secondary Alexa Fluor 488 goat antirabbit IgG antibodies (ab150077, Abcam; 1:350) supplemented with Hoechst 33,342 to visualize the nuclei $\left(1 / 10,000\right.$; Abcam) for $1 \mathrm{~h}$ at $20^{\circ} \mathrm{C}$. Coverslips were washed 3 times for $5 \mathrm{~min}$ in washing buffer and mounted with Fluoroshield Mounting Medium (Abcam). Images were captured using a Leica DMI6000 microscope with 100× immersion objective and analyzed using ImageJ software (http://rsb.info.nih.gov/ij). Corrected total cell fluorescence (CTCF) was calculated according to $\mathrm{M}$. Fitzpatrick's protocol (https://theolb.readthedocs.io/en/latest/imaging/measuring-cell-fluorescenceusing-imagej.html) as CTCF $=$ Integrated density $-($ area of selected cell $\times$ background fluorescent signal). The research was done using equipment of the Core Centrum of Institute of Developmental Biology (Russian Academy of Sciences, Moscow, Russia).

\subsection{Assessment of Genetic Stability of 4T1luc2 Clones}

To assess genetic stability of rtTERT-expressing 4T1luc2 clones, cells were stained for $\gamma-\mathrm{H} 2 \mathrm{AX}$ foci with anti- $\gamma-\mathrm{H} 2 \mathrm{AX}$ mouse monoclonal antibodies Ab26350 (Abcam) as described previously [45] using secondary Alexa Fluor 594 goat anti-mouse antibodies (ab150116, Abcam) mixed with Hoechst 
33,342 for nuclear staining. Images were captured and analyzed as described above for the analysis of expression of endogenous TERT.

\subsection{Cell Cycle Analysis of $4 T 11 u c 2$ Clones}

At harvest, live cells were washed twice in PBS and incubated with $20 \mu \mathrm{M}$ DRAQ5 (ab108410, Abcam) for $10 \mathrm{~min}$ at $37^{\circ} \mathrm{C}$. Samples were kept in the dark and analyzed on the BD FACSCanto II cytometer (BD Biosciences, Franklin Lakes, NJ, USA). A total of 100,000 cells per sample were used for the analysis. All samples were analyzed in independent triplicates. Live (gate P1) and single (gate P2) cells were gated in NovoExpress Software (ACEA Biosciences, Inc, San Diego, CA, USA) (Supplementary Figure S3). DRAQ5-stained cells were analyzed at the APC channel. Distribution of cells in SubG1, G1/G0, S, G2/M and SuperG2 areas was assessed using Watson pragmatic algorithm [46] in the NovoExpress software. In control groups, peak G1 was determined manually according to the manufacturer's recommendations, peak G2 was set at $\times 1.75$ of G1 peak (Supplementary Figure S4). Further analysis was performed automatically with pre-set G1 and G2 peaks and coefficients of variation $(\mathrm{CV})$ at all samples.

\subsection{Animals and Animal Experiments}

Eight-week-old BALB/c mice from Laboratory Animal Center University of Tartu (Tartu, Estonia) were housed under a 12/12 h light/dark cycle with ad libitum access to water and food. Experiments were carried in compliance with the bioethical principles adopted by the European Convention for the Protection of Vertebrate Animals Used for Experimental and Other Scientific Purposes (Strasbourg, France, 1986). Experimental procedures were approved by the ethics committee of the Latvian Animal Protection Ethics Committee of the Latvian Food and Veterinary Service, permit No 99 from 4 April 2018. Inhalation anesthesia in mice was induced in a ventilated chamber containing air with $4 \%$ isoflurane and maintained with $2.5 \%$ isoflurane/air mix administered through a facial mask during all intradermal injections and electroporation.

\subsection{DNA Immunization of Mice}

BALB/c mice were primed with two $20 \mu \mathrm{g}$ doses of either pVax-TERT $(n=5)$, or pVax-TERT-HA $(n=5)$, or empty vector PVAX1 $(n=5)$, and after 3 weeks boosted with $15 \mu \mathrm{g}$ of the same plasmids mixed with $5 \mu \mathrm{g}$ of pVaxLuc2 (20 $\mu \mathrm{g}$ of DNA per site in total). At each immunization, mice received two intradermal (id) injections of plasmid DNA solution in PBS delivered to the left and to the right from the back of the tail. Plasmids were administered with 29G-needle insulin syringes. Injections were followed by electroporation using CUY21EditII (BEX Co., Tokyo, Japan) in vivo electroporator with fork-plate $($ CUY663-5 $\times 10)$ electrode $(B E X$ Co., Tokyo, Japan) with a poration pulse of $400 \mathrm{~V}$ ( $0.1 \mathrm{~ms}$ with a $20 \mathrm{~ms}$ break) followed by 8 altering polarity $(+/-)$ driving pulses of $10 \mathrm{~ms}$ performed at $100 \mathrm{~V}$ with $20 \mathrm{~ms}$ intervals [47].

\subsection{In Vivo Bioluminescent Imaging}

Bioluminescence from the sites of injections of a mixture of DNA-immunogen or vector DNA and pVaxLuc2 was measured on days 1, 2, 5, 7, 9, and 12 after the boost by in vivo imaging (Spectrum; Perkin Elmer, Waltham, MA, USA) as described previously [47,48]. Prior to capturing of the luminescent signal, mice were injected intraperitoneally with a solution of XenoLight D-Luciferin potassium salt (Perkin Elmer) in PBS at a dose of $150 \mu \mathrm{g} / \mathrm{g}$ body weight. Then, $10 \mathrm{~min}$ later, anesthesia was induced by $4 \%$ isoflurane and maintained by $2.5 \%$ isoflurane throughout the imaging procedure. Regions of interest (ROI) were localized around the injection sites, and the bioluminescence signal was quantified as the total photon flux (photons/s). Bioluminescence imaging data were processed using the Living Image ${ }^{\circledR}$ software version 4.5 (Perkin Elmer). 


\subsection{End Point of DNA Immunization Experiment}

DNA immunization experiment was terminated 2 weeks after the boost. Mice were bled through tail vein, blood was collected into $1.5 \mathrm{~mL}$ tubes, centrifugated, and sera were frozen at $-20{ }^{\circ} \mathrm{C}$ for further antibody assays. After bleeding, mice were humanely euthanized by cervical dislocation, spleens were excised and homogenized, and single cell cultures were prepared using nylon $70 \mu \mathrm{m}$ cell strainers (Nunc, Roskilde, Denmark). ACK Lysing Buffer (Thermo Fisher) was used to remove the erythrocytes. Stocks of murine splenocytes were prepared in RPMI containing 50\% fetal calf serum and $10 \%$ DMSO, frozen at $-80{ }^{\circ} \mathrm{C}$ for 1 week, and then transferred to liquid nitrogen for later assessment by flow cytometry.

\subsection{Assessment of Cellular Immune Response}

Cellular immune responses were assessed by multiparametric flow cytometry. Splenocytes of TERT-immunized and control vector-immunized mice were stimulated for $5 \mathrm{~h}$ in a $\mathrm{CO}_{2}$ incubator at $37^{\circ} \mathrm{C}$ with solutions of TERT-derived peptides (Table $1 ; 10 \mu \mathrm{g} / \mathrm{mL}$ ) or with a mix of mitogenic stimuli phorbol 12-myristate 13-acetate (PMA) $(50 \mathrm{ng} / \mathrm{mL})$ and ionomycin $(1 \mu \mathrm{g} / \mathrm{mL})$ (both from Sigma-Aldrich, St. Louis, MO, USA) in the presence of Golgi plug reagent (BD Pharmingen, Franklin Lakes, NJ, USA). After incubation, cells were stained for viability with the Fixable Viability Stain 660 (FVS660; BD Horizon \#564405). Thereafter, cell surface staining was performed with a mixture of antibodies including FITC-conjugated anti-mouse CD8a (\#553031) and APC-H7-conjugated anti-mouse CD4 (\#560181). Cells were then washed, fixed, permeabilized using PerFix-nc Kit (Beckman Coulter, Brea, CA, USA), and stained with PE-conjugated anti-mouse IFN- $\gamma$ antibodies (\#557649), BV421-conjugated anti-mouse IL-2 antibodies (\#562969), and BV510-conjugated anti-mouse TNF- $\alpha$ antibodies (\#563386); all above antibodies were from BD Pharmingen. All stainings were performed in duplicates. Totally, five staining runs were done, each run including one sample from each of three groups. Stained samples were analyzed on a FACSAria II cytometer (BD Biosciences, Franklin Lakes, NJ, USA). Data were exported as FCS3.0 files using FACSuite software and analyzed using FlowJo X.07 program (FlowJo LLC, Ashland, DE, USA). First, general lymphocyte population was defined, and viable cells were identified by the lack of FSV660 staining. From the viable population, cells of interest were defined by the expression of CD4 and CD8 surface markers and for production of cytokines IFN- $\gamma$, IL-2, and TNF- $\alpha$ (Supplementary Figure S5). Data were presented as percent of CD4+ or CD8+ cells producing one, two, or three cytokines, from the total population of CD4+ or CD8+ cells. Percent of cells positive for IFN- $\gamma$, IL-2, and TNF- $\alpha$ after stimulation with growth medium (background) was subtracted from all values.

\subsection{Assessment of Anti-TERT Antibody Response}

Plates (MaxiSorp, Sigma-Aldrich, St. Louis, MO, USA) were coated with TERT-derived peptides (Table 1) diluted in carbonate-bicarbonate buffer ( $\mathrm{pH} 9.3$ ) at concentration of $10 \mu \mathrm{g} / \mathrm{mL}$ by keeping overnight at room temperature and then incubated for 3 days at $6{ }^{\circ} \mathrm{C}$ or coated with rtTERT freshly diluted in PBS (pH 7.6) at concentration $0.3 \mu \mathrm{g} / \mathrm{mL}$ by keeping overnight at $6^{\circ} \mathrm{C}$. Plates were washed and blocked with PBS containing 10\% normal goat serum, $2 \%$ bovine serum albumin, and $0.05 \%$ Tween 20 (Scan Buffer) for $1 \mathrm{~h}$ at room temperature. Blocking buffer was discarded prior to further assessment. Sera were diluted 1:100 with Scan Buffer and preincubated overnight at $6{ }^{\circ} \mathrm{C}$. Then, they were further diluted with Scan Buffer in two- to threefold steps, distributed on pre-blocked plates, and incubated overnight at $6^{\circ} \mathrm{C}$. After that, plates were washed six times with PBS containing $0.1 \%$ Tween 20 and incubated for $1 \mathrm{~h}$ at $37^{\circ} \mathrm{C}$ with goat anti-mouse IgG conjugated to HRP (Dako, Santa Clara, CA, USA) diluted in Scan Buffer. Thereafter, plates were washed as described above, dried by repeated tapping on filter paper, and incubated with $100 \mu \mathrm{L}$ of freshly made 3,3',5,5'-tetramethylbenzidine solution (Dako) for $10 \mathrm{~min}$ at room temperature. The reaction was stopped by adding $50 \mu \mathrm{L} 0.1 \mathrm{M}$ sulfuric acid, and plates were read on ELISA reader (Multiskan, Thermo Fisher, Waltham, MA, USA) at dual 
wave length of 450 and $620 \mathrm{~nm}$. Optical density values were represented as OD450-OD620 (OD $450-620)$. The end point dilution titer was established as serum dilution at which the $\mathrm{OD}_{450-620}$ of a well with immune mouse serum became equal to or lower than the average $\mathrm{OD}_{450-620}$ of 3 to 5 control mouse sera assessed on the same plate or $\leq 0.1$.

\subsection{Assessment of In Vivo Tumorigenicity of 4T1luc2 Clones Expressing rtTERT}

The capacity of 4T1luc2 derivative clones expressing rtTERT to form tumors and metastases was tested by their ectopic implantation into 8-weeks-old female BALB/c mice done as was described previously [42]. Briefly, suspensions of parental or daughter rtTERT expressing 4T1luc 2 clones in the doses of $2.5 \times 10^{3}, 5 \times 10^{3}$, and $1 \times 10^{4}$ cells in $50 \mu \mathrm{L}$ of RPMI-1640 were injected into mice to the right and to the left of the base of the tail ( $n=4$ per dose per cell line). Injections were performed subcutaneously with a 25G needle mounted on an insulin syringe (B Braun, Melsungen, Germany). Tumor size was assessed by morphometric measurements done at regular intervals using calipers; tumor volume was calculated using standard formula for xenograft volume $V=x y^{2} / 2$. Cell growth was also assessed by bioluminescence imaging (BLI) as described above. Monitoring of bioluminescence was performed directly after the implantation, then on days 1,2,3,5, and then every 2-3 days until the tumor volume of the first mouse in the experiment reached the volume of $1 \mathrm{~cm}^{3}$. Mice were weighed at each monitoring timepoint.

2.17. End Point of Tumor Challenge Experiment, Collection of Mouse Organs, and Rapid Ex Vivo Assessment of Metastases

When tumor volume of the first mouse in the experiment reached the volume of $1 \mathrm{~cm}^{3}$ (day 21 after implantation), mice were weighed and injected intraperitoneally with freshly prepared solution of XenoLight D-luciferin potassium salt (Perkin Elmer) in PBS in the amount of $150 \mu \mathrm{g} / \mathrm{g}$ based on the actual weight. After $8 \mathrm{~min}$, mice were humanely euthanized. Tumors, lungs, liver, kidneys, and spleens were dissected with surgical scissors. Immediately after this, all organs were transferred into individual wells of 24-well black tissue culture test plates (Wallac, Turku, Finland) containing 2 mL RPMI-1640 medium and subjected to ex vivo BLI to assess the presence of Luc-expressing cells as described previously [42]. Thereafter, tumors, lungs, livers, kidneys, and 1/2 of the spleens were transferred into $5 \mathrm{~mL}$ of $4 \%$ formaldehyde solution in PBS, incubated for 24 to $48 \mathrm{~h}$ at $6{ }^{\circ} \mathrm{C}$, then washed five times with PBS, and used to prepare FFPE blocks. The other half of the spleens was used in the evaluation of cellular immune response to TERT.

\subsection{Evaluation of Cellular Response against TERT in Mice Implanted with 4T1luc2 Clones}

The residual part of the spleens was homogenized and then, single cell cultures were prepared and frozen at $-80^{\circ} \mathrm{C}$ until the evaluation of cellular response against TERT by multiparametric flow cytometry. Cells were thawed at two occasions and assessed for the response against TERT1, TERT2, TERT6, and TERT8. Assessment was done for 4 mice per group (totally 12) in independent runs of 6 mice (two per group) each, as described above for DNA-immunized mice. PMA was used as a positive, and RPMI alone was used as a negative control. Percent of cells positive for IFN- $\gamma$, IL-2, and TNF- $\alpha$ after stimulation with growth medium (background) was subtracted from all values.

\subsection{Tumor Histology and Ex Vivo Assessment of the Metastases}

FFPE blocks were prepared from the formalin-fixed tumor tissues and organs. FFPE blocks were sectioned on a microtome according to the standard protocols (https:/www.protocolsonline.com/ histology/sample-preparation/paraffin-processing-of-tissue/). Sections mounted on glass slides were dewaxed, rehydrated, and stained with Mayer's hematoxylin solution. Then, they were washed, rinsed, and counterstained with eosin Y solution, and after that, they were dehydrated, washed with absolute alcohol, and covered with cover slips for microscopic evaluation. The slides were examined by light microscopy (Leica DM500, Wetzlar, Germany). Histological evaluation of tumors 
was based on the standard parameters such as acinar formation, nucleus size and pleomorphism, and mitotic activity [49]. Grades of the tumors were calculated according to [50]. Lymphocytes infiltration was assessed in 15 high power (400x) microscope fields of hematoxylin-eosin-stained slides by computer-assisted morphometry using specialized NIS-Elements software (Nikon, Tokyo, Japan). Formalin-fixed, Paraplast-embedded liver tissues were used to diagnose and evaluate the formation of metastases. For each mouse, the area of tumor metastases was quantified in 15 high power (400×) microscope fields of hematoxylin-eosin-stained slides by computer-assisted morphometry using specialized NIS-Elements software (Nikon, Tokyo, Japan).

\subsection{Statistical Analysis}

Total photon flux from the site of coinjection of TERT DNA or TERT-HA DNA and Luc DNA was compared using ordinary two-way ANOVA with Dunnett's multiple comparison test (GraphPad Prism 6, San Diego, CA, USA). Corrected total cell fluorescence (CTCF) was analyzed using ordinary one-way ANOVA with Holm-Sidak multiple comparison test (GraphPad Prism 6, Graphpad Software Inc., San Diego, CA, USA). Cell cycle analysis was analyzed using two- tailed $t$-test. Total photon flux from the site of injection of cells in tumorigenicity assessment was compared using RM two-way ANOVA with Dunnett's multiple comparison test (GraphPad Prism 6). Relative percent of CD8+ and CD4+ T cells expressing one, two, or three cytokines after stimulation with each of TERT peptides, end point titers of mouse sera, and tumor volumes were compared using nonparametric Kruskal-Wallis and Mann-Whitney tests (Statistica AXA 11.0; TIBCO Software Limited, London, UK). Total photon flux values were correlated to relative percent of CD8+ and CD4+ T cells expressing one, two, or three cytokines after stimulation with each of TERT peptides. Relative rtTERT mRNA expression was correlated to the amount of $r t T E R T$ locus insertions in genome. Correlations were performed using Spearman ranking test (Statistica AXA 11.0). $p$ values $<0.05$ were considered significant.

\section{Results}

\subsection{Design and Expression of Synthetic Rat TERT Gene}

TERT of different species is a highly conserved protein with four major structural/functional domains: N-terminal (TEN), RNA-binding (TRBD), the reverse transcriptase (RT) domains, and the C-terminal extension (CTE) (Figure 1A). RT domain, bearing homology to other reverse transcriptases, is the enzyme which builds telomeres, whereas other domains are involved in RNA interaction and protein stabilization [51]. Rat TERT was chosen as the immunogen as it differs in sequence from TERT of mice and humans (UniProtKB, rat TERT Q673L6; mouse TERT O70372; human TERT O14746; Figure 1B) and could, therefore, be expected to overcome immune tolerance in these species in the stage of preclinical and clinical trials. Numerous amino acid mismatches between TERT variants could be seen in peptides encompassing clusters of T- and B-cell epitopes shown to be recognized by the murine and human immune system (Figure 1C, Table 1, and references therein).

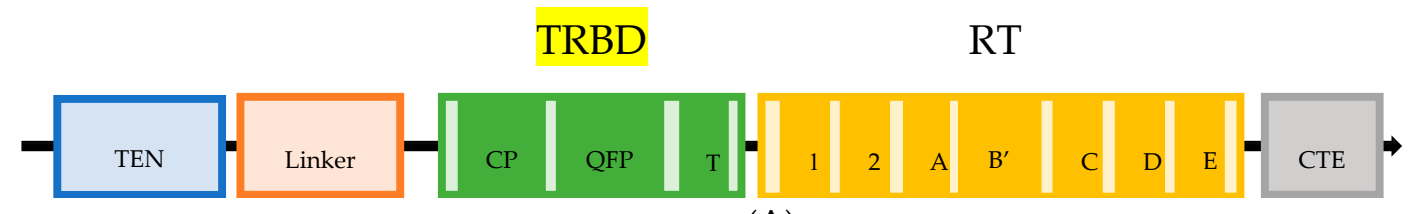

(A)

Figure 1. Cont. 


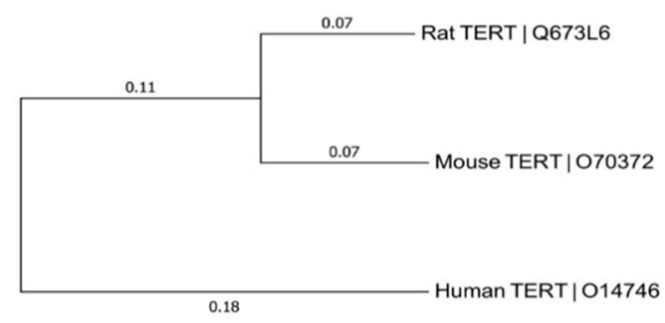

Rat TERT

Mouse TERT

Human TERT type 1

TERT 1356

Tert351 [34]

Tert288_1 [35]

Tert288_2 [35]
(B)

$\begin{array}{ccccc}360 & 370 & 380 & 390 & 400 \\ \text { | } & \mid & \mid & \mid & \mid\end{array}$

\section{LLNSLPPSLTGARRLVEI IFLGSRPRTSGPFCRTRRLPRRYWQMRPLFQQ}

$\ldots$ SN.Q.N. . . . . . . . . . . . . . . . . . .

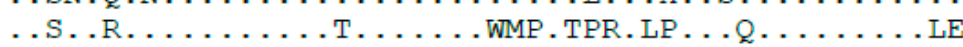

---- PPSLTGARRLVEI IFLGSRPRTSGPFC-----------

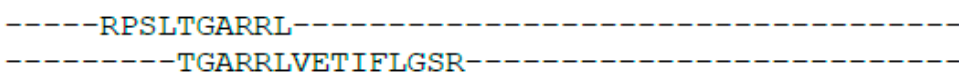

-ETIFLGSRPWMPGTP

(C)

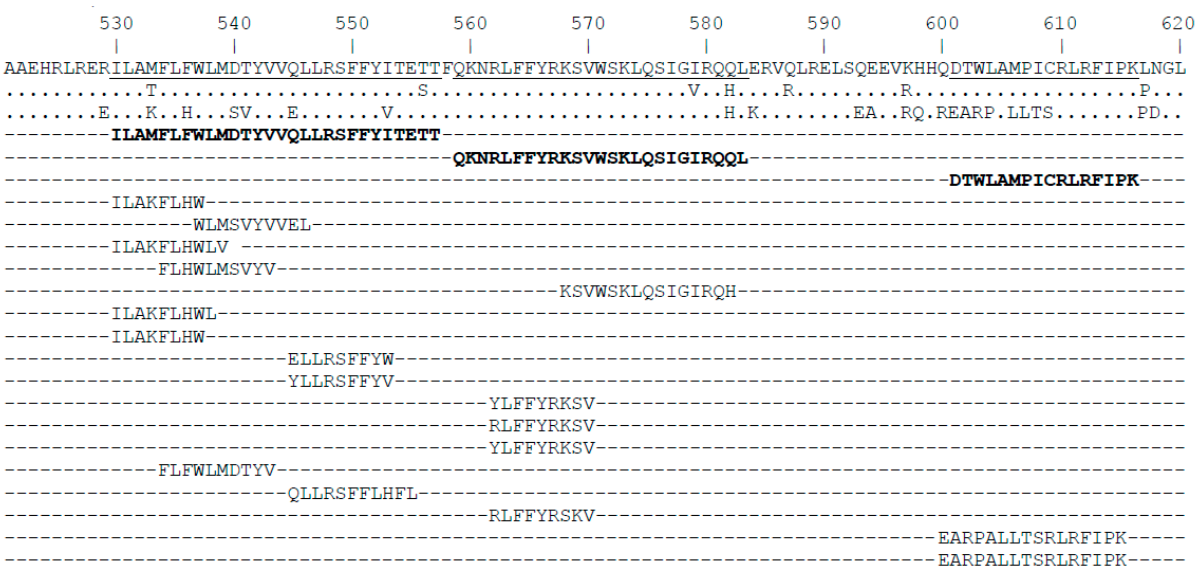

(D)

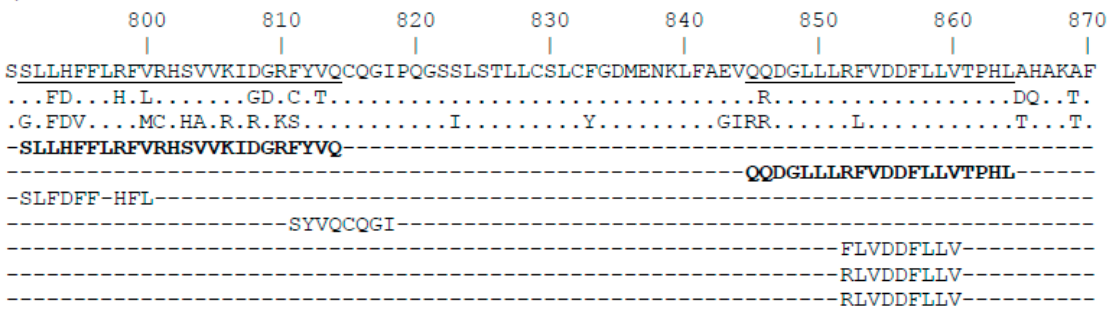

(E)

Figure 1. Cont. 


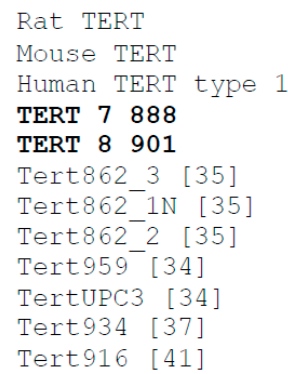

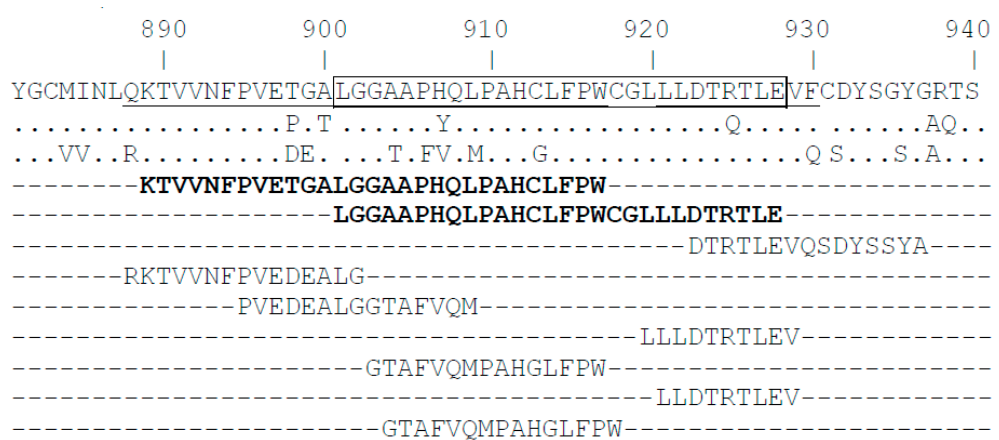

(F)

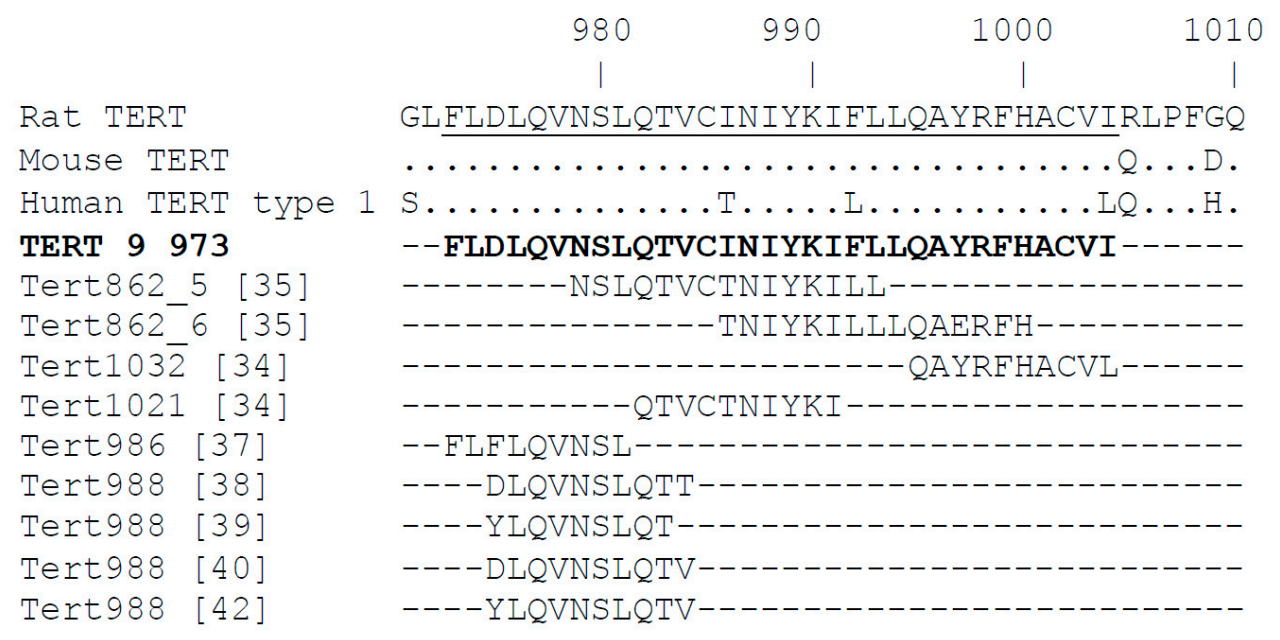

(G)

Figure 1. Domain structure (A), evolutionary tree of rat, murine and human telomerase reverse transcriptase (TERT) proteins (UniProtKB, Q673L6, O70372, and O14746, respectively) (B); and regions of rat TERT containing clusters of $\mathrm{T}$ cell epitopes recognized by immune system of mice and humans: aa 351-400 in the TERT oligomerization domain, containing part of the ciliate-specific motif CP (C); aa 520-620 (D); aa 790-870 containing active center of telomerase reverse transcriptase LVVV required for nucleotide incorporation and primer extension (E); aa 891-940 containing motif required for oligomerization and sequence WCGLL responsible for primer grip (F); aa 971-1010 containing part of the C-Terminal Extension domain CTE (G). The domain structure of TERT includes: TEN-telomerase essential N-terminal domain, CTE-C-terminal extension; TRBD—telomerase RNA-binding domain; and RT-reverse transcriptase domain. Domain information is given according to UNIPROT (www. uniprot.org/uniprot/O14746) and review by Rubtsova M.P. et al. [52]. The evolutionary history was inferred using the neighbor-joining method [53]. The evolutionary distances were computed using the p-distance method [54] and were presented in the units reflecting the number of amino acid differences per site. Final dataset had a total of 1109 positions. Evolutionary analyses were conducted in Molecular Evolutionary Genetics Analysis software (MEGA7) [55]. To visualize regions of rat TERT containing clusters of $\mathrm{T}$ cell epitopes recognized by immune system of mice and humans, epitope-rich fragments of rat TERT were aligned to the respective fragments of human TERT isotype 1 (UniProtKB \# O14746.1) and mouse TERT (UniProtKB \# O70372.1). Peptides representing known epitopes localized in these regions are abbreviated as "TERT" followed by the position of the first amino acid residue of the peptide according to their enumeration in rat TERT (UniProtKB \#Q673L6.1) and reference to respective publications. Peptides TERT1 to TERT9 chosen for the analysis of immune response induced by TERT DNA based on the epitope analysis are outlined in bold letters in the alignment; their sequences within rat TERT (UniProtKB \#Q673L6.1) are underlined or given in rectangular. 
Coding sequence of TERT optimized for expression in mammalian cells was designed and synthesized. We also designed TERT variant with a C-terminal hemagglutinin tag (TERT-HA) to enhance the antigenic dissimilarity (GenBank submissions MK749423 and MK749424). Synthetic genes were cloned into plasmid vector for DNA immunization pVAX1. Expression of the synthetic genes was tested in 293T cells. Staining with commercial rabbit polyclonal anti-TERT antibodies revealed weak bands corresponding to a protein with expected molecular mass of approximately $125 \mathrm{kDa}$ (Supplementary Figure S6). The level of expression was low, which supports earlier observations of high proteolytic instability of TERT, shown to be efficiently degraded by the proteasome [56-58].

\subsection{TERT Epitope Map and Selection of TERT-Derived Peptides for the Analysis of Anti-TERT Immune Response}

TERT-derived peptides were selected based on the published epitope data [30-39] and predictions of processing and presentation of TERT epitopes in the context of MHC class I and II, done using web tools of the Immune Epitope Database IEDB (www.iedb). Regions found to contain clusters of known B- and T cell epitopes are presented in Figure 1C-G. Peptides from these regions were selected, which had high probability of recognition by the immune system of BALB/c mice as containing cytotoxic T-cell (MHC-I Binding Predictions tool generating "Class I scores"; restriction to $\mathrm{H} 2 \mathrm{Db}$ and H2 Dd) and/or T-helper cell and B-cell epitopes (MHC-II Binding Predictions tool generating "Class II scores"; http://tools.iedb.org/mhcii/) (Figure 1C-G and Table 1).

\subsection{Immunization and In Vivo Assessment of the Development of Immune Response by Bioluminescent Imaging}

We used a method to assess the integral immune response against TERT which we named "antigen challenge" [47]. Specifically, we primed mice with TERT DNA or TERT-HA DNA, and then boosted with the same plasmids mixed with DNA encoding firefly luciferase (Luc DNA) (Figure 2A). We have earlier shown that immune response induced by DNA immunogen in prime eliminates cells coexpressing DNA immunogen and Luc after the boost with plasmid mixture. This results in a rapid loss of bioluminescence signal from the sites of booster injections in DNA-immunized mice compared to control mice [47]. Here, boosting of TERT or TERT-HA DNA-immunized mice with plasmids encoding TERT/TERT-HA and Luc resulted in a significant loss of bioluminescence signal in comparison to that in the control mice primed with pVAX1 and boosted with pVAX1 mixed with Luc DNA ( $p<0.05$; Figure 2B,C). Dynamics of the loss of photon flux in TERT- and TERT-HA-immunized groups were similar $(p>0.5$; Figure 2B,C). Rapid loss of TERT/luciferase-expressing cells indicated that TERT- and TERT-HA DNA-immunization induced an immune response able to eliminate cells coexpressing TERT (TERT-HA) and Luc from the sites of immunization.

\subsection{Assessment of Cellular Immune Response}

Recognition by murine CD4+ and CD8+ T cells of the panel of TERT-derived peptides selected as potentially immunogenic was assessed at the experimental end point (Table 1, Figure 1C-G, and Supplementary Figure S5). Data were presented as percentage of CD4+ and CD8+ T cells reacting to stimulation with TERT peptides by production of one, two, or three cytokines (Figure 3). CD4+ T cells specifically recognized peptides TERT1, 3, 5-8 and CD8+ T cells, TERT1, 5-8 (Figure 3A-C). Peptide TERT4 was not recognized, and TERT2 and TERT9 stimulated cytokine production in both TERT/TERT-HA and vector-immunized mice, i.e., contained autoepitopes of TERT (Figure 3A-C). Recognition was manifested by simultaneous production of IFN- $\gamma / \mathrm{IL}-2$, IFN- $\gamma / \mathrm{TNF}-\alpha$, or IFN- $\gamma / \mathrm{IL}-2 / \mathrm{TNF}-\alpha$ by CD4+ (Figure 3A,C) and CD8+ T cells (Figure 3B,C). Specific production of IL-2/TNF- $\alpha$ combination by CD4+ or CD8 $+\mathrm{T}$ cells was not detected (data not shown). Production of monocytokines by CD4+ and CD8+ T cells was mostly unspecific (Supplementary Figure S7). Both TERT and TERT-HA DNA-immunized mice developed specific multicytokine CD4+ and CD8+ T cell response, significantly exceeding the response levels in the control animals (Figure $3 \mathrm{~A}-\mathrm{C}$ ). At the 
same time, TERT/TERT-HA DNA and vector-immunized mice did not differ in their response to stimulation with mitogen PMA (Figure 3D). There was no difference in the spectrum or magnitude of responses in mice receiving TERT and TERT-HA DNA (Figure 3A,B), indicating that these two groups can be considered as one group of mice DNA-immunized with TERT.

A

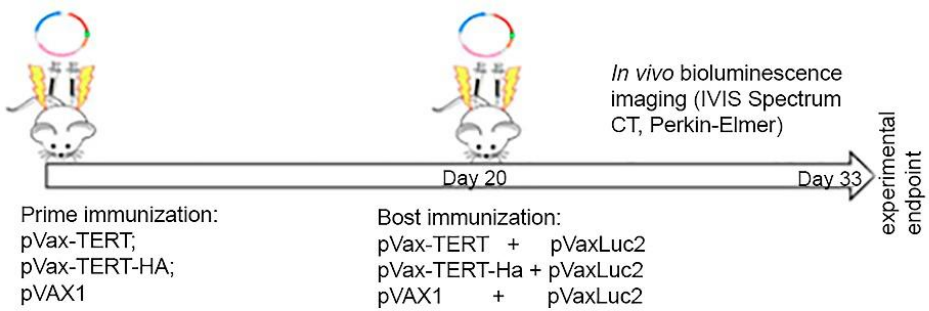

B

pVax-TERT-Ha + pVaxLuc2

VAX1 + pVaxLuc2
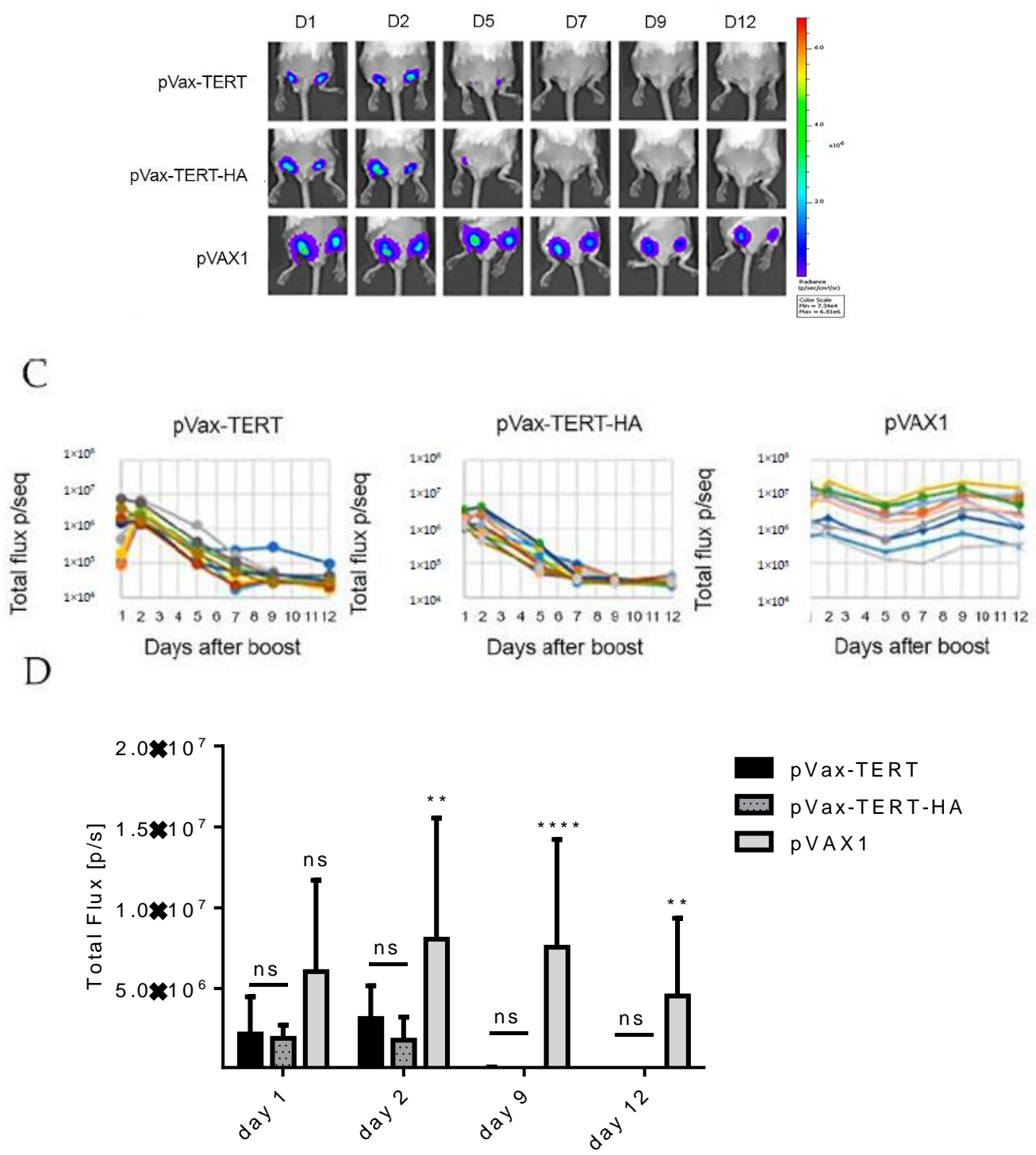

Figure 2. Immunization of BALB/c mice with TERT DNA, TERT variant with a C-terminal hemagglutinin tag (TERT-HA DNA), and empty vector followed by booster immunization with given plasmids mixed with DNA encoding firefly luciferase (Luc DNA), with follow up of luciferase expression by in vivo imaging. Scheme of the immunization (A); results of in vivo bioluminescence imaging of booster sites at days 1-12 post injection, example of 3 mice-one from TERT, one from TERT-HA, and one from empty vector group (B); dynamics of bioluminescence signal change in TERT, TERT-HA DNA, and empty vector-immunized mice on days 1-12 post booster injection; each line of 
different colors corresponds to one site of injection (two per mouse) (C); relative average level of bioluminescence signal for each group on days 1 to 12 post booster injection (D). Bioluminescence signal is represented by the total flux from site of immunization, mean $\pm \mathrm{SD}$. Analyzed by ordinary two-way ANOVA with Dunnett's multiple comparison test, ${ }^{* *}-p<0.01$; ${ }^{* * * *}-p<0.0001$; ns-not significant.

We further looked whether recognition of TERT peptides was related to the difference between amino acid sequences of rat and murine TERT. Peptide TERT5 contains 8, TERT1 and TERT7-3, TERT2, TERT3, and TERT8 - 2, and TERT6 - just 1 amino acid mismatch and were all able to stimulate $\mathrm{CD} 4+$ and/or CD8+ $\mathrm{T}$ cell response in immunized mice. TERT4 sequence in mice and rats is identical, and the peptide was not immunogenic. At the same time, TERT9, also identical in rats and mice, was recognized by $\mathrm{CD} 4+$ and $\mathrm{CD} 8+\mathrm{T}$ cells of both immunized and control animals, indicating presence of an autoepitope (Figure 1G, Table 1, Figure 3A-C, and Supplementary Figure S7). Another autoepitope recognized by control mice colocalized with TERT2, contained two amino acid mismatches between rat and murine TERT2 sequences. (Figure 1D, Table 1, Figure 3A-C, and Supplementary Figure S7). The immune recognition of both TERT2 and TERT9 reflected an immune response to endogenous TERT, not rat TERT introduced by DNA immunization. On the overall, the degree of amino acid dissimilarity between TERT sequences in the immunogen and in the host was not translated into stronger or weaker specific immune recognition.

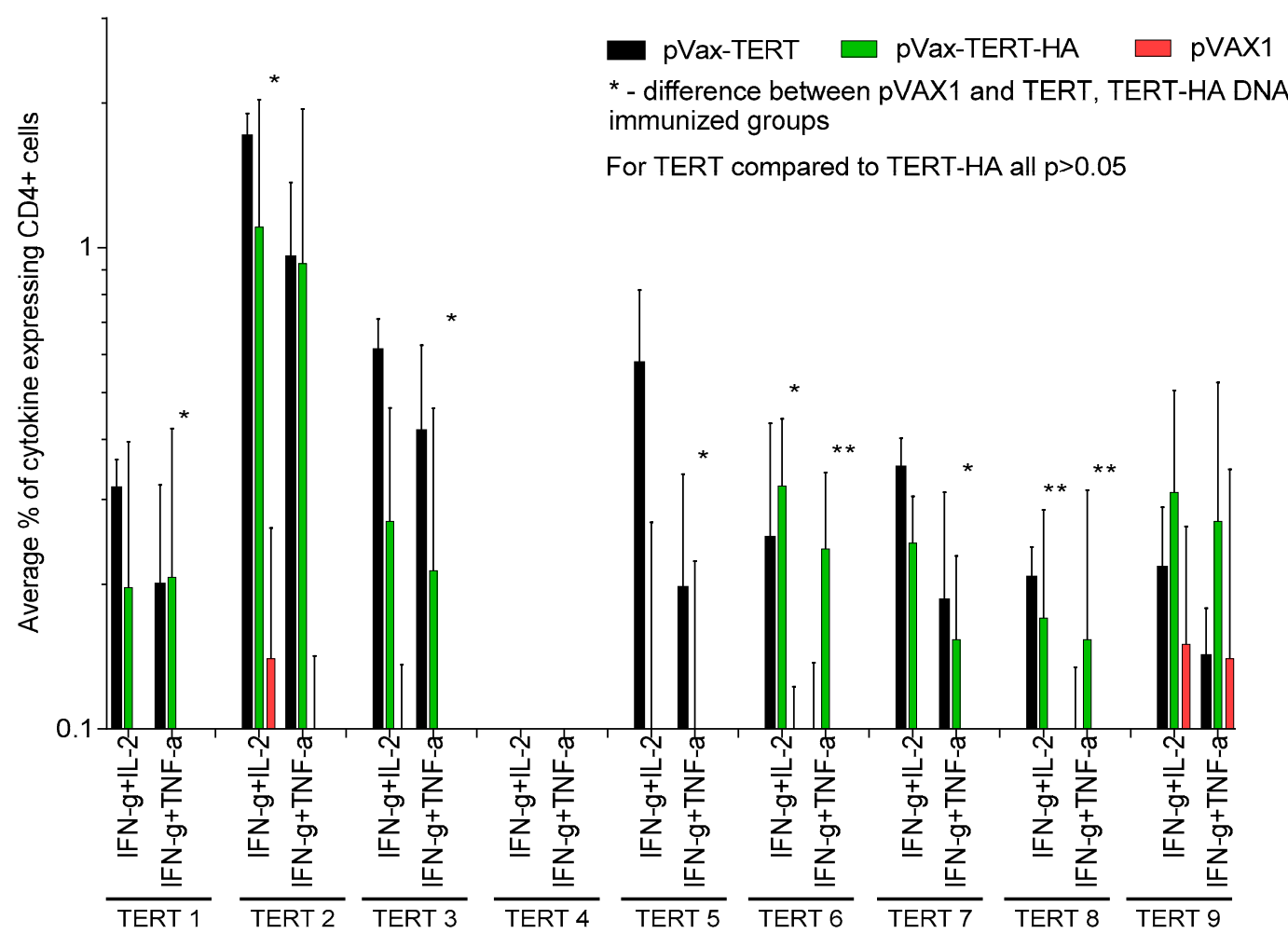

(A)

Figure 3. Cont. 


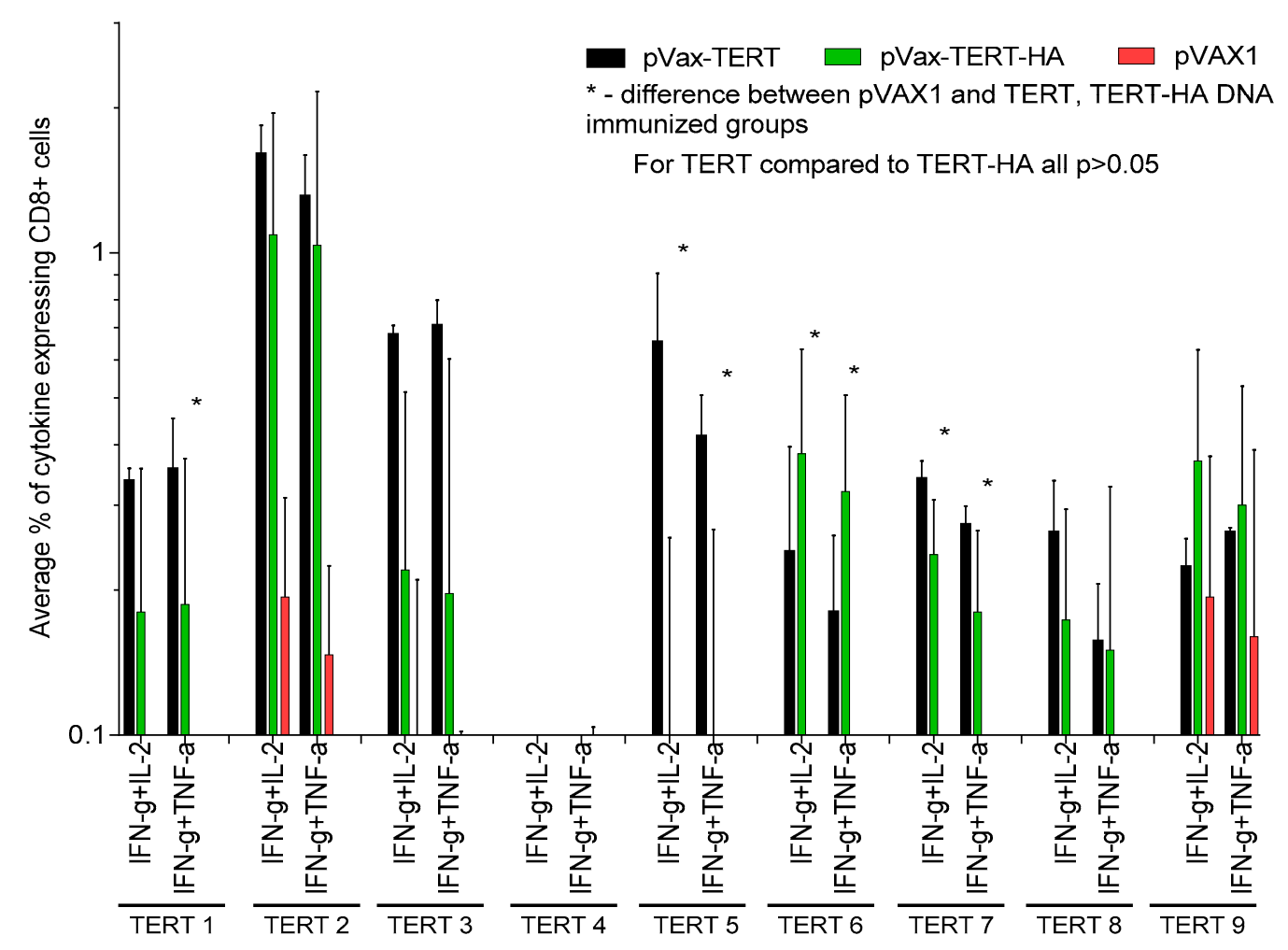

(B)

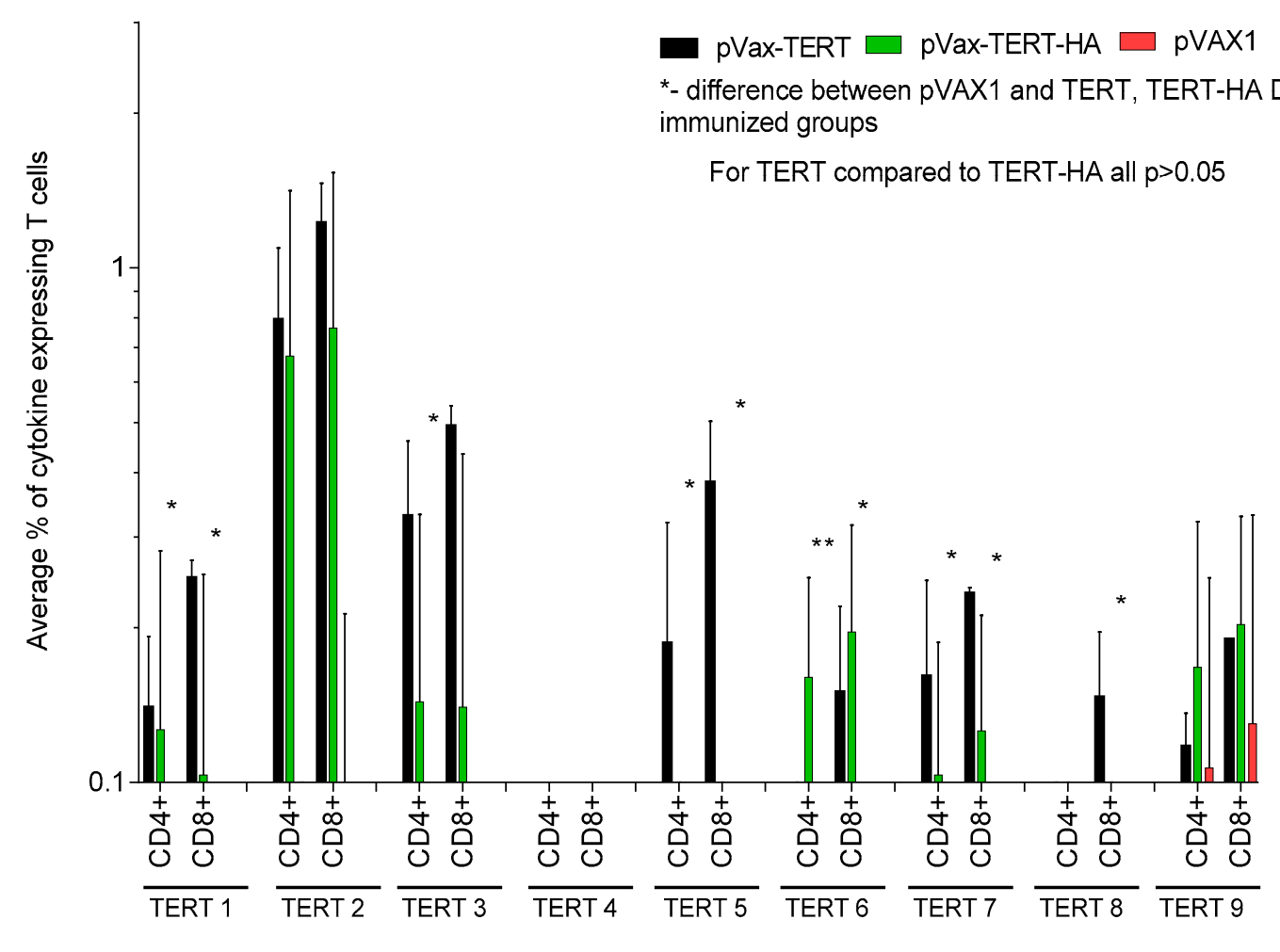

(C)

Figure 3. Cont. 


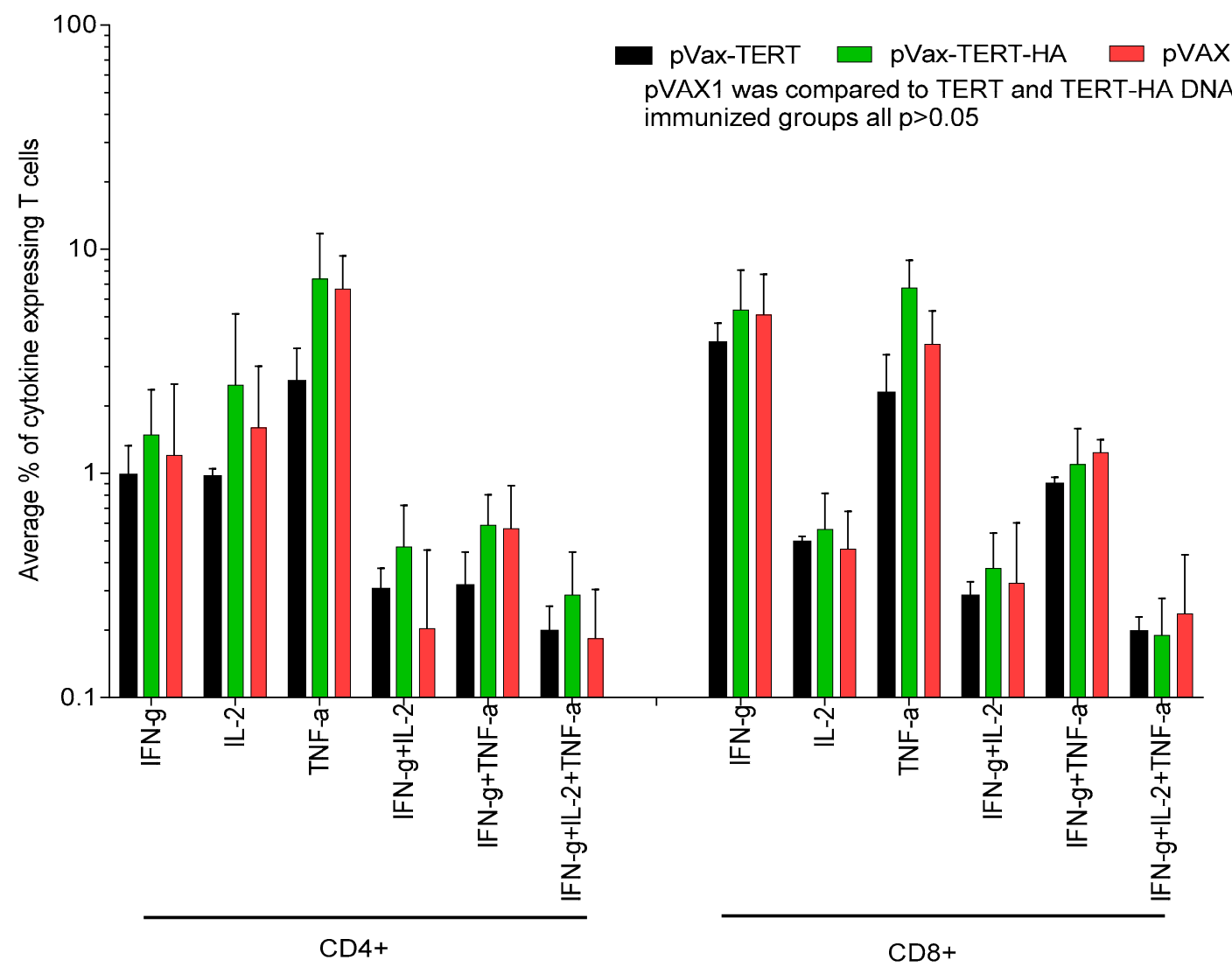

(D)

Figure 3. Immune recognition of TERT-derived peptides (Table 1) by CD4+ and CD8+ T cells of mice DNA immunized with TERT or TERT-HA compared to vector-immunized mice analyzed by multiparametric flow cytometry. Percent of $\mathrm{CD} 4+(\mathbf{A})$ and CD8+ T cells $(\mathbf{B})$ cells reacting to stimulation with TERT peptides by double cytokine production; percent of CD4+ and CD8+ T cells reacting with triple cytokine production (C); and cytokine production by CD4+ and CD8+ T lymphocytes stimulated with phorbol 12-myristate 13-acetate (PMA) (D). Values represent mean of all mice in each group \pm SD. Difference between TERT, TERT-HA DNA-immunized, and control vector-immunized mice was analyzed by Mann-Whitney test. Difference between TERT, TERT-HA DNA-immunized, and control vector: ${ }^{*}-p<0.05 ;{ }^{* *}-p<0.01$. No difference between TERT and TERT-HA DNA-immunized mice was found, all $p>0.05$.

Further, we looked into the immune recognition of peptides which have induced specific immune stimulation in $>0.1 \%$ of CD4+ and CD $8+\mathrm{T}$ cells (Figure 3A-C) in individual TERT and TERT-HA DNA-immunized mice. This limited the peptide panel to TERT1 and TERT6-8 (Figure 4A,B). Results were presented as pile-up of populations of CD4+ and CD8+ T cells which responded to peptide stimulation by production of just one, or two, or all three cytokines (nonoverlapping populations). Analysis of the profiles of cellular immune response in mice immunized with TERT/TERT-HA DNA demonstrated that TERT1, TERT6, TERT7, and TERT8 harbored epitopes of CD4+ and CD8+ T cells capable of multiple cytokine secretion, with dominance of IFN- $\gamma$ (Figure $4 \mathrm{~A}, \mathrm{~B})$. To check the functionality of this response, we looked for the correlations between percent of CD4+ and CD8+ T cells producing IFN- $\gamma$, IL-2, and/or TNF- $\gamma$ in different combinations and loss of bioluminescence from the sites of TERT (TERT-HA)/Luc DNA boosts. Residual percent of bioluminescence left at immunization sites by days 9 and 12 after the boost inversely correlated with the magnitude of multicytokine response of CD4+ T cells to stimulation with TERT6, TERT7, and TERT8 and of CD8+ T cells, to stimulation with TERT6 and TERT8 ( $p<0.01$; Supplementary Table S3). Correlation of the loss of bioluminescence with 
cellular response to TERT1 and TERT5 was of less significance and involved only IFN- $\gamma /$ IL-2/TNF- $\gamma$ producing CD8+ T cells (day 12; Supplementary Table S3). These correlations pointed at the lytic potential of CD8+ and CD4+ T cells specific to the epitopes localized between aa 845-929 of TERT, i.e., in the RT domain.

\subsection{Antibody Response}

TERT and TERT-HA DNA induced an antibody response recognizing recombinant rtTERT and two peptides from this region, TERT7 and TERT 8, with IgG titers in the range of 2-7 $\times 10^{3}$ (Figure 5). Other TERT peptides were not recognized (Figure 5). Thus, B-cell response induced by TERT DNA immunization was targeted against aa 888-929 of TERT, within the region containing a cluster of epitopes of CD4+ and CD8+ T cells.

With this, we have shown that immunization with TERT DNA induces cellular and antibody response targeting the region between aa 845 and 929 localized within RT domain of TERT (rtTERT), and this response correlates to in vivo clearance of TERT/reporter coexpressing cells. This positions rtTERT as a necessary and sufficient component of cancer vaccine.

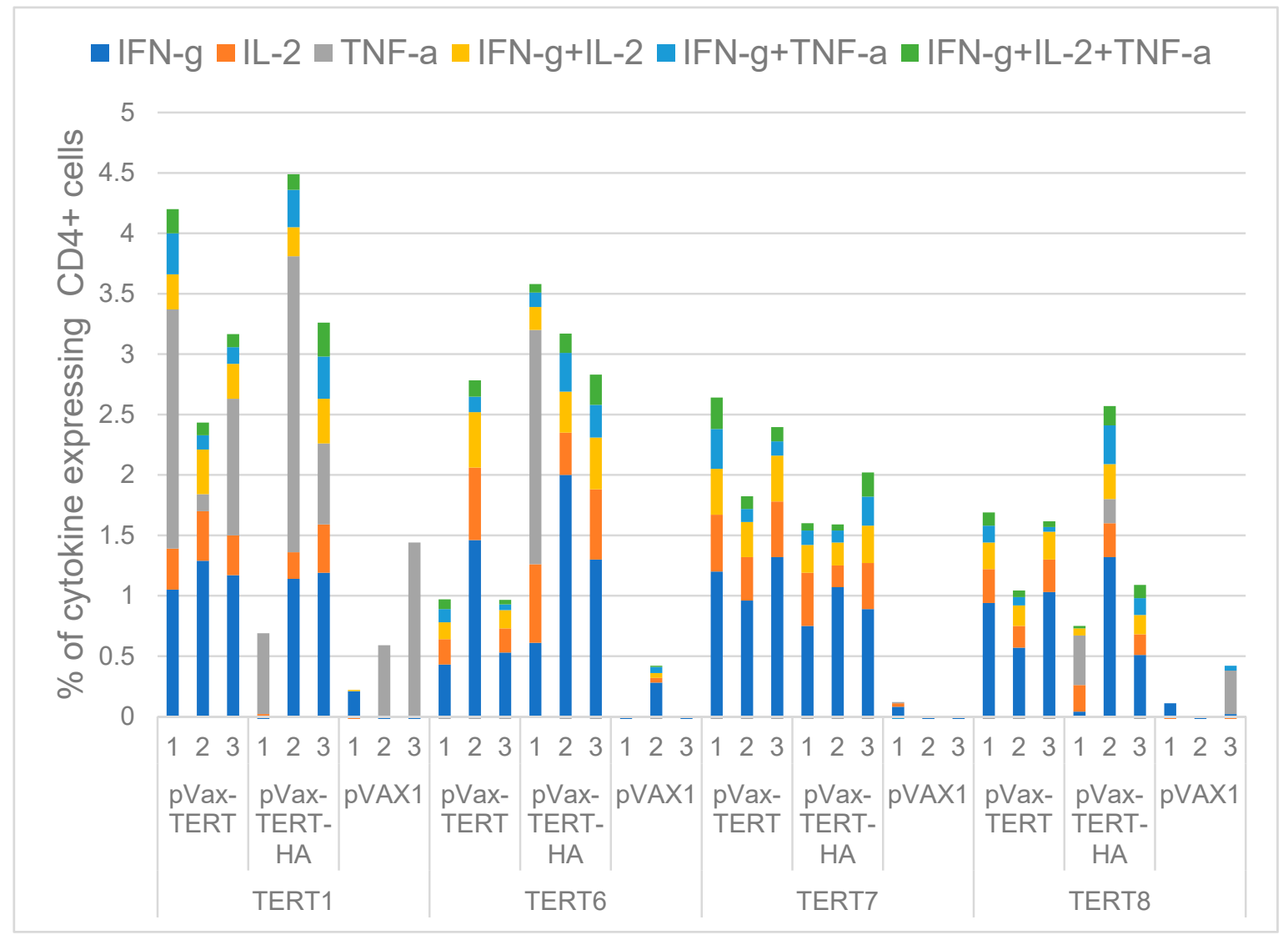

(A)

Figure 4. Cont. 


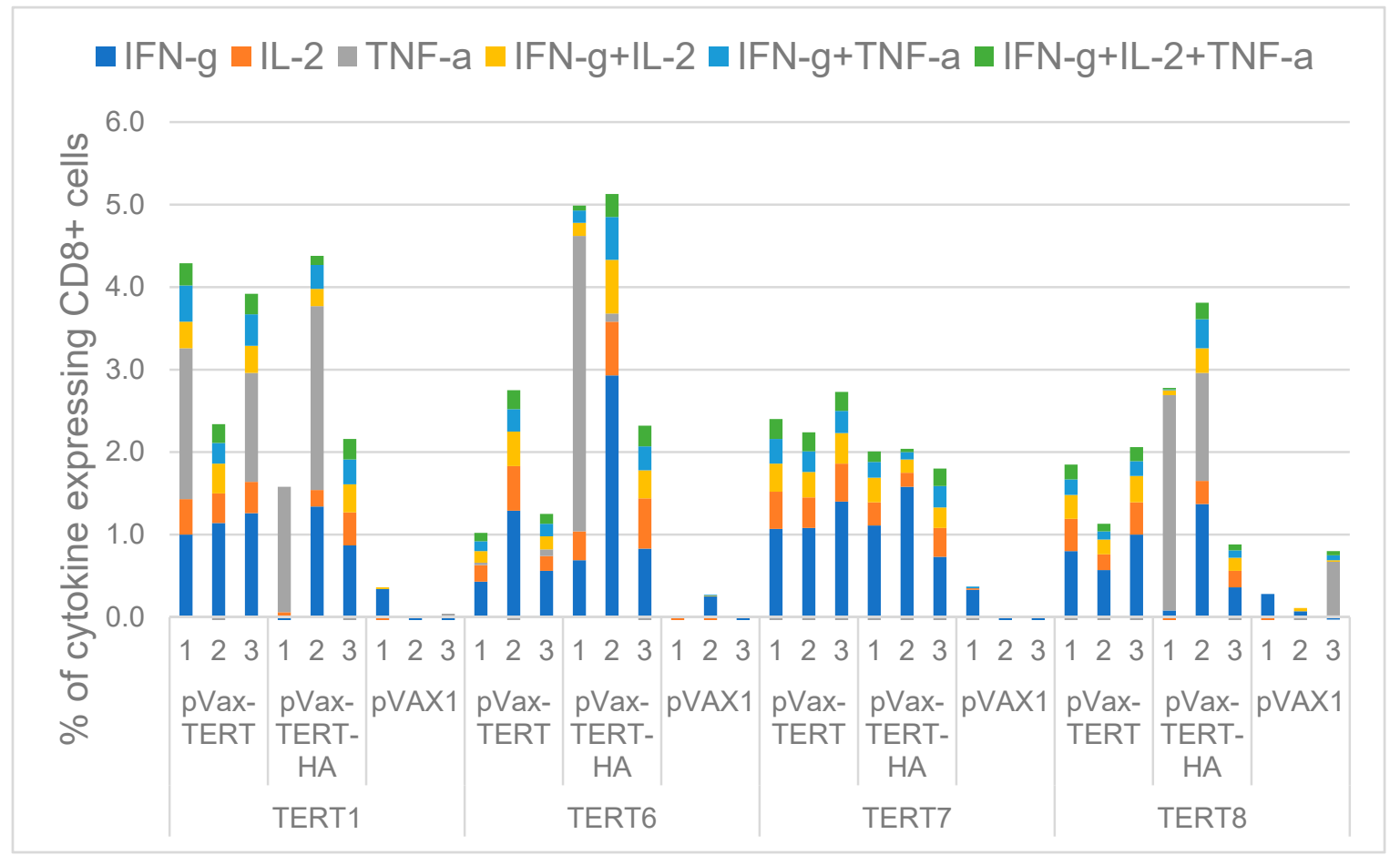

(B)

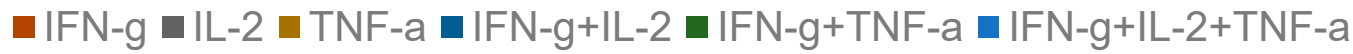

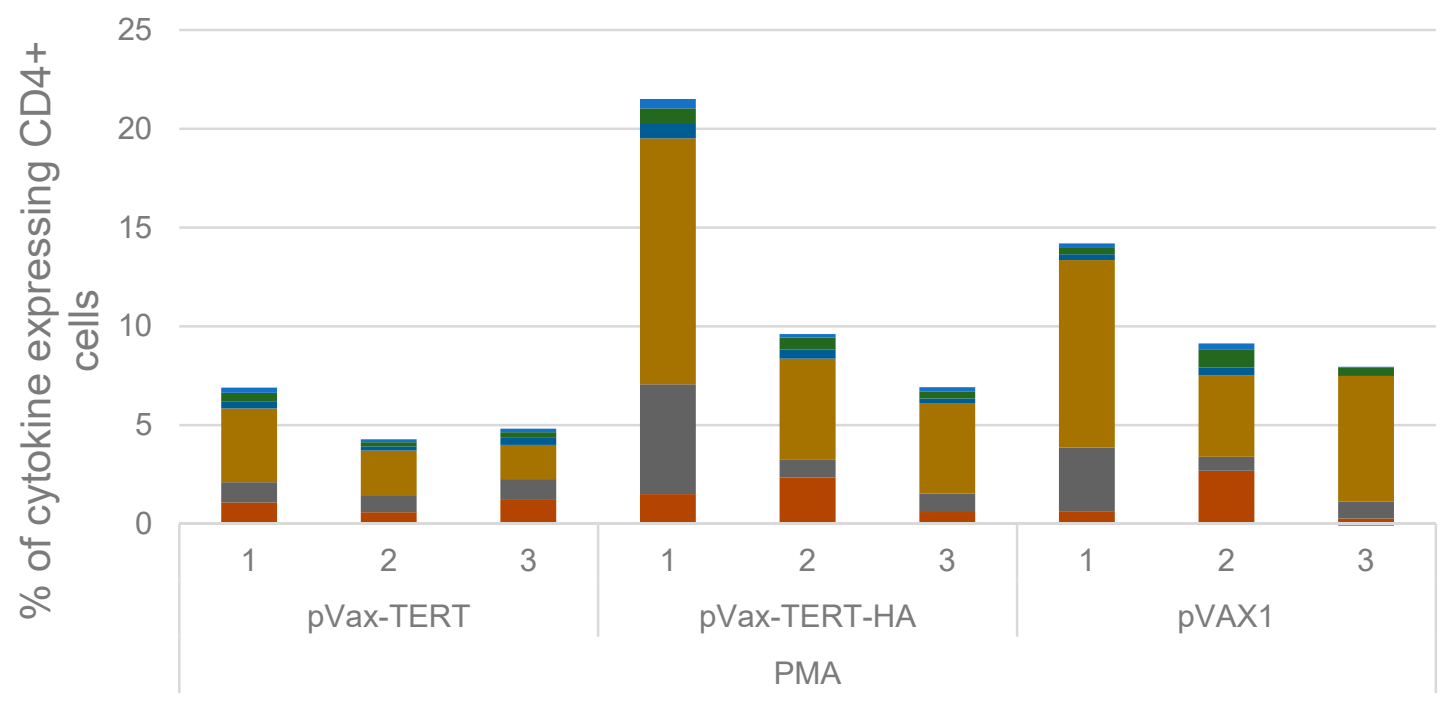

(C)

Figure 4. Cont. 


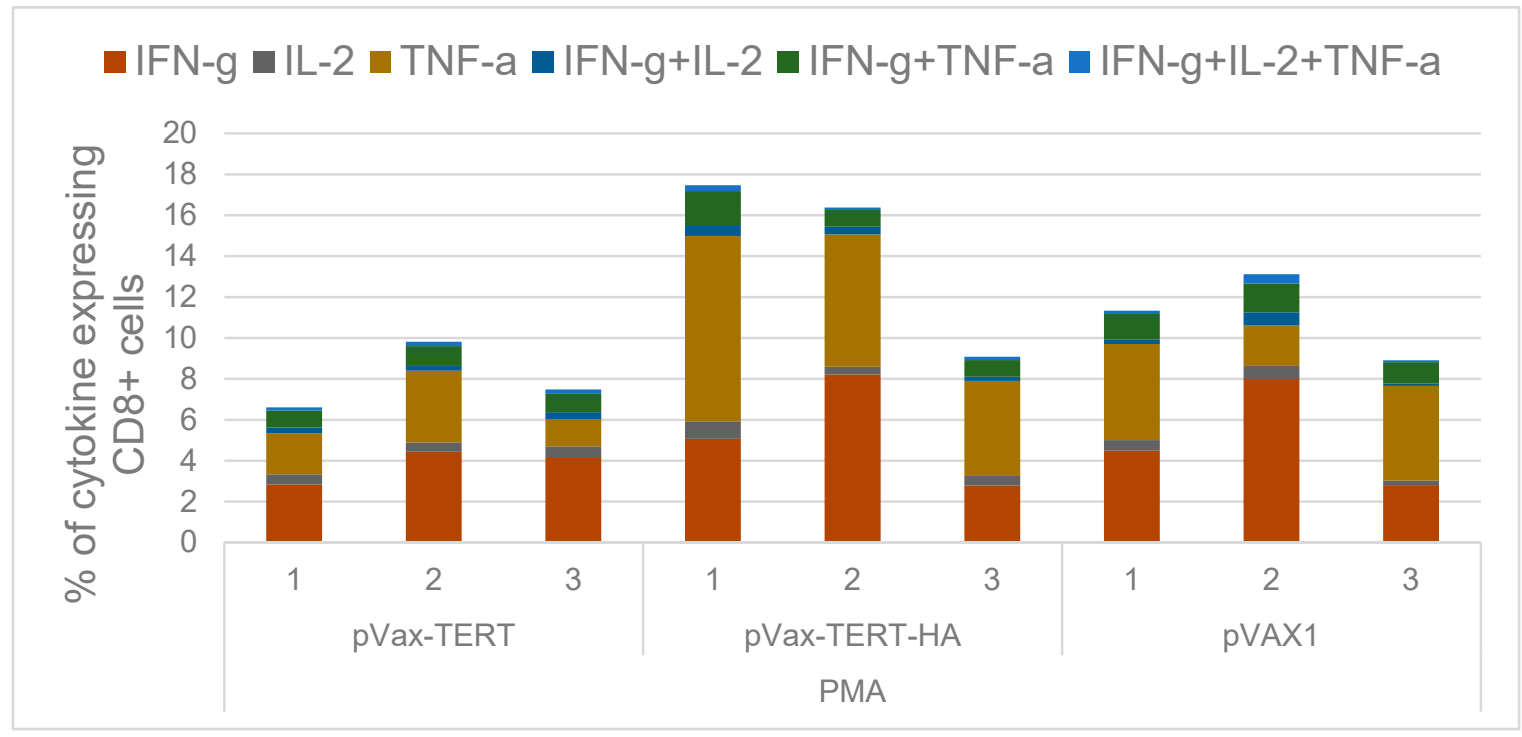

(D)

Figure 4. Immune recognition of peptides TERT 1, 6, 7, and 8 (Table 1) (A,B) and mitogen PMA (C,D) by splenocytes of individual TERT DNA, TERT-HA DNA, and vector-immunized mice, represented as a pile-up of the average percent of $C D 4+(A, C)$ and $C D 8+T$ cells $(\mathbf{B}, \mathbf{D})$ responding to in vitro antigen stimulation by production of only one, or only two, or only three cytokines (IFN- $\gamma$, IL-2, TNF- $\gamma$ or IFN- $\gamma / \mathrm{IL}-2$, IFN- $\gamma / \mathrm{TNF}-\gamma$ or IFN- $\gamma / \mathrm{IL}-2 / \mathrm{TNF}-\gamma$, respectively, i.e., cell populations are nonoverlapping).

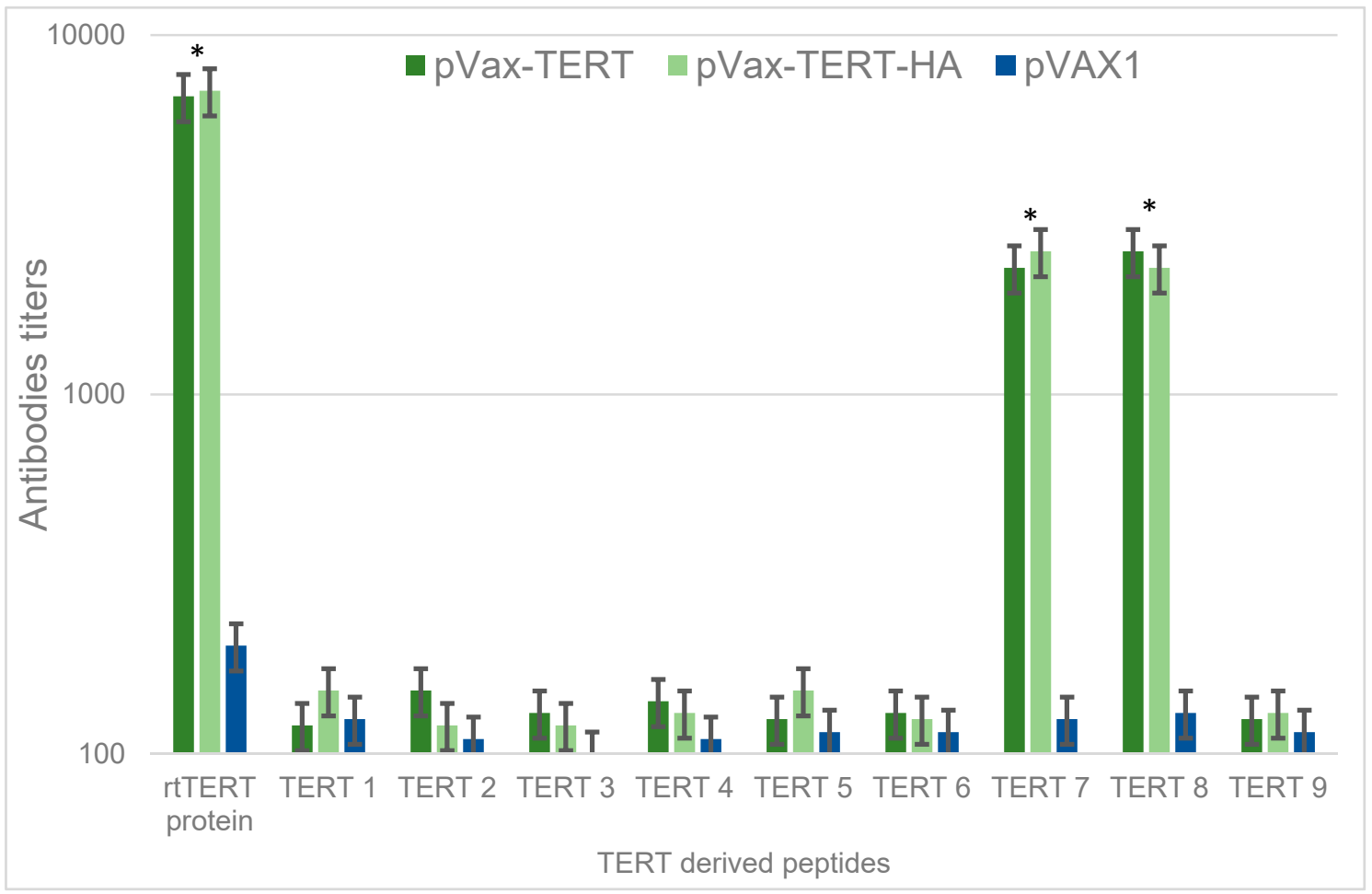

Figure 5. Recognition of the recombinant rtTERT and TERT-derived peptides by pooled sera of mice DNA-immunized with TERT and TERT-HA as compared to vector-immunized mice. Values represent average end point antibody titers of pooled sera in two independent ELISA runs performed in duplicate, with STDEV. * , significant difference between titers in TERT/TERT-HA DNA-immunized mice and control mice, $p<0.05$. 


\subsection{Generation of 4 T1luc2 Clones Expressing RT Domain of Rat TERT}

Earlier, we found that expression of HIV-1 RT by murine mammary adenocarcinoma 4T1luc2 cells enhances their tumorigenic and metastatic activity [42]. We inquired if this could be the case for RT domain of TERT, which, in this case, will be unsafe to use as a vaccine component. To test this possibility, we generated variants of 4T1luc2 cells expressing rtTERT and evaluated their capacity to form tumors and metastasis. Transduction of 4 T1luc 2 cells with lentivirus encoding rtTERT yielded four daughter clones with genomic inserts of rtTERT (i.e., 4T1luc2_rtTERT_C6, 4T1luc2_rtTERT_B5, 4T1luc2_rtTERT_H9, and 4T1luc2_rtTERT_F1; Table 2).

Table 2. Characterization of daughter clones of 4T1luc2 expressing rtTERT by the copy number of $r t T E R T$ inserts and by the expression of $r t T E R T$ mRNA. Copy number of $r t T E R T$ was assessed by digital droplet PCR (ddPCR) in relation to Mstn and Actb. Levels of $r t T E R T$ mRNA were normalized to HPRT1 and calculated as fold change compared to 4T1luc2_rtTERT_B5 clone characterized by the lowest level of $r$ TERT expression. Data represent an average of at least two independent assays. Nn: number, N/A: not applicable.

\begin{tabular}{lllll}
\hline $\begin{array}{l}\text { Clones of 4T1luc2 } \\
\text { Cells with rtTERT } \\
\text { Inserts, Full Name }\end{array}$ & $\begin{array}{l}\text { Abbreviated } \\
\text { Name }\end{array}$ & $\begin{array}{l}\text { Nn of Genomic } \\
\text { Copies of } \boldsymbol{r t T E R T} \\
\text { by } \text { Actb }\end{array}$ & $\begin{array}{l}\text { Nn of Genomic } \\
\text { Copies of } \boldsymbol{r t T E R T} \\
\text { by } \text { Mstn }\end{array}$ & $\begin{array}{l}\text { rtTERT mRNA } \\
\text { Expression } \\
\text { Relative to HPRT1 }\end{array}$ \\
\hline 4T1luc2_rtTERT_B5 & B5 & $0.57 \pm 0.08$ & $0.45 \pm 0.02$ & $1.00 \pm 0.00$ \\
4T1luc2_rtTERT_C6 & C6 & $1.33 \pm 0.14$ & $1.05 \pm 0.09$ & $6.56 \pm 1.63$ \\
4T1luc2_rtTERT_H9* & H9 & $2.96 \pm 0.24$ & $1.66 \pm 0.19$ & $15.28 \pm 1.72$ \\
4T1luc2_rtTERT_F1 & F1 & $0.70 \pm 0.06$ & $0.70 \pm 0.06$ & $5.95 \pm 0.70$ \\
4T1luc2 & 4T1luc2 & N/A & N/A & N/A \\
\hline
\end{tabular}

* No difference between nn of genomic copies of rtTERT determined using Actb and Mstn reference genes for all clones except 4T1luc2_rtTERT_H9 *.

Number of inserts of $r$ TERT into 4T1luc2 genome was assessed using ddPCR and compared with the copy number of two housekeeping genes, beta-actin (Actb) and myostatin (Mstn), both with ploidy 1 (two copies per genome). For three cell lines, Mstn/Actb relative copy number was close to 2 , and for 4T1luc2_rtTERT_H9 line, it was close to 3.5, which implies a change in the relative copy number of these house-keeping genes towards each other (Table 2 and Supplementary Figure S2D). Level of expression of rtTERT mRNA by the generated clones was assessed using real-time PCR, calculated by 2-ddCt method and normalized to the level of rtTERT mRNA in the 4T1luc2_rtTERT_B5 cell line where it was the lowest (Table 2). All clones demonstrated detectable levels of expression of $r t T E R T$ mRNA (Table 2) which tended to correlate to the copy number of $r$ TERT (Spearman test, $r=1, p=0.08, n=4$ ).

We performed cell cycle analysis of the daughter clones compared to the parental 4 T1luc 2 cells. The analysis revealed that three daughter clones had reduced population of cells in G0/G1 and increased population of cells in S and G2/M phase areas (Figure 6C) indicative of increased cell proliferation. At the same time, the doubling time for all subclones was similar to that of the parental cells over 3 weeks of consequent observations (Kruskal-Wallis, $p>0.05, n=10$ ).

Observed changes in the cell cycle prompted us to evaluate the genomic stability of rtTERT-expressing 4T1luc2 subclones. The assay was done using immunofluorescent microscopy with antibodies detecting phosphorylated form of $\mathrm{H} 2 \mathrm{~A}$ histone family member $\mathrm{X}$, which forms in response to double-stranded DNA breaks ( $\gamma$-H2AX foci; [59]). Interestingly, highly malignant tumor cell line 4T1luc2, genetically unstable, p53 ${ }^{\text {null }}$, with complex aneuploid karyotype [60-62], and two of the subclones, 4T1luc2_rtTERT_C6 and 4T1luc2_rtTERT_H9, appeared to be relatively genomically stable (few $\gamma$-H2AX foci; Figure 7A, panel I, and Figure 7A, panel II,III,E). On contrary, 4T1luc2_rtTERT_F1 and 4T1luc2_rtTERT_B5 exhibited intense disperse anti- $\gamma$-H2AX nucleus staining (Figure 7A, panel IV,V,E) indicative of double-stranded DNA breaks, a hallmark of genomic instability. 


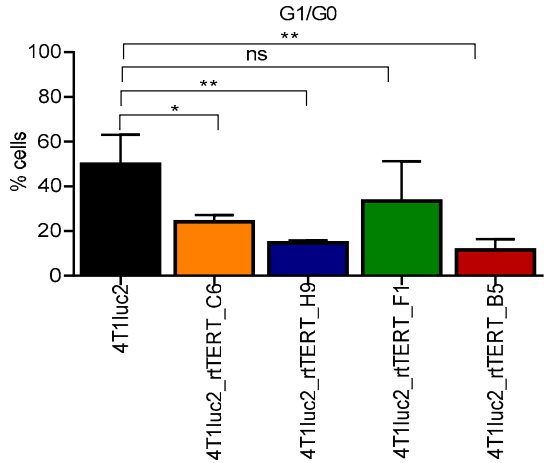

(A)

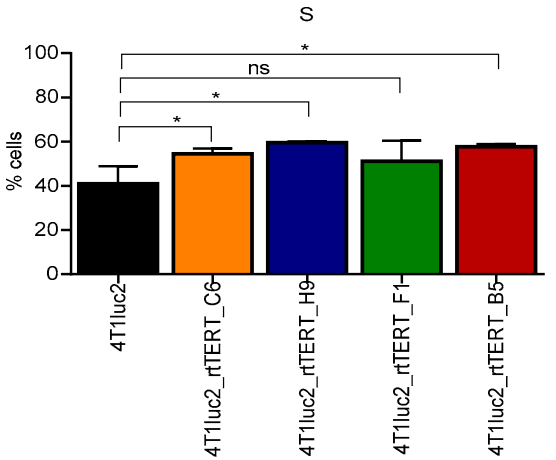

(B)

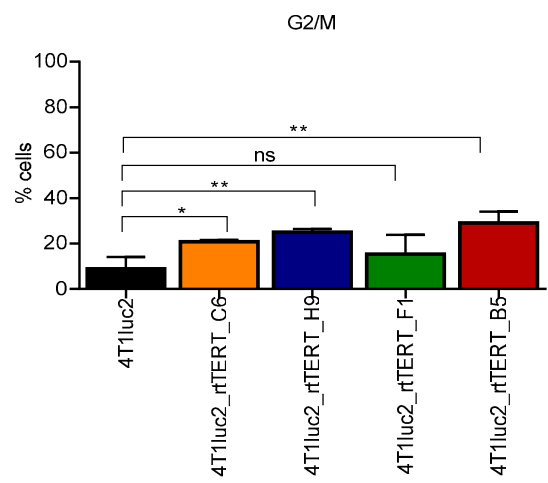

(C)

Figure 6. Cell cycle distribution for daughter clones of 4T1luc2 expressing rtTERT: G1/G0 phase (A), $S$ phase (B), and G2/M phase (C). Distribution of cells in G1/G0, S, and G2/M areas was assessed using Watson pragmatic algorithm [46] in the NovoExpress software. In control groups, peak G1 was determined manually according to the manufacturer's recommendations and peak G2 was set at $\times 1.75$ of G1 peak. Further analysis was performed automatically with preset G1 and G2 peaks and CVs at all samples. Data were analyzed using two-tailed $t$-test, ${ }^{*} p<0.05 ;{ }^{* *} p<0.01 ;$ ns-not significant.

High genomic instability can induce overexpression of the endogenous TERT via multiple nonexclusive mechanisms [63,64]. We analyzed if this was the case for the clones overexpressing rtTERT. The level of expression of endogenous TERT was assessed by immunofluorescence staining of cells with anti-TERT antibodies against an epitope outside its reverse transcriptase domain (Ab 191523), i.e., not detecting the expression of rtTERT introduced by lentiviral transduction (Figure 7A, panels I-V). Series of simultaneous daughter and parental cell line stainings with Ab191523 were performed, immunofluorescence signals of single cells were quantified, and the average ratio of anti-TERT signal generated by daughter clones to that of the parental 4T1luc2 cells was calculated. This revealed a significant increase in the expression of endogenous TERT by 4T1luc2_rtTERT_F1 and 4T1luc2_rtTERT_B5 cells (which exhibited genomic instability), whereas the levels of expression of endogenous TERT by two other clones did not differ from that in 4T1luc2 cells (Figure 7A, panels IV, V versus panels II, III, compared to I, respectively; Figure 7A).

Thus, among four generated clones, two were significantly different from the parental 4T1luc2 cells in their cell cycle characteristics, the degree of genomic instability, and levels of expression of endogenous TERT. These made them inapplicable for the study of the effect(s) of rtTERT expression on the capacity of 4T1luc2 cells to form tumors and metastasis. Of note, both B5 and F1clones were characterized by the low number of rtTERT genomic inserts and low levels of expression of rtTERT (Table 2) indicating that the observed alterations were unrelated to overexpression of exogenous rtTERT. Two remaining clones 4T1luc2_rtTERT_C6 and 4T1luc2_rtTERT_H9, similar to 4T1luc2 in genomic 
stability, cell cycle parameters, and levels of expression of endogenous TERT, were taken for further in vivo assessment of tumorigenicity.
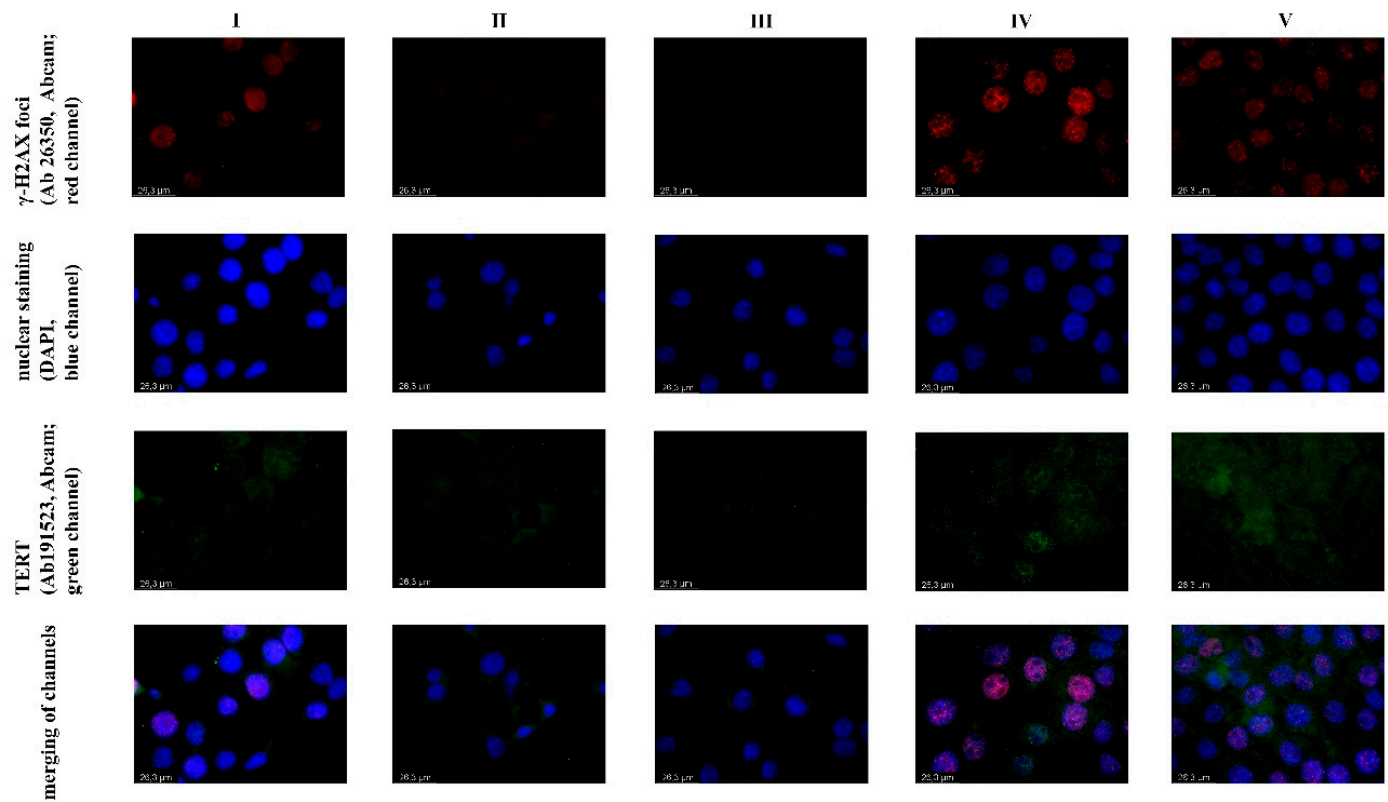

I-4T1luc2, II-C6, III-H9, IV-F1, V-B5

(A)

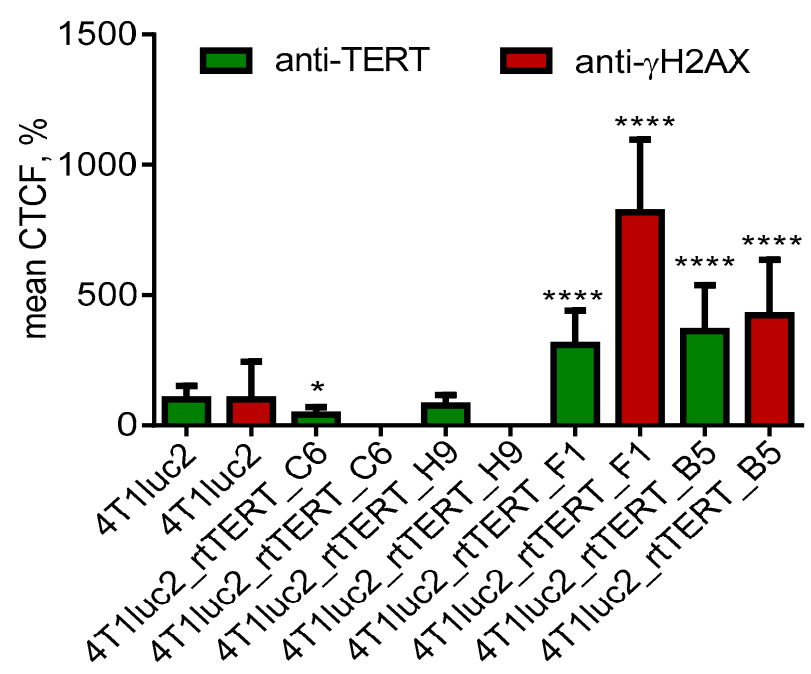

(B)

Figure 7. Fluorescent microscopy of 4T1luc2 cells (Panel I) and daughter clones expressing rtTERT: 4T1luc2_rtTERT_C6 (II), 4T1luc2_rtTERT_H9 (III), 4T1luc2_rtTERT_F1 (IV), and 4T1luc2_rtTERT_B5 (V). Staining of $\gamma$-H2AX foci (Ab 26350, Abcam; red channel); nuclear staining (DAPI, blue channel); TERT (Ab191523, Abcam; green channel); merging of channels (A); corrected total cell fluorescence (CTCF) for anti- $\gamma$-H2AX (red signal) and anti-TERT (green signal) relative to that exhibited by 4T1luc2, in percentage (B). For each cell line, at least five microscopic fields were assessed, and the average CTCF generated by specific staining were counted. CTCF was calculated for all cells as described in Materials and Methods. Results were analyzed using Kruskal-Wallis test with Dunn's multiple comparison test. ${ }^{*} p<0.05 ;{ }^{* * *} p<0.0001$. 


\subsection{Tumorigenic Potential of 4T1luc2 Clones Expressing RT-TERT}

Clones 4T1luc2_rtTERT_C6, 4T1luc2_rtTERT_H9, and parental 4T1luc2 cells were ectopically implanted into 8-week-old female BALB/c mice in three different doses, and tumor formation was monitored by in vivo BLI and calipering (Figure 8). After injection of $2.5 \times 10^{3}$ cells, rtTERT-expressing cell lines either formed small tumors, which grew at a slower rate than the parental clones (clone H9), or rejected tumors without growth (clone C6) (Figure 8A). Injections of $5 \times 10^{3}$ and $1 \times 10^{4}$ 4T1luc2_rtTERT_H9 cells led to the formation of slowly growing tumors, which by experimental end point were $3-5$ times smaller than tumors formed by the parental clone (Figure 8B-E). Of eight injections of $5 \times 10^{3}$ or $1 \times 10^{4} 4$ T1luc2_rtTERT_C6 cells, six were rejected after transient growth or without growth (Figure 8B-E). Mice that rejected tumors had scars at the site of injection (after healing of inflammatory infiltrates) sized $<1 \mathrm{~mm}^{3}$.
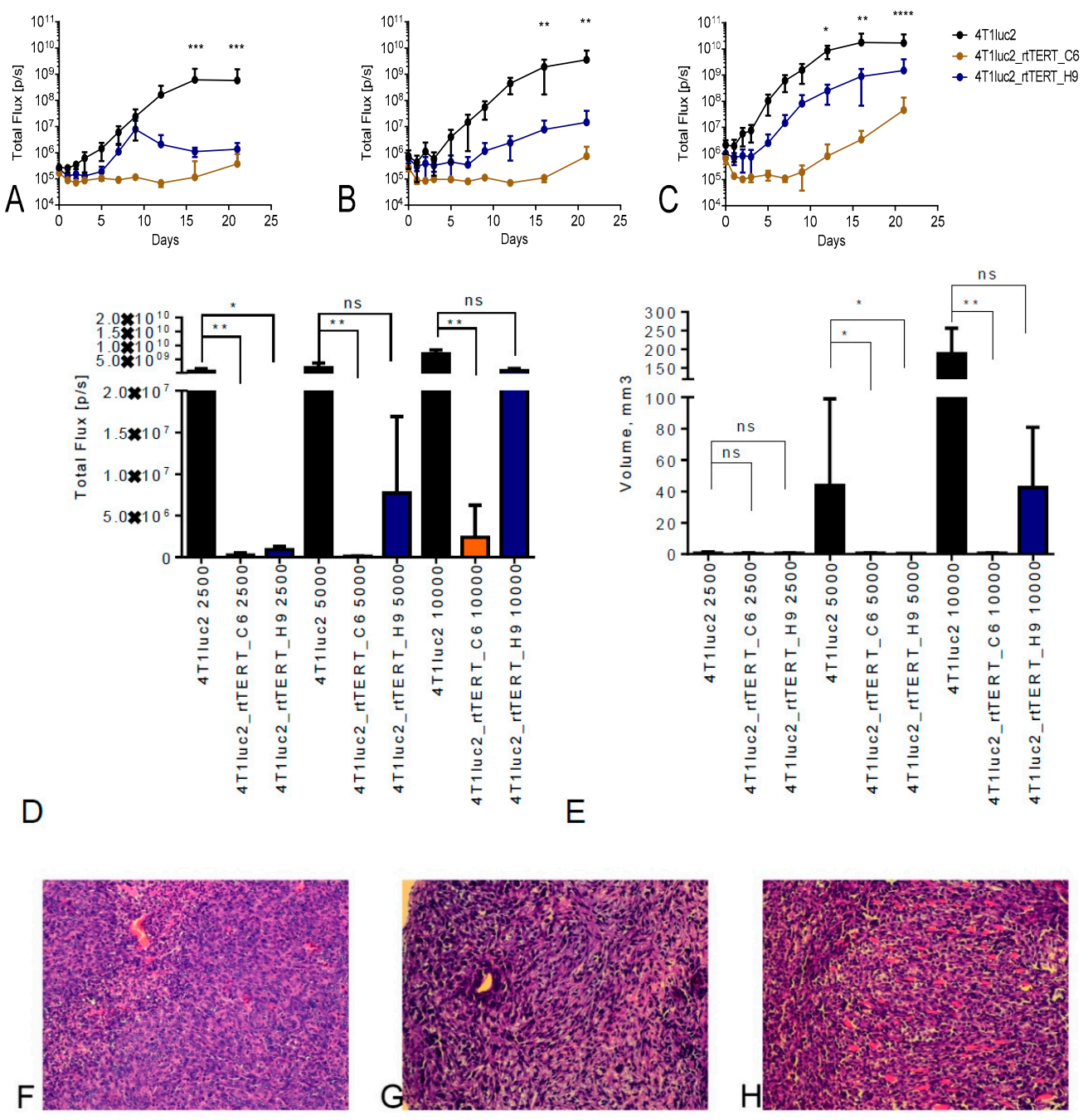

Figure 8. Generation of tumors by 4T1luc2 clones expressing rtTERT. Tumor growth rate was assessed using total fluorescence signal from the site of injection of 2500 (A), 5000 (B), and 10,000 (C) cells. Tumor volume was evaluated by total fluorescence signal from the site of cell injection by day 16 (D) or by calipering at day 21 (E). Histochemical characterization of the solid tumors formed by the parental 4T1luc2 cells (F) and their derivatives expressing rtTERT 4T1luc2_rtTERT_C6 (G); 4T1luc2_rtTERT_H9 (H) after ectopic implantation into BALB/c mice (H\&E staining, magnification 200×). Results of tumor growth (A-C) were analyzed using RM two-way ANOVA with Dunnett's multiple comparison test. Data on tumor volumes (D,E) were analyzed using Kruskal-Wallis with Dunn's multiple comparison test. ${ }^{*} p<0.05 ;{ }^{* *} p<0.01 ;{ }^{* * *} p<0.001 ;{ }^{* * * *} p<0.0001$; ns-not significant. 
Tumors were excised, fixed, paraffin embedded, sectioned, stained with hematoxylin and eosin, and subjected to the analysis of morphology with tumor grading (Figure $8 \mathrm{~F}-\mathrm{H}$ ). All tumors could be characterized as high grade (G3) tumors of low differentiation with mixed epithelioid (dominant) and sarcomatoid appearance. Multitude of cells within tumors had pleomorphic nuclei with several nucleoli. For 4T1luc2 and 4T1luc2_rtTERT_C6, the mitotic activity was low to moderate, whereas for tumors formed by 4T1luc2_rtTERT_H9, the mitotic activity was high. Atypical mitosis was presented in all samples. Tumors had multiple areas of multifocal necrosis surrounded by the inflammatory infiltrates consisting mostly of neutrophils and mononuclear cells; non-necrotic intratumoral tissues contained single tumor cells. Tumors demonstrated invasive growth into muscles and subcutaneous fat (Figure 8F-H). Altogether, morphologically, tumors were undistinguishable from those formed by the parental clone, i.e., expression of rtTERT limited the in vivo tumor growth, but not the characteristics of the tumors formed by 4 T1luc 2 clones.

\subsection{Metastatic Potential of 4T1luc2 Clones Expressing rtTERT}

Further, we compared the metastatic activity of 4T1luc2 and rtTERT-expressing daughter clones. For this, we assessed organs of mice excised at the experimental end point for the presence of Luc-expressing tumor cells using ex vivo imaging [42]. Specifically, we monitored total photon flux from lungs, liver, spleen, and kidneys of mice implanted with 4T1luc2_rtTERT_C6 and 4T1luc2_rtTERT_H9 as compared to the parental 4T1luc2 cells. Photon flux from lungs and livers of mice bearing rtTERT-expressing tumors was significantly lower than signal emitted by lungs and livers of mice implanted with 4T1luc2 (Figure 9A,B, respectively). Photon flux from other organs of 4T1luc2_rtTERT_C6- and 4T1luc2_rtTERT_H9-implanted mice did not exceed the background levels indicating that these organs, on contrary to the organs of 4T1luc2-implanted mice, were not infiltrated by Luc-expressing tumor cells (Figure 9C,D).

Liver appears to be a highly representative organ for the histological assessment of metastatic activity of 4T1luc 2 cells [42,65]. Although 4T1luc2 cells poorly metastasize into the liver, more aggressive 4T1luc2 variants readily form liver metastases [42]. With this in mind, we performed the histochemical study of the livers of mice implanted with 4T1luc2 cells expressing rtTERT. Livers were excised, fixed, paraffin embedded, sectioned, stained with hematoxylin and eosin, and analyzed for the presence of metastases, single infiltrating tumor cells, and leukocytes (Figure 9E-G). Cell lines 4T1luc2_rtTERT_H9 and 4T1luc2_rtTERT_C6 generated significantly lower average number of liver metastases than the parental cell line $(p<0.001$; Figure 9H). The average size of liver metastases did not differ (Figure 9I). Number of liver metastases correlated with the photon flux (max radiance) from the liver, reflecting the number of Luc-expressing tumor cells infiltrating the liver $(\mathrm{R}=0.5 ; p=0.024$; Supplementary Figure S8A). The latter demonstrated the usefulness of ex vivo organ imaging as a rapid high-throughput method of evaluation of metastatic activity.

We have also assessed leukocyte infiltration into the liver. Implantation of 4T1luc2_rtTERT_C6 induced significantly lower leukocyte infiltration into the liver than implantation of 4T1luc2 $(p<0.01)$; for 4T1luc2_rtTERT_H9 cells, the effect was similar to that of the parental cells (Figure 9J; $p>0.05$ ). Leukocyte infiltration into the liver correlated with the number of liver metastases $(p=0.00001$; Supplementary Figure S8B), indicating that infiltrating tumor cells attracted cells of the immune system. Thus, we confirmed that rtTERT expressing 4T1luc2 clones were compromised in their capacity to grow in vivo and form metastasis in the distal organs. 


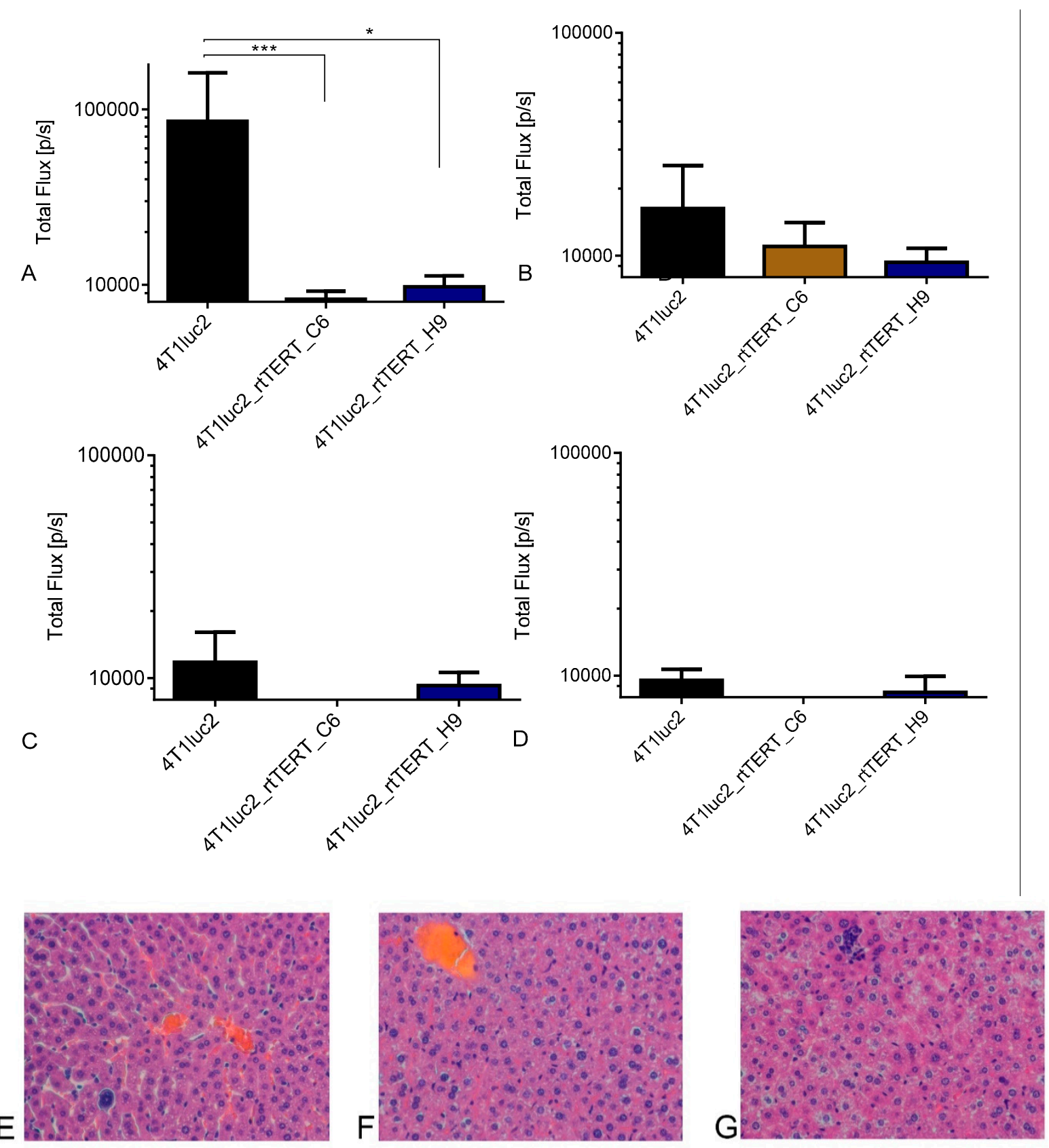

Figure 9. Cont. 

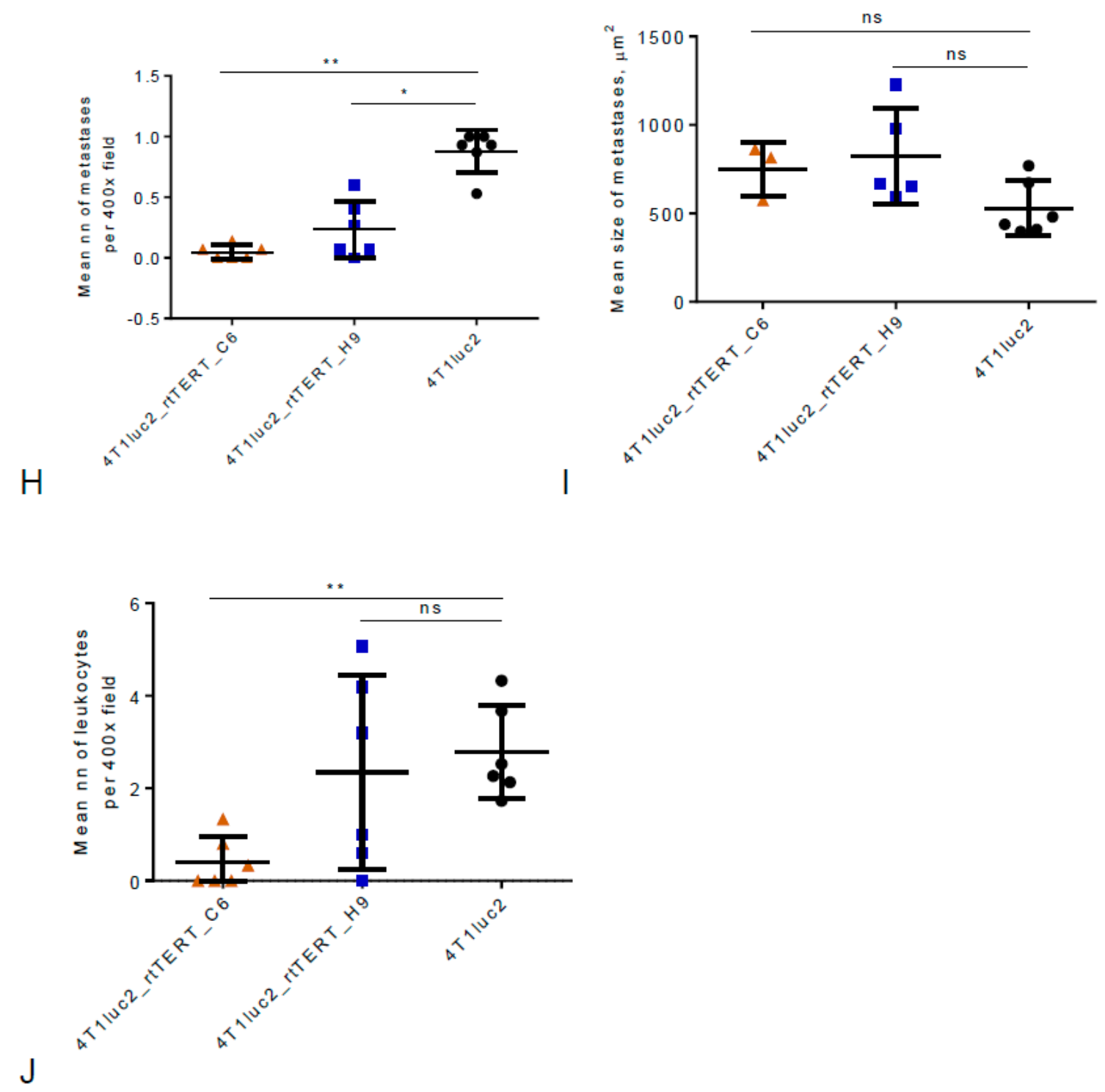

Figure 9. Assessment of the level of infiltration of Luc-expressing tumor cells into the organs of BALB/c mice ectopically implanted with 4T1luc2 and derivative clones 4T1luc2_rtTERT_C6 and 4T1luc2_rtTERT_H9 expressing rat rtTERT. Infiltration of organs by Luc-expressing tumor cells assessed by ex vivo BLI of lungs (A), liver (B), spleen (C), and kidneys (D). Values represent the mean total flux $(\mathrm{p} / \mathrm{s}) \pm \mathrm{SD}(n=6)$. Histochemical characterization of liver metastases formed by the parental 4T1luc2 cells (E) and their derivatives 4T1luc2_rtTERT_C6 (F) and 4T1luc2_rtTERT_H9 (G); H\&E staining, magnification $400 \times$. Comparison of the average number of liver metastases $(\mathbf{H})$, each figure (red triangle, blue rectangular and black circle) represents single mouse), average size of liver metastases, in $\mu \mathrm{m}^{2}$ (I), each figure (red triangle, blue rectangular and black circle) represents single metastase), and average nn of leukocytes infiltrating the liver (J), each figure (red triangle, blue rectangular and black circle) represents single mouse). Number and size of metastases and number of infiltrating leukocytes were calculated in 15 high power $(400 \times)$ microscope fields of hematoxylin-eosin-stained slides by computer-assisted morphometry. Data were analyzed by Kruskal-Wallis test followed by Mann-Whitney test. ${ }^{*} p<0.05 ;{ }^{* *} p<0.01{ }^{* * *} p<0.001$; ns-not significant.

3.9. Cellular Immune Response against Epitopes of TERT in Mice Implanted with rtTERT-Expressing 4 T1luc2 Cells

Finally, we assessed if limited growth of rtTERT-expressing tumors was related to an adaptive immune response against TERT/rtTERT. For this, we assessed immune response to TERT by splenocytes 
of representative number of mice from each of the groups, slitting them into those rejecting tumors $(n=4)$, restricting tumor growth $(n=4)$, and not restricting tumor growth $(n=4)$. Mice were assessed in two independent runs, taking two mice from each cluster. Their splenocytes were tested for the capacity to produce IFN- $\gamma$, IL-2, and TNF- $\alpha$ in response to stimulation with TERT6 and TERT8, which we have shown to be specifically recognized by T cells of mice DNA-immunized with rat TERT (TERT7 was excluded as it partially overlapped TERT8) and against epitopes of TERT lying outside rtTERT: TERT1 as an epitope inducing T cell response in DNA-immunized mice and TERT2 as an autoepitope of TERT recognized by all mice. Cytokine production was assessed by multiparametric flow cytometry and presented as percent of mono-, di-, and tricytokine producing CD4+ and CD8+ T cells (as for DNA immunized mice). Stimulation with PMA served as a positive control. To get an integrative overview of $\mathrm{T}$ cell reactivity, we presented data as a pile up of all TERT-reactive T cell populations (Figure 10A,B).

Mice implanted with 4T1luc2_rtTERT_C6 line not developing tumors demonstrated no cytokine response to stimulation with any of the TERT-derived peptides (Figure 10A,B and Supplementary Figure S9). Mice implanted with 4T1luc2-rtTERT_H9, capable to restrict tumor growth, exhibited increased percent of CD4+ and CD8+ T cells responding to stimulation with TERT1, 6, and 8 by monoand multicytokine production, dominated by secretion of TNF- $\gamma$ (up to $6 \%$ of CD4+ and 11\% of CD8+ T cells) and also cytokine response to the autoepitope in TERT2 (Figure 10A,B and Supplementary Figure S9). Mice implanted with the parental cell line, unable to limit tumor growth, responded to TERT1, 6, and 8 by limited cytokine production: reactive CD $4+$ constituted $1-2 \%$, and CD $8+-2-5 \%$ of respective $\mathrm{T}$ cell populations (Figure 10A,B). At the same time, their $\mathrm{T}$ cells strongly reacted to stimulation with TERT2: reactive CD4+ and reactive CD8+ constituted $6 \%$ and over $10 \%$ of the total CD4+ and CD8+ T cells, respectively (Figure 10A,B and Supplementary Figure S9).

We analyzed the overall profile of cytokine response to TERT epitopes by the Friedman ANOVA test with Kendall Coefficient of concordance applying a stringent criterion of statistical difference ( $p$ value was set at $<0.01$ to detect only highly significant differences). Analysis demonstrated similarity in the overall profile of cytokine response to the autoepitope in TERT2 in all mice with growing tumors (implanted with 4T1luc2 or with 4T1luc2_rtTERT_H9), whereas mice that rejected challenge with 4T1luc2_rtTERT_C6 demonstrated no response to TERT2 by either CD4+ or CD8+ T cells (Figure 10A,B; Supplementary Figure S9; and Supplementary Table S4). There was no difference in response to TERT2 in mice able (4T1luc2_rtTERT_H9) and unable (4T1luc2) to restrict tumor growth $(p>0.05$; Supplementary Figure S9A,B). This indicated that $\mathrm{T}$ cell immune response against the autoepitope in TERT2 was not involved in the immune control of tumor growth. TERT1 induced strong TNF- $\alpha$ production, mainly by CD8+ T cells, in mice that restricted growth of 4T1luc2_rtTERT_H9 tumors, low response in mice with unrestricted growth of 4T1luc2 tumors, and no response in mice rejecting challenge with 4T1luc2_rtTERT_C6 cells (Figure 10A,B and Supplementary Table S4). Major difference was noted in the T cell response to stimulation with TERT6 and TERT8, presented by rtTERT-expressing 4T1luc2 cells. TERT6 and TERT8 induced strong multicytokine response of CD4+ and CD8+ cells in mice that restricted growth of 4T1luc2_rtTERT_H9 tumors, low response in mice with unrestricted growth of 4T1luc2 tumors, and no response in mice rejecting 4T1luc2_rtTERT_C6 cells (Figure 10A,B; Supplementary Figure S9C-F; and Supplementary Table S4). Assessment of the overall profile of cytokine production in response to TERT6 and TERT8 allowed to discriminate mice with growing tumors (4T1luc2) from those restricting tumor growth (4T1luc2_rtTERT_H9) and those rejecting tumors (4T1luc2_rtTERT_C6) (Supplementary Figure S9C-F and Supplementary Table S4). This phenomenon was not related to the overall reactivity of T cells, as 4T1luc2-, 4T1luc2_rtTERT_C6-, and 4T1luc2_rtTERT_H9-implanted mice did not differ in their response to stimulation with mitogen PMA (Supplementary Figure S10A-D and Supplementary Table S4). 

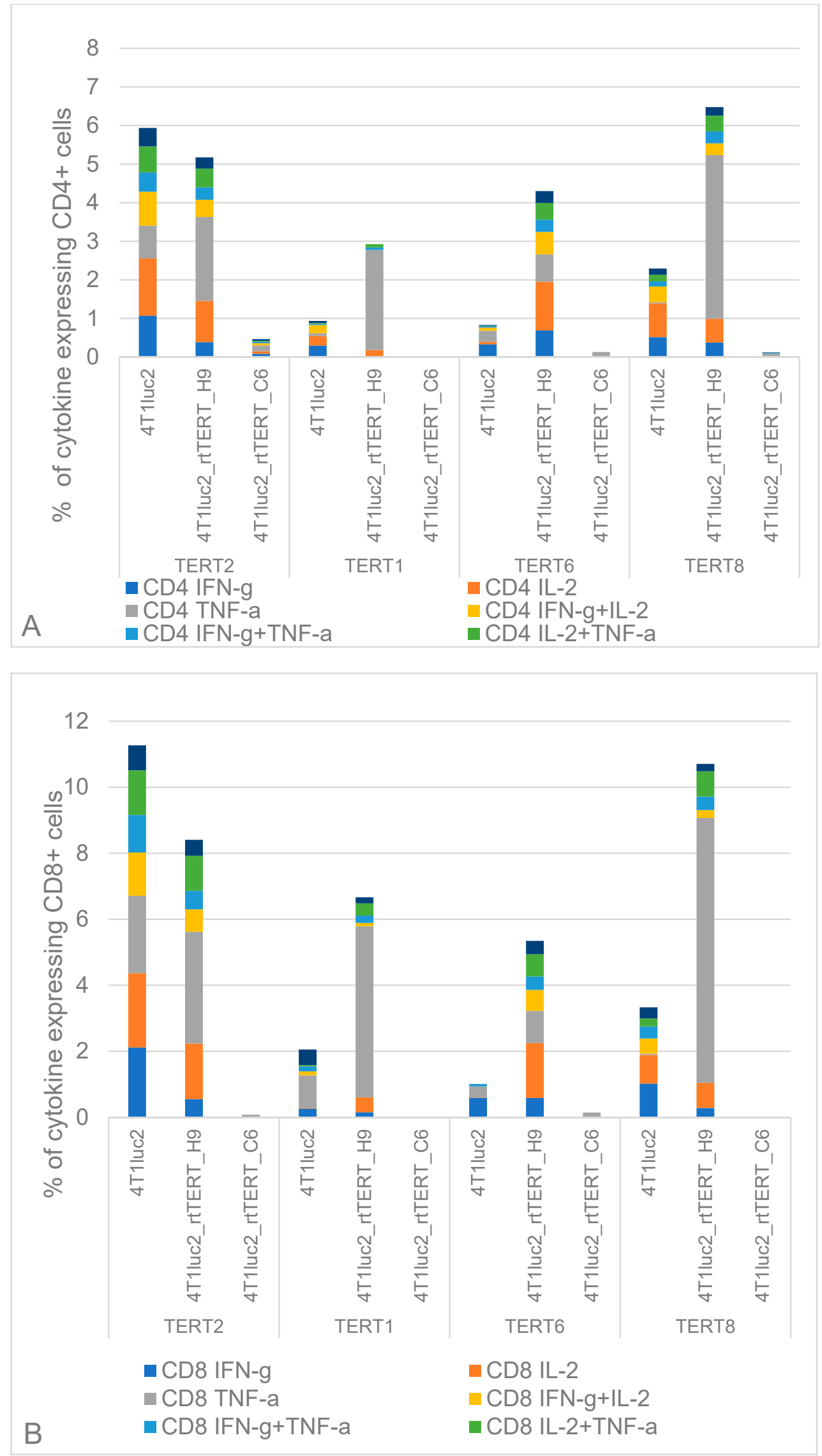

Figure 10. Immune recognition of TERT derived peptides by splenocytes of mice implanted with 
4T1luc2,4T1luc2_rtTERT_H9, or 4T1luc2_rtTERT_C6. Immune recognition is represented as percent of CD4+ (A) and CD8+ T cells (B) responding to stimulation with TERT 1, 2, 6, and 8 (Table 1) by production of IFN- $\gamma$, IL-2, TNF- $\alpha$, IFN- $\gamma /$ IL-2, IFN- $\gamma /$ TNF- $\alpha$, and IFN- $\gamma /$ IL-2/TNF- $\alpha$ registered by multiparametric flow cytometry. Graphs show a pile up of the average percent of cytokine secreting CD4+ and CD8+ T cells of four mice per group, assessed in two independent runs taking two mice from each group.

Further, we assessed the relation between growth of tumors in mice implanted with 4T1luc2 clones (by tumor size at the experimental end point) and specific parameters of cellular immune response against autoepitope TERT2 and epitopes represented by TERT1, 6 , and 8 on the example of IFN- $\gamma /$ IL-2 secreting CD4+ and CD8+ T cells. As was shown for the overall profile of cytokine production by CD4+ and CD8+ T cells (Supplementary Figure S9 and Supplementary Table S4), mice not restricting or partially restricting tumor growth did not differ in the percent of TERT2-specific IFN- $\gamma / \mathrm{IL}-2$ secreting CD4+ or CD8+ T cells (Supplementary Figure S11A,B). At the same time, mice partially suppressing tumor growth tended to have higher percent of IFN- $\gamma / \mathrm{IL}-2$-positive CD8+ responding to TERT1, 6, and 8; difference for CD4+ T cells did not reach the level of significance (Supplementary Figure S11C,D). Mice that rejected the tumors had no TERT-specific CD4+ or CD8+ T cells (Supplementary Figure S11A-D).

Next, we correlated the parameters of CD4+ and CD8+ T cell response to TERT1, 2, 6, 8, to tumor growth. Percent of CD4+ or CD8+ T cell specific to TERT1, TERT6, or TERT8 did not correlate with either photon flux from tumors by day 16 or tumor size by the experimental end point (all $p$ values $>0.05$; data not shown). At the same time, tumor size tended to correlate to the percent of TERT2-specific CD4+ T cells responding TERT2 stimulation by production of IL-2, IFN-g/IL-2, and IFN-g/IL-2/TNF-a ( $p$ values in the range of $0.058-0.071$ ), whereas no correlation was observed for TERT2-specific CD8+ T cells (Supplementary Figure S11E,F). Furthermore, for mice implanted with 4T1luc2_rtTERT_C6 and 4T1luc2_rtTERT_H9 cells, photon flux from the sites of injections positively correlated with percent of CD4+ T cells responding to TERT2 with production of TNF-a, and tended to correlate with percent of TERT2-specific IFN- $\gamma /$ TNF- $\gamma$ - and IFN- $\gamma /$ IL-2/TNF- $\gamma$-positive CD4+ T cells (Supplementary Figure S11G). Statistical significance in correlations was difficult to reach since all mice that rejected tumors without growth or after transient growth had no tumors, only measurable were the scars entered as formations with the size 0.5 to $1 \mathrm{~mm}^{3}$.

Thus, mice with growing tumors developed strong multicytokine response to autoepitope in TERT2, which was positively correlated to tumor growth. Capacity to build multicytokine CD4+ and CD8+ T cell response against epitopes in TERT1, TERT6, and TERT8 (specifically, TERT6 and TERT8, Supplementary Table S4) discriminated mice that were able to restrict tumor growth. The response was elicited mainly by IFN- $\gamma /$ IL-2-secreting CD8+ T cells (Supplementary Figure S11D). However, magnitude of the response expressed as populations of IFN- $\gamma / \mathrm{IL}-2 / \mathrm{TNF}-\gamma$ producing TERT6- and TERT8-specific CD4+ and CD8+ T cells showed no inverse correlation to the size of the rtTERT-expressing tumors (i.e., it was not a decisive factor in tumor rejection). Finally, mice that completely suppressed tumor growth demonstrated no $\mathrm{T}$ cell response to TERT, either autoepitope TERT2 or CD4+ and CD8+ T cell epitopes represented by TERT1, TERT6, and TERT8, i.e., the rejection was not dependent on the adaptive immune response. The latter phenomenon needs further study to define the underlying mechanism(s), which act in vivo, as cell line in question, 4T1luc2_rtTERT_C6, demonstrated in vitro growth parameters undistinguishable from 4T1luc2 and 4T1luc2_rtTERT_H9.

\section{Discussion}

Cancer vaccines of today widely employ nucleic acids, as naked DNA, RNA, or viral vectors. Vaccines based on TERT, a classical TAA overexpressed in the majority of tumors, are not an exclusion: four are based on plasmid DNA (NCT00753415, NCT02960594, NCT03265717, and NCT03502785). The best were shown to induce notable immune response in clinical trials [28,29]. However, 
fine specificity of anti-TERT immune response and immune correlates of their antitumor activity remain largely unknown. Here, we have developed and tested a new DNA vaccine targeting TERT based on the amino acid sequence of rat TERT, expected to overcome potential tolerance in preclinical trials in mice and potential clinical trials. Rat TERT and its variant with the C-terminal HA-tag encoded by synthetic expression-optimized genes, were used to immunize mice using an optimized protocol consisting of repeated intradermal injections followed by electroporation [47]. The effector potential of integral anti-TERT immune response was assessed in the "antigen challenge" experiment. Mice were primed with TERT or TERT-HA DNA and then boosted with the same plasmids mixed with DNA encoding luciferase (Luc); bioluminescence from the sites of booster injections was followed by in vivo bioluminescent imaging. Mice DNA-immunized with TERT/Luc demonstrated rapid disappearance of bioluminescence compared to controls boosted with vector/Luc, indicating presence of an effector immune response against TERT capable to clear TERT/Luc-coexpressing cells from the sites of immunization.

Next, we analyzed specificity of anti-TERT immune response, identifying types of the involved T cells and mapping their epitopes. For this, we assembled an epitopic map of TERT and localized regions containing clusters of $\mathrm{T}$ cell epitopes recognized by cancer patients and by animals (mainly mice) in the preclinical vaccine trials (Figure 1). These regions were represented by synthetic peptides (TERT1 to TERT9; Table 1). Assessment of CD4+ and CD8+ T cells of immunized mice for the capacity to produce IFN-g, IL-2, and TNF-a in response to stimulation with TERT peptides done by multiparametric flow cytometry demonstrated that out of nine peptides, eight (all except TERT4) contained T cell epitopes recognized by the immune system of BALB/c mice. TERT1, TERT3, and TERT5- 8 were recognized by mice DNA immunized with TERT/TERT-HA, whereas TERT2 and TERT9 induced potent cytokine secretion in all tested animals, including vector-immunized controls, i.e., contained autoepitopes of TERT. Specific immune response was manifested by coproduction of IFN- $\gamma / \mathrm{IL}-2 / \mathrm{TNF}-\alpha$ characteristic to the effector CD8+ and CD4+ T cells, which can eliminate tumor cells [66]. Importantly, loss of bioluminescence in the "antigen challenge" test was proportional to the percent of CD4+ and CD8+ T cells responding to stimulation with TERT6, TERT7, and TERT8 by simultaneous production of two or three cytokines. All three localized at aa 845-929 of TERT within the RT domain of TERT (rtTERT). HA-tag had no effect on the magnitude or profile of TERT-specific immune response. TERT DNA-immunized mice also developed an antibody response against TERT7 and TERT8 and recombinant rtTERT (but not other TERT-derived peptides). Earlier, a study of therapeutic TERT vaccine (viral vector in prime, DNA in boost) demonstrated its efficacy in treatment of canine lymphomas [67]. Its therapeutic effect correlated with the development of anti-TERT antibodies assessed by ELISA made using pools of TERT-derived peptides [67]. Our study indicates that these B-cell epitopes may be localized at aa 888-929 of TERT within rtTERT domain. Thus, we found the main immunogenic region of TERT to be localized in its RT domain, whereas immune response to other TERT regions was either autoimmune in nature or dispensable as not related to the immune clearance of TERT-expressing tumor cells.

This data led us to the hypothesis that DNA vaccine targeting TERT can be based on rtTERT and omit the rest of the protein. RT domain, located near the C-terminus of TERT (Figure 1), contains seven motifs (1, 2, A, B, C, D, and E) that are conserved in all RT families. These motives are located in the fingers and palm subdomains. They mediate specific interactions with the template, primer, and nucleotides and perform similar functions in all RTs, including RT of HIV-1, except for an insertion between motifs A and B' within the fingers subdomain, which is involved in multiple repeat addition exerted solely by TERT [68]. As we have found earlier, expression by tumor cells of HIV-1 RT makes them to form large and fast-growing tumors, as well as enhances their metastatic activity in mice [42]. If this is a property of all RTs, it can make DNA immunization with rtTERT unsafe, specifically in case of promising intratumoral immunotherapy [69], rtTERT expression by rtTERT-based DNA vaccine may enhance tumor aggressiveness. 
To delineate if this could be the case, we generated clones of murine mammary gland adenocarcinoma cell line 4T1luc2 expressing rtTERT and evaluated their in vitro properties and their potential to form tumors and metastasis upon implantation into syngenic BALB/c mice as compared to the parental cells. Of four 4T1luc2 clones made to express rtTERT, three had increased population of cells in S and G2/M phase areas indicative of enhanced cell proliferation, corroborating earlier findings of transgenic expression of TERT extending cell proliferation phase [70], a property which could thus be attributed to the expression of RT domain. Two of three clones with increased cell proliferation exhibited multiple foci formed by the phosphorylated form of H2A histone family member X ( $\gamma$-H2AX foci; [59]), significantly exceeding their level in the parental cell line. Such foci may reflect genomic instability of the clones [59] due to lentiviral transduction. The other explanation could be formation of the foci over uncapped (shelterin unprotected) telomeres (telomer dysfunction induced-foci, TIFs) because they are overexpressed, or too short to allow protein binding, or both [71,72]. Such dysfunctional telomeres or telomer-like structures can be synthesized by rtTERT complemented with TERT RNA-binding domain (TRBD) of endogenous TERT in complex with the endogenous telomerase RNA template (TERC) abundant in cancer cells [73]. Of note, RT domain alone can extend DNA and RNA primers to form short dsDNA and RNA/DNA hybrids [73,74]. Defective telomeres are exposed to DNA damage surveillance and could be degraded and/or subjected to end-to-end fusion events resulting in the overall genomic instability [72,75]. Resulting genomic instability/DNA damage can recruit endogenous TERT increasing its expression [63,64,76-79]. Indeed, clones with multiple $\gamma$-H2AX foci demonstrated increased levels of endogenous TERT, however, this involved only clones with a low number of $r t T E R T$ genomic inserts ( $<1$, Table 2). It is left to be found if (i) $\gamma$-H2AX foci reflect genomic instability of these specific clones after lentiviral transduction, causing overexpression of endogenous TERT or (ii) expression of exogenous rtTERT was the primary event leading to the synthesis of dsDNA and/or DNA/RNA hybrids and/or aberrant TERT activity due to complementation with endogenous TRBD and TERC resulting in the aberrant formation of uncapped telomeres, both causing formation of $\gamma-\mathrm{H} 2 \mathrm{AX}$ foci/TIFs and (compensatory) overexpression of endogenous TERT. Mechanistic aspects of this model of ectopic expression of rtTERT deserve a separate study. In the current one, we concluded that the genomic instability and increase in expression of endogenous TERT made clones 4T1Luc2_rtTERT_F1 and 4T1Luc2_rtTERT_B5 unfit (inadequate) for a comparative in vivo tumorigenicity study. Study of the in vivo effects of expression of RT TERT on tumorigenicity of murine adenocarcinoma 4T1luc2 cells was, therefore, carried on cell lines 4T1luc2_rtTERT_C6 and 4T1luc2_rtTERT_H9.

In vivo study in syngenic BALB/c mice demonstrated that 4T1luc2_rtTERT_C6 cells were severely compromised and 4T1luc2_rtTERT_H9 cells restricted in the capacity to grow in vivo. Tumors either did not grow (4T1luc2_rtTERT_C6) or grew slower and were of smaller size than those formed by the parental cells. Thus, on contrary to the effect of HIV-RT [42], expression by 4T1luc2 cells of RT domain of TERT did not lead to increase of their tumorigenicity, but instead restricted or even prohibited tumor growth. Metastatic activity of rtTERT-expressing 4T1luc2 cells was evaluated by ex vivo BLI of murine organs revealing presence of tumor cells. Tumor cells disseminated mainly into the lungs, whereas tumor cells in other organs were either very few or not detected. Ex vivo imaging data were corroborated by histochemical assessment done for the liver to compare with the data generated for HIV RT-expressing 4T1luc2 cells [42]. Importantly, maximum radiance from the liver correlated with the number of liver metastasis ( $R=0.5 ; p=0.024$; Supplementary Figure S7A), supporting the utility of BLI of excised organs as a high-throughput method to detect and quantify the metastasis. Altogether, data obtained by ex vivo bioluminescent organ imaging and selective histochemical assessment demonstrated that rtTERT-expressing 4T1luc2 clones were severely compromised in the metastatic activity compared to 4T1luc2 cells expressing HIV-1 RT [42], to the ancestral 4T1 cells and even to the parental 4T1luc2 cells (here and [65]).

Finally, at the experimental end point, we assessed anti-TERT immune response induced in mice injected with 4T1luc2 subclones. Mice restricting tumor growth were characterized by high percent of 
CD4+ and CD8 + T cells responding to TERT6 and TERT8 by multicytokine production (Supplementary Table S4). Such cells were low or absent in mice bearing adenocarcinomas formed by 4T1luc2 cells (Supplementary Table S4). Multicytokine response against these epitopes in rtTERT was dominated by the production of TNF- $\gamma$. In DNA-immunized mice, such response correlated with the loss of TERT/Luc-coexpressing cells from the sites of immunization. However, here, it did not show any correlation with the tumor size (Supplementary Figure S11). Furthermore, mice rejecting tumors exhibited no CD4+ or CD8+ T response to TERT1, TERT6, or TERT8, indicating that T cell response against these epitopes was not a critical determinant of the restricted tumor growth.

Earlier studies described the rejection of tumor cells after transient growth or without growth by neutrophils and macrophages (not tumor-associated macrophages) [80]. In this and other cases, rejection depended on the local availability (secretion or introduction) of multiple cytokines (IFN- $\gamma$, IL-2, IL-4, IL-7, IL-12, TNF- $\gamma$, GM CSF, and IFN- $\gamma / \beta$ ) [80-87]. Much attention had been drawn to type I IFNs constituting the first line of defense against cancer cells [88,89]. Type I IFNs are expressed in response to intracellular sensing of DNA, RNA, and DNA/RNA hybrids by the sensor proteins, such as Activation of the STimulator of INterferon Genes (STING), Retinoic acid-inducible gene-I (RIG-I), and Toll Like Receptors 7, 8, and 9 [90,91]. In transplanted tumor models in mice, systemic activation of DNA and RNA sensors triggers potent production of IFN $\alpha / \beta$ resulting in the death of tumor cells [92-95]. DNA sensing in cancer cells may be disrupted, but they retain a functional RNA-sensing mechanism [96]. We hypothesize that expression of rtTERT could have promoted this type of response through rtTERT-mediated expression of telomeric repeat-containing intracellular, shorter, and more stable cell-free RNA (TERRA and cfTERRA) [97,98] and/or telomeric DNA/RNA hybrids as regular (by)products of TERT activity [99]. TERRA, inside secreted exosomes, had been shown to mediate short-range innate immune signaling [97,98]. DNA/RNA hybrids are also effective in triggering type I IFNs [95]. Their formation detected by nucleic acid sensors could switch production of type I IFNs, which would restrict the growth of rtTERT-expressing tumor cells.

In both 4T1luc2- and 4T1luc2_rtTERT_H9-implanted mice developing tumors, we observed potent autoimmune response against TERT2, an autoepitope localized outside rtTERT. Percent of IFN- $\gamma /$ IL-2 secreting CD4+ T cells specific to this autoepitope positively correlated with the tumor size. No such correlation was observed for CD8+ T cells, indicating that the magnitude of immune response, at least by CD8+ T cells, was not straightforwardly determined by the tumor size and availability of endogenous TERT as immunogen. Of note, in DNA immunization, clearance of TERT/Luc-coexpressing cells was not correlated to the percent of CD4+ or CD8+ T cells specific to TERT2. Altogether, these data pointed at inability of TERT2-specific T cells to eradicate TERT-expressing (tumor) cells and limit tumor growth and even indicated a promotion of tumor growth by TERT2-specific CD4+ cells. This is in line with the earlier studies in BALB/c mice, which have shown that depletion of CD4+ T cells specific to TAA causes regression of syngenic tumors [100]. This observation is highly relevant to human cancer, as it was earlier shown that strong anti-TERT response by CD4+ T cells manifested by the production of IFN- $\gamma /$ IL-2 supports aggressive tumor growth [101].

In the context of cancer, CD4+ T cell subpopulations, immunosuppressive regulatory (Tregs), and pro-inflammatory Thelper 17 (Th17) cells, which normally act to fine-balance the adaptive immune responses, promote cancer progression and metastasis. Th17 cells shape tumor microenvironment, defining tumor phenotypes; Tregs promote metastasis and metastatic tumor foci development [102]. Recognition of certain TAA autoepitopes by T cells lacking lytic potential, particularly by Tregs and/or Th17 CD4+ T cells, may lead to their infiltration into tumors and mouse organs harboring tumor cells, with subsequent stimulation of tumor growth and metastases formation. Indeed, we observed a correlation between the numbers of organ infiltrating leukocytes and resident tumor cells. Presence of such CD4+ epitope(s) in a cancer vaccine is highly undesirable. Vaccine candidate(s) are preferable that could suppress an autoimmune inflammatory response in favor of a lytic response against epitopes, preferably of CD8+ T cells, not preexisting, but induced by immunization. Interestingly, mice which completely suppressed or restricted tumor growth exhibited no TERT2-specific autoimmune response, 
registered in all control animals. Disappearance of this response may indicate induction of tolerance (depletion of reactive clones from $\mathrm{T}$ cell repertoire). Possibility of such retargeting of the immune response away from the decoy (auto) epitopes, which induce inflammation and promote tumor growth, requests further study.

Thus, we have shown that DNA immunization with rat TERT induces a specific cellular and antibody response against its RT domain with a lytic potential, which may be harnessed to control tumor growth. On the contrary to HIV-1 RT, expression of rtTERT does not enhance tumorigenic properties of cancer cells (4T1luc2), but instead reduces their capacity to form tumors and metastasis, induces CD8+ T cell immune response to epitopes within rtTERT associated with restriction of tumor growth, and suppresses CD4+ T cell response to an autoepitope of TERT associated with tumor growth and metastatic activity. This indicates that TERT vaccine based on its RT domain would be safe to use, even for intratumoral immunization.

This raises a question whether cancer vaccine should in fact be based on the full length TERT, or rtTERT domain may be sufficient? Use of a single domain may provide certain benefits: (a) focusing of the immune response on the epitopes of lytic CD8+ and CD4+ T cells and reducing the immune response, which has no lytic potential and is not protective; (b) excluding autoepitopes as decoy epitopes with specific $\mathrm{T}$ cell immune response potentiating tumor growth; and (c) reducing size of DNA vaccine, which would result in a more efficacious DNA delivery [103,104].

Another aspect worth mentioning is the safety issue of TERT DNA vaccination. Deletion of the catalytic VDD triplet (and in some studies, of the nucleolar localization sequence) is considered sufficient to make TERT safe as DNA vaccine $[30,105]$. However, it was shown that the effect of TERT on cell proliferation is only in part linked to its enzymatic activity, as inactivated TERT can still stimulate cell proliferation $[106,107]$. TERT enzymatic activity is not a sole factor determining TERT-driven cell immortalization. TERT is a multifunctional protein capable to regulate gene expression, modulate cell signaling, influence cell cycle progression, inhibit apoptosis, protect mitochondria, and modulate DNA damage response [108]. Some of these functions are not linked to the enzymatic activities of TERT, but to intracellular interactions of TERT, specifically activation of Wnt/ $\beta$-catenin [108] and of NF-kB signaling pathways $[109,110]$. Mechanism(s) behind these effects of TERT are yet unknown and may be linked to interaction of TERT with specific cellular partners such as Myc involved in numerous cell-signaling cascades. Direct protein-protein interaction stabilizes Myc and promotes its transcription activity, including the protooncogenic ones. In the absence of TERT, Myc is degraded by the proteasome (as in normal cells). In malignant cells expressing TERT, interaction of TERT with Myc through its MBI domain stabilizes both proteins and promotes protooncogenic activity of Myc supporting proliferation of malignant cells, in part by direct activation of TERT transcription [111]. Inability of cells to degrade TERT together with TERT-stimulated cell proliferation are the prerequisites of TERT-induced cell immortalization. These properties (interaction with Myc with its stabilization and interference with cell signaling) are not abrogated by TERT inactivation. Some interactions (as interaction with Myc) involve yet unidentified domains/motives of TERT. Their "neutralization" would require a dramatic protein modification. Use of relatively short RT domain of TERT could be a solution. Besides, our data indicate that RT domain of TERT may act not only as an immunogen but also as a source of RNA and RNA/DNA triggering production of type I IFNs, i.e., provide in-built adjuvant(s) triggering the desired type of innate immune response against cancer cells.

\section{Conclusions}

In conclusion, topical, antigen/epitope specific retargeting of antitumor immune response may pave a way to new cancer vaccines. With this study, we have shown that it can be achieved by using single TAA domains, circumventing the complexity and variability of the full-length TAAs. This will also help to reduce an unwanted/excessive autoimmune response which could damage the host and support tumor growth. Such "module" vaccines can be introduced both systemically and intratumorally (by intratumoral DNA immunization or viral transduction). Such "tagged" tumors would then be 
made visible to the immune system trained by cancer vaccine. Intratumoral administration of rtTERT could also trigger production of type I IFNs, change tumor microenvironment, aiding to development of efficient adaptive antitumor response. We plan to test this approach in application to TERT in murine cancer models.

Supplementary Materials: The following are available online at http://www.mdpi.com/2076-393X/8/2/318/s1, Figure S1: Lentiviral vector pRRLSIN.cPPT.PGK used for transduction of 4T1luc2 cell line. Position of insertion of rtTERT gene marked in red. PGK-seq and LVT-200R PCR primers were used to confirm the insertion of lentiviruses encoding rtTERT into genome of 4T1luc2 cells, Figure S2: Results of primers validation. Two clearly distinguishable clusters of positive and negative droplets for Actb (A), Mstn (B), Tert (C); copy number of Mstn gene in relation to Actin B in 4T1luc2 and daughter clones (D), Figure S3: Gating of live and single cells. Green G1/G0 phase, yellow - S phase, turquoise - G2/M phase, Figure S4: Histograms of cells in different cell cycle phases. Green - G1/G0, yellow - S, turquoise - G2/M. Three replicates for each cell line, Figure S5: The example of the multiparametric flow cytometry analysis of the splenocytes stimulated by the incubation in the presence of peptide TERT8 inducing activation of both helpers and cytotoxic T-lymphocytes. The size of IFN- $\gamma$, double IFN- $\gamma /$ IL-2 and triple IFN- $\gamma / \mathrm{IL}-2 / \mathrm{TNF}-\alpha$-expressing cells populations are shown as proportion of respective cytokine-producing CD4+ or CD8+ cells, Figure S6: Expression of rat TERT in 293Tcells transiently transfected with rat TERT-encoding plasmids. Western blotting of the lysates of 293Tcells transfected with vector pVAX1 (lane 1), pVax-TERT (lane 2), and pVax-TERT-HA (lane 3). Blots were stained with commercial rabbit polyclonal anti-TERT antibodies raised against synthetic peptide (A), and re-stained with monoclonal anti-actin antibodies (B). Positions of molecular mass markers are given to the right in kDa, Figure S7: Immune recognition of TERT-derived peptides (Table 1) by CD4+ and CD8+ T cells of mice DNA-immunized with TERT or TERT-HA compared to vector-immunized mice analyzed by multiparametric flow cytometry. Percent of CD4+ (A) and CD8+ (B) T cells reacting to stimulation with TERT peptides by single cytokine expression. Values represent mean \pm SD. Difference between TERT, TERT-HA DNA-immunized and control vector-immunized mice was analyzed by Mann-Whitney test. Difference between TERT, TERT-HA DNA-immunized and control vector ${ }^{*}-p<0.05 ;{ }^{* *}-p<0.01$. No difference between TERT and TERT-HA DNA-immunized mice was found, all $p>0.05$, Figure S8: Correlates of the number of metastases in liver of mice implanted with 4T1luc2 cells expressing rtTERT. Average number of liver metastases correlates with max radiance from liver in ex vivo organ imaging $(R=0.5 ; p=0.024)(\mathrm{A})$; average number of liver metastases and their size correlates to the number of liver-infiltrating leukocytes $\left(R=0.83, p<10^{-4}\right)(B)$, Figure S9: Comparison of the overall profile of in vitro cytokine response of CD4+ (A, C, E) and CD8+ (B, D, F) T cells of mice implanted with rtTERT expressing cell lines 4T1luc2_rtTERT_H9 $(\mathrm{H} 9 ; \mathrm{n}=4)$ and 4T1luc2_rtTERT_C6 $(\mathrm{C} 6 ; \mathrm{n}=4)$ and parental cell line (4T1luc2; $\mathrm{n}=4$ ) to stimulation with TERT peptides: TERT2 presenting an autoepitope (A, B); TERT6 (C, D); and TERT8 (E, F). Cytokine production was assessed by multiparametric flow cytometry and presented as percent of mono-, di- and tri-cytokine producing CD4+ and CD8+ T cells. Statistical analysis was performed by Friedman ANOVA test and Kendall Coefficient of concordance (Statistica AXA 11.0). Criteria of statistically significant difference were set at $p<0.01$, Figure S10: Overall profile of in vitro cytokine response of CD4+ (A) and CD8+ (B) T cells of mice implanted with rtTERT expressing cell lines 4T1luc2_rtTERT_H9 (H9; $\mathrm{n}=4$ ) and 4T1luc2_rtTERT_C6 $(\mathrm{C} 6 ; \mathrm{n}=4)$ and parental cell line (4T1luc2; $\mathrm{n}=4)$ to stimulation with mitogen PMA. Cytokine production was assessed by multiparametric flow cytometry and presented as percent of mono-, di- and tri-cytokine-producing CD4+ and CD8+ T cells. Statistical analysis of the profile for CD4+ (C) and CD8+ T cells (D) was performed by Friedman ANOVA test and Kendall Coefficient of concordance (Statistica AXA 10.0); $p<0.01$ was considered as significant, Figure S11: Features of anti-TERT immune response promoting and restricting tumor growth. Percent of IFN/g/IL-2 secreting CD4+ (A, C) and CD8+ (B, D) T cells specific to TERT 2 (A, B) and TERT1, TERT6 and TERT8 (TERT168, summed) (C, D) in mice with aggressively growing tumors $(n=4)$, non-aggressive tumors (restricted tumor growth, $\mathrm{n}=4$ ) and no tumors (rejected tumors or tumors $<10 \mathrm{~mm} 3, \mathrm{n}=4$ ); Correlation of the tumor size (mm2) by experimental end-point to the percent of TERT2- specific CD4 (E) and CD8 (F) T cells secreting one, two or three cytokines; Correlation of tumor growth as photon flux from tumor implantation site by day 16 to percent of TNF-a secreting CD4+ positive T cells specific to TERT2 $(G, n=8)$. Multiple comparisons are done using Kruskal Wallis, and pair-wise, using Mann Whitney test; correlations, using Spearman ranking test (Statistica Axa 11), all $p$ values $<0.05$ are considered as significant, and $p<0.1$ as tendency to a difference. Immune recognition of TERT-derived peptides (Table 1) by CD4+ and CD8+ T cells of mice DNA-immunized, Table S1: Primers used in PCR, RT-PCR and ddPCR assays, Table S2: Thermal cycling protocol for ddPCR, Table S3: Correlations between \% of CD4+ and CD8+ T cells of TERT/TERT_HA DNA-immunized mice capable to respond to in vitro stimulation with peptides derived from aa of TERT (TERT5 - TERT8; Table 1) by secretion of multiple cytokines, and capacity of respective mice to clear cells co-expressing TERT/TERT-HA and Luc assessed by in vivo imaging (BLI) in antigen challenge (see Materials and Methods for description). BLI data represent loss of the photon flux from the site of booster injection with TERT/TERT-HA and Luc DNA on days 7, 9 and 12 (d7, d9, d12) compared to day 1 (d1) after the boost, in \%. Table shows Spearman correlation coefficients R, significant correlations $(p<0.05$ and $p<0.01)$ are depicted in red, Table S4: Comparison of the profiles of in vitro cytokine production by CD4+ and CD8+ T cells of mice implanted with rtTERT expressing cell lines 4T1luc2_rtTERT_H9 $(\mathrm{H} 9 ; \mathrm{n}=4)$ and 4T1luc2_rtTERT_C6 $(\mathrm{C} 6 ; \mathrm{n}=4)$ and parental cell line (4T1luc2; $\mathrm{n}=4)$ to stimulation with TERT2 presenting an autoepitope; TERT6, 8 and co-stimulation with TERT6 and TERT8. Cytokine production was assessed by multiparametric flow cytometry and presented as percent of mono-, di- and tri-cytokine-producing 
CD4+ and CD8+ T cells. Statistical analysis of integral profile of cytokine production was performed by Friedman ANOVA test and Kendall Coefficient of concordance (Statistica AXA 10.0), $p<0.01$ was considered as significant.

Author Contributions: Conceptualization, M.I., E.B., J.J., and D.K.; methodology, E.B., J.J., D.S., I.F., D.K., A.K. (Anastasia Kostysheva), E.D., D.A., A.K. (Alla Kondrashova), V.V.-E., O.L., O.E., S.P., M.A., L.H., I.K., T.G., I.G., and M.I.; software, J.J., E.B., A.K. (Alisa Kurlanda), I.F., D.K., A.K. (Anastasia Kostyusheva), A.A., D.A., A.K. (Alla Kondrashova), S.P., L.H., and I.K.; validation, D.S., I.F., D.K., E.S., A.I., and I.G.; formal analysis, J.J., E.B., I.F., D.K., and M.I.; investigation, J.J., E.B., D.K., and M.I.; resources, D.K., E.D., A.I., I.G., and M.I.; data curation, J.J., E.B., D.K., A.A., T.G., and M.I.; writing-original draft preparation J.J., E.B., and M.I.; writing-review and editing E.B., D.K., I.G., and M.I.; visualization, J.J., E.B., I.F., D.K., A.K. (Anastasia Kostyusheva), A.A., and E.S.; supervision, M.I.; project administration, J.J., D.S., E.D., and I.G. and funding acquisition, A.I. and M.I. All authors have read and agreed to the published version of the manuscript.

Funding: This research was funded by Latvian Science Council LZP-2018/2-0308, RFBR grants 17_54_30002, 17-00-00085, 17_04_00583, and COST actions CA17140 NANO2CLINIC, and CA16231 ENOVA. M.I. was part-time supported by H2020 project EAVI 681137. The APC was funded by Latvian Science Council LZP-2018/2-0308.

Acknowledgments: Authors wish to thank the Core Centrum of the Institute of Developmental Biology of Russian Academy of Sciences (Moscow) for help in performing fluorescent microscopy; the Center for Precision Genome Editing and Genetic Technologies for Biomedicine (Moscow) for help in application of the methods of genetic research; and the Department of Pathology, Riga Stradins University for support in the histochemical analysis of mouse tissues. We gratefully acknowledge technical assistance of Ms. Svetlana Capkevic (Riga Stradins University, Riga, Latvia) in the preparation of tissue slides.

Conflicts of Interest: Authors declare no conflicts of interests.

Data Availability: All data used to support the findings of this study are included within the article and the supplementary information file(s). Data not shown in the article used to support the findings of this study are available from the corresponding author upon request.

\section{References}

1. Liu, D.; Staveley-O'Carroll, K.F.; Li, G. Immune-based therapy clinical trials in hepatocellular carcinoma. J. Clin. Cell. Immunol. 2015, 6, 376. [CrossRef] [PubMed]

2. Harding, J.J.; El Dika, I.; Abou-Alfa, G.K. Immunotherapy in hepatocellular carcinoma: Primed to make a difference? Cancer 2016, 122, 367-377. [CrossRef] [PubMed]

3. Longo, V.; Gnoni, A.; Gardini, A.C.; Pisconti, S.; Licchetta, A.; Scartozzi, M.; Memeo, R.; Palmieri, V.O.; Aprile, G.; Santini, D. Immunotherapeutic approaches for hepatocellular carcinoma. Oncotarget 2017, 8, 33897. [CrossRef]

4. Cheever, M.A.; Higano, C.S. PROVENGE (Sipuleucel-T) in prostate cancer: The first FDA-approved therapeutic cancer vaccine. Clin. Cancer Res. 2011, 17, 3520-3526. [CrossRef] [PubMed]

5. Kalos, M.; June, C.H. Adoptive T cell transfer for cancer immunotherapy in the era of synthetic biology. Immunity 2013, 39, 49-60. [CrossRef]

6. Xie, Y.; Xiang, Y.; Sheng, J.; Zhang, D.; Yao, X.; Yang, Y.; Zhang, X. Immunotherapy for Hepatocellular Carcinoma: Current Advances and Future Expectations. J. Immunol. Res. 2018, 2018, 8740976. [CrossRef] [PubMed]

7. Greten, T.F.; Forner, A.; Korangy, F.; N’Kontchou, G.; Barget, N.; Ayuso, C.; Ormandy, L.A.; Manns, M.P.; Beaugrand, M.; Bruix, J. A phase II open label trial evaluating safety and efficacy of a telomerase peptide vaccination in patients with advanced hepatocellular carcinoma. BMC Cancer 2010, 10, 209. [CrossRef]

8. Trimble, C.L.; Morrow, M.P.; Kraynyak, K.A.; Shen, X.; Dallas, M.; Yan, J.; Edwards, L.; Parker, R.L.; Denny, L.; Giffear, M. Safety, efficacy, and immunogenicity of VGX-3100, a therapeutic synthetic DNA vaccine targeting human papillomavirus 16 and 18 E6 and E7 proteins for cervical intraepithelial neoplasia 2/3: A randomised, double-blind, placebo-controlled phase $2 \mathrm{~b}$ trial. Lancet 2015, 386, 2078-2088. [CrossRef]

9. Duperret, E.K.; Wise, M.C.; Trautz, A.; Villarreal, D.O.; Ferraro, B.; Walters, J.; Yan, J.; Khan, A.; Masteller, E.; Humeau, L.; et al. Synergy of Immune Checkpoint Blockade with a Novel Synthetic Consensus DNA Vaccine Targeting TERT. Mol. Ther. 2018, 26, 435-445. [CrossRef]

10. Impellizeri, J.A.; Ciliberto, G.; Aurisicchio, L. Electro-gene-transfer as a new tool for cancer immunotherapy in animals. Vet. Comp. Oncol. 2014, 12, 310-318. [CrossRef]

11. Gabai, V.; Venanzi, F.M.; Bagashova, E.; Rud, O.; Mariotti, F.; Vullo, C.; Catone, G.; Sherman, M.Y.; Concetti, A.; Chursov, A. Pilot study of p62 DNA vaccine in dogs with mammary tumors. Oncotarget 2014, 5, 12803. [CrossRef] [PubMed] 
12. Riccardo, F.; Aurisicchio, L.; Impellizeri, J.A.; Cavallo, F. The importance of comparative oncology in translational medicine. Cancer Immunol. Immunother. 2015, 64, 137-148. [CrossRef] [PubMed]

13. Ferraro, B.; Morrow, M.P.; Hutnick, N.A.; Shin, T.H.; Lucke, C.E.; Weiner, D.B. Clinical applications of DNA vaccines: Current progress. Clin. Infect. Dis. 2011, 53, 296-302. [CrossRef] [PubMed]

14. Flingai, S.; Czerwonko, M.; Goodman, J.; Kudchodkar, S.B.; Muthumani, K.; Weiner, D.B. Synthetic DNA vaccines: Improved vaccine potency by electroporation and co-delivered genetic adjuvants. Front. Immunol. 2013, 4, 354. [CrossRef]

15. Alvarez, R.D.; Huh, W.K.; Bae, S.; Lamb, L.S., Jr.; Conner, M.G.; Boyer, J.; Wang, C.; Hung, C.F.; Sauter, E.; Paradis, M.; et al. A pilot study of pNGVL4a-CRT/E7(detox) for the treatment of patients with HPV16+ cervical intraepithelial neoplasia 2/3 (CIN2/3). Gynecol. Oncol. 2016, 140, 245-252. [CrossRef]

16. Lopes, A.; Vandermeulen, G.; Preat, V. Cancer DNA vaccines: Current preclinical and clinical developments and future perspectives. J. Exp. Clin. Cancer Res. 2019, 38, 146. [CrossRef]

17. Mizukoshi, E.; Kaneko, S. Telomerase-Targeted Cancer Immunotherapy. Int. J. Mol. Sci. 2019, $20,1823$. [CrossRef]

18. Collins, K.; Mitchell, J.R. Telomerase in the human organism. Oncogene 2002, 21, 564-579. [CrossRef]

19. Cong, Y.-S.; Wright, W.E.; Shay, J.W. Human telomerase and its regulation. Microbiol. Mol. Biol. Rev. 2002, 66, 407-425. [CrossRef]

20. Harley, C.B.; Futcher, A.B.; Greider, C.W. Telomeres shorten during ageing of human fibroblasts. Nature 1990, 345, 458-460. [CrossRef]

21. Shay, J.; Bacchetti, S. A survey of telomerase activity in human cancer. Eur. J. Cancer 1997, 33, 787-791. [CrossRef]

22. Chiba, K.; Lorbeer, F.K.; Shain, A.H.; McSwiggen, D.T.; Schruf, E.; Oh, A.; Ryu, J.; Darzacq, X.; Bastian, B.C.; Hockemeyer, D. Mutations in the promoter of the telomerase gene TERT contribute to tumorigenesis by a two-step mechanism. Science 2017, 357, 1416-1420. [CrossRef] [PubMed]

23. Wu, K.J.; Grandori, C.; Amacker, M.; Simon-Vermot, N.; Polack, A.; Lingner, J.; Dalla-Favera, R. Direct activation of TERT transcription by c-MYC. Nat. Genet. 1999, 21, 220-224. [CrossRef] [PubMed]

24. Jafri, M.A.; Ansari, S.A.; Alqahtani, M.H.; Shay, J.W. Roles of telomeres and telomerase in cancer, and advances in telomerase-targeted therapies. Genome Med. 2016, 8, 69. [CrossRef] [PubMed]

25. Vinagre, J.; Almeida, A.; Populo, H.; Batista, R.; Lyra, J.; Pinto, V.; Coelho, R.; Celestino, R.; Prazeres, H.; Lima, L.; et al. Frequency of TERT promoter mutations in human cancers. Nat. Commun. 2013, 4, 2185. [CrossRef]

26. Kailashiya, C.; Sharma, H.B.; Kailashiya, J. Telomerase based anticancer immunotherapy and vaccines approaches. Vaccine 2017, 35, 5768-5775. [CrossRef]

27. Sohn, H.J.; Lee, J.Y.; Lee, H.J.; Sohn, D.H.; Cho, H.I.; Kim, H.J.; Kim, T.G. Simultaneous in vitro generation of CD8 and CD4 T cells specific to three universal tumor associated antigens of WT1, survivin and TERT and adoptive $\mathrm{T}$ cell transfer for the treatment of acute myeloid leukemia. Oncotarget 2017, 8, 44059-44072. [CrossRef]

28. Teixeira, L.; Medioni, J.; Garibal, J.; Adotevi, O.; Doucet, L.; Durey, M.D.; Ghrieb, Z.; Kiladjian, J.J.; Brizard, M.; Laheurte, C.; et al. A First-in-Human Phase I Study of INVAC-1, an Optimized Human Telomerase DNA Vaccine in Patients with Advanced Solid Tumors. Clin. Cancer Res. 2020, 26, 588-597. [CrossRef]

29. Aurisicchio, L.; Fridman, A.; Mauro, D.; Sheloditna, R.; Chiappori, A.; Bagchi, A.; Ciliberto, G. Safety, tolerability and immunogenicity of V934/V935 hTERT vaccination in cancer patients with selected solid tumors: A phase I study. J. Transl. Med. 2020, 18, 39. [CrossRef]

30. Thalmensi, J.; Pliquet, E.; Liard, C.; Escande, M.; Bestetti, T.; Julithe, M.; Kostrzak, A.; Pailhes-Jimenez, A.S.; Bourges, E.; Loustau, M.; et al. Anticancer DNA vaccine based on human telomerase reverse transcriptase generates a strong and specific T cell immune response. Oncoimmunology 2016, 5, e1083670. [CrossRef]

31. Yan, J.; Pankhong, P.; Shin, T.H.; Obeng-Adjei, N.; Morrow, M.P.; Walters, J.N.; Khan, A.S.; Sardesai, N.Y.; Weiner, D.B. Highly optimized DNA vaccine targeting human telomerase reverse transcriptase stimulates potent antitumor immunity. Cancer Immunol. Res. 2013, 1, 179-189. [CrossRef] [PubMed]

32. Fenoglio, D.; Parodi, A.; Lavieri, R.; Kalli, F.; Ferrera, F.; Tagliamacco, A.; Guastalla, A.; Lamperti, M.G.; Giacomini, M.; Filaci, G. Immunogenicity of GX301 cancer vaccine: Four (telomerase peptides) are better than one. Hum. Vaccin. Immunother. 2015, 11, 838-850. [CrossRef] [PubMed] 
33. Fridman, A.; Finnefrock, A.C.; Peruzzi, D.; Pak, I.; La Monica, N.; Bagchi, A.; Casimiro, D.R.; Ciliberto, G.; Aurisicchio, L. An efficient T-cell epitope discovery strategy using in silico prediction and the iTopia assay platform. Oncoimmunology 2012, 1, 1258-1270. [CrossRef]

34. Adotevi, O.; Mollier, K.; Neuveut, C.; Dosset, M.; Ravel, P.; Fridman, W.H.; Tartour, E.; Charneau, P.; Wain-Hobson, S.; Langlade-Demoyen, P. Targeting human telomerase reverse transcriptase with recombinant lentivector is highly effective to stimulate antitumor CD8 T-cell immunity in vivo. Blood 2010, 115, 3025-3032. [CrossRef] [PubMed]

35. Patel, K.P.; Vonderheide, R.H. Telomerase as a tumor-associated antigen for cancer immunotherapy. Cytotechnology 2004, 45, 91-99. [CrossRef] [PubMed]

36. Gross, D.A.; Graff-Dubois, S.; Opolon, P.; Cornet, S.; Alves, P.; Bennaceur-Griscelli, A.; Faure, O.; Guillaume, P.; Firat, H.; Chouaib, S.; et al. High vaccination efficiency of low-affinity epitopes in antitumor immunotherapy. J. Clin. Investig. 2004, 113, 425-433. [CrossRef]

37. Dosset, M.; Godet, Y.; Vauchy, C.; Beziaud, L.; Lone, Y.C.; Sedlik, C.; Liard, C.; Levionnois, E.; Clerc, B.; Sandoval, F.; et al. Universal cancer peptide-based therapeutic vaccine breaks tolerance against telomerase and eradicates established tumor. Clin. Cancer Res. 2012, 18, 6284-6295. [CrossRef]

38. Hernandez, J.; Garcia-Pons, F.; Lone, Y.C.; Firat, H.; Schmidt, J.D.; Langlade-Demoyen, P.; Zanetti, M. Identification of a human telomerase reverse transcriptase peptide of low affinity for HLA A2.1 that induces cytotoxic T lymphocytes and mediates lysis of tumor cells. Proc. Natl. Acad. Sci. USA 2002, 99, 12275-12280. [CrossRef]

39. Brunsvig, P.F.; Aamdal, S.; Gjertsen, M.K.; Kvalheim, G.; Markowski-Grimsrud, C.J.; Sve, I.; Dyrhaug, M.; Trachsel, S.; Moller, M.; Eriksen, J.A.; et al. Telomerase peptide vaccination: A phase I/II study in patients with non-small cell lung cancer. Cancer Immunol. Immunother. 2006, 55, 1553-1564. [CrossRef]

40. Ivanov, A.V.; Korovina, A.N.; Tunitskaya, V.L.; Kostyuk, D.A.; Rechinsky, V.O.; Kukhanova, M.K.; Kochetkov, S.N. Development of the system ensuring a high-level expression of hepatitis $C$ virus nonstructural NS5B and NS5A proteins. Protein Expr. Purif. 2006, 48, 14-23. [CrossRef]

41. Latanova, A.; Petkov, S.; Kuzmenko, Y.; Kilpelainen, A.; Ivanov, A.; Smirnova, O.; Krotova, O.; Korolev, S.; Hinkula, J.; Karpov, V.; et al. Fusion to Flaviviral Leader Peptide Targets HIV-1 Reverse Transcriptase for Secretion and Reduces Its Enzymatic Activity and Ability to Induce Oxidative Stress but Has No Major Effects on Its Immunogenic Performance in DNA-Immunized Mice. J. Immunol. Res. 2017, 2017, 7407136.

42. Bayurova, E.; Jansons, J.; Skrastina, D.; Smirnova, O.; Mezale, D.; Kostyusheva, A.; Kostyushev, D.; Petkov, S.; Podschwadt, P.; Valuev-Elliston, V. HIV-1 Reverse Transcriptase Promotes Tumor Growth and Metastasis Formation via ROS-Dependent Upregulation of Twist. Oxidative Med. Cell. Longev. 2019, 2019, 1-28. [CrossRef]

43. Giry-Laterriere, M.; Verhoeyen, E.; Salmon, P. Lentiviral vectors. Methods Mol. Biol. 2011, 737, $183-209$.

44. Zhang, J.D.; Ruschhaupt, M.; Biczok, R. ddCt Method for qRT-PCR Data Analysis. Available online: https:// www.bioconductor.org/packages/devel/bioc/vignettes/ddCt/inst/doc/rtPCR.pdf. (accessed on 27 April 2020).

45. Brezgin, S.; Kostyusheva, A.; Bayurova, E.; Gordeychuk, I.; Isaguliants, M.; Goptar, I.; Nikiforova, A.; Smirnov, V.; Volchkova, E.; Glebe, D. Replenishment of Hepatitis B Virus cccDNA Pool Is Restricted by Baseline Expression of Host Restriction Factors In Vitro. Microorganisms 2019, 7, 533. [CrossRef]

46. Watson, J.V.; Chambers, S.H.; Smith, P.J. A pragmatic approach to the analysis of DNA histograms with a definable G1 peak. Cytom. J. Int. Soc. Anal. Cytol. 1987, 8, 1-8. [CrossRef]

47. Latanova, A.; Petkov, S.; Kilpelainen, A.; Jansons, J.; Latyshev, O.; Kuzmenko, Y.; Hinkula, J.; Abakumov, M.; Valuev-Elliston, V.; Gomelsky, M. Codon optimization and improved delivery/immunization regimen enhance the immune response against wild-type and drug-resistant hiv-1 reverse transcriptase, preserving its th2-polarity. Sci. Rep. 2018, 8, 8078. [CrossRef]

48. Petkov, S.; Starodubova, E.; Latanova, A.; Kilpelainen, A.; Latyshev, O.; Svirskis, S.; Wahren, B.; Chiodi, F.; Gordeychuk, I.; Isaguliants, M. DNA immunization site determines the level of gene expression and the magnitude, but not the type of the induced immune response. PLOS ONE 2018, 13, e0197902. [CrossRef]

49. Abolins, A.; Vanags, A.; Trofimovics, G.; Miklasevics, E.; Gardovskis, J.; Strumfa, I. Molecular subtype shift in breast cancer upon trastuzumab treatment: A case report. Pol. J. Pathol. 2011, 62, 65-68.

50. Elston, C.W.; Ellis, I.O. Pathological prognostic factors in breast cancer. I. The value of histological grade in breast cancer: Experience from a large study with long-term follow-up. Histopathology 1991, 19, 403-410. [CrossRef] 
51. Zvereva, M.I.; Shcherbakova, D.M.; Dontsova, O.A. Telomerase: Structure, functions, and activity regulation. Biochemistry (Mosc) 2010, 75, 1563-1583. [CrossRef]

52. Rubtsova, M.P.; Vasilkova, D.P.; Malyavko, A.N.; Naraikina, Y.V.; Zvereva, M.I.; Dontsova, O.A. Telomere lengthening and other functions of telomerase. Acta Nat. 2012, 4, 44-61. [CrossRef]

53. Saitou, N.; Nei, M. The neighbor-joining method: $A$ new method for reconstructing phylogenetic trees. Mol. Biol. Evol. 1987, 4, 406-425.

54. Nei, M.; Kumar, S. Molecular Evolution and Phylogenetics; Oxford University Press: Oxford, UK, 2000.

55. Kumar, S.; Stecher, G.; Tamura, K. MEGA7: Molecular evolutionary genetics analysis version 7.0 for bigger datasets. Mol. Biol. Evol. 2016, 33, 1870-1874. [CrossRef]

56. Huang, Y.; Sun, L.; Liu, N.; Wei, Q.; Jiang, L.; Tong, X.; Ye, X. Polo-like Kinase 1 (Plk1) Up-regulates Telomerase Activity by Affecting Human Telomerase Reverse Transcriptase (hTERT) Stability. J. Biol. Chem. 2015, 290, 18865-18873. [CrossRef]

57. Kim, J.H.; Park, S.M.; Kang, M.R.; Oh, S.Y.; Lee, T.H.; Muller, M.T.; Chung, I.K. Ubiquitin ligase MKRN1 modulates telomere length homeostasis through a proteolysis of hTERT. Genes Dev. 2005, 19, 776-781. [CrossRef]

58. Jung, H.Y.; Wang, X.; Jun, S.; Park, J.I. Dyrk2-associated EDD-DDB1-VprBP E3 ligase inhibits telomerase by TERT degradation. J. Biol. Chem. 2013, 288, 7252-7262. [CrossRef]

59. Georgoulis, A.; Vorgias, C.E.; Chrousos, G.P.; Rogakou, E.P. Genome Instability and gammaH2AX. Int. J. Mol. Sci. 2017, 18, 1979. [CrossRef]

60. Dai, C.; Sun, F.; Zhu, C.; Hu, X. Tumor environmental factors glucose deprivation and lactic acidosis induce mitotic chromosomal instability-an implication in aneuploid human tumors. PLoS ONE 2013, 8, e63054. [CrossRef]

61. Matouk, I.J.; Mezan, S.; Mizrahi, A.; Ohana, P.; Abu-Lail, R.; Fellig, Y.; Degroot, N.; Galun, E.; Hochberg, A. The oncofetal H19 RNA connection: Hypoxia, p53 and cancer. Biochim. Biophys. Acta 2010, 1803, 443-451. [CrossRef]

62. Bakhoum, S.F.; Ngo, B.; Laughney, A.M.; Cavallo, J.A.; Murphy, C.J.; Ly, P.; Shah, P.; Sriram, R.K.; Watkins, T.B.K.; Taunk, N.K.; et al. Chromosomal instability drives metastasis through a cytosolic DNA response. Nature 2018, 553, 467-472. [CrossRef]

63. Ribeyre, C.; Shore, D. Regulation of telomere addition at DNA double-strand breaks. Chromosoma 2013, 122, 159-173. [CrossRef]

64. Yuan, X.; Larsson, C.; Xu, D. Mechanisms underlying the activation of TERT transcription and telomerase activity in human cancer: Old actors and new players. Oncogene 2019, 38, 6172-6183. [CrossRef] [PubMed]

65. Baklaushev, V.P.; Kilpelainen, A.; Petkov, S.; Abakumov, M.A.; Grinenko, N.F.; Yusubalieva, G.M.; Latanova, A.A.; Gubskiy, I.L.; Zabozlaev, F.G.; Starodubova, E.S.; et al. Luciferase Expression Allows Bioluminescence Imaging But Imposes Limitations on the Orthotopic Mouse (4T1) Model of Breast Cancer. Sci. Rep. 2017, 7, 7715. [CrossRef] [PubMed]

66. Hadrup, S.; Donia, M.; Thor Straten, P. Effector CD4 and CD8 T cells and their role in the tumor microenvironment. Cancer Microenviron 2013, 6, 123-133. [CrossRef] [PubMed]

67. Impellizeri, J.A.; Gavazza, A.; Greissworth, E.; Crispo, A.; Montella, M.; Ciliberto, G.; Lubas, G.; Aurisicchio, L. Tel-eVax: A genetic vaccine targeting telomerase for treatment of canine lymphoma. J. Transl. Med. 2018, 16, 349. [CrossRef] [PubMed]

68. Lue, N.F.; Lin, Y.C.; Mian, I.S. A conserved telomerase motif within the catalytic domain of telomerase reverse transcriptase is specifically required for repeat addition processivity. Mol. Cell Biol. 2003, 23, 8440-8449. [CrossRef]

69. Aznar, M.A.; Tinari, N.; Rullan, A.J.; Sanchez-Paulete, A.R.; Rodriguez-Ruiz, M.E.; Melero, I. Intratumoral Delivery of Immunotherapy-Act Locally, Think Globally. J. Immunol. 2017, 198, 31-39. [CrossRef]

70. Hidema, S.; Fukuda, T.; Date, S.; Tokitake, Y.; Matsui, Y.; Sasaki, H.; Nishimori, K. Transgenic expression of Telomerase reverse transcriptase (Tert) improves cell proliferation of primary cells and enhances reprogramming efficiency into the induced pluripotent stem cell. Biosci. Biotechnol. Biochem. 2016, 80, 1925-1933. [CrossRef]

71. Takai, H.; Smogorzewska, A.; de Lange, T. DNA damage foci at dysfunctional telomeres. Curr. Biol. 2003, 13, 1549-1556. [CrossRef] 
72. De Lange, T. Shelterin: The protein complex that shapes and safeguards human telomeres. Genes Dev. 2005, 19, 2100-2110. [CrossRef]

73. O'Connor, C.M.; Lai, C.K.; Collins, K. Two purified domains of telomerase reverse transcriptase reconstitute sequence-specific interactions with RNA. J. Biol. Chem. 2005, 280, 17533-17539. [CrossRef]

74. Brown, A.F.; Podlevsky, J.D.; Qi, X.; Chen, Y.; Xie, M.; Chen, J.J.-L. A self-regulating template in human telomerase. Proc. Natl. Acad. Sci. USA 2014, 111, 11311-11316. [CrossRef] [PubMed]

75. Smith, E.M.; Pendlebury, D.F.; Nandakumar, J. Structural biology of telomeres and telomerase. Cell Mol. Life Sci. 2020, 77, 61-79. [CrossRef] [PubMed]

76. Segal-Bendirdjian, E.; Geli, V. Non-canonical Roles of Telomerase: Unraveling the Imbroglio. Front. Cell Dev. Biol. 2019, 7, 332. [CrossRef] [PubMed]

77. Park, J.-I.; Venteicher, A.S.; Hong, J.Y.; Choi, J.; Jun, S.; Shkreli, M.; Chang, W.; Meng, Z.; Cheung, P.; Ji, H. Telomerase modulates Wnt signalling by association with target gene chromatin. Nature 2009, 460, 66-72. [CrossRef]

78. Shkreli, M.; Sarin, K.Y.; Pech, M.F.; Papeta, N.; Chang, W.; Brockman, S.A.; Cheung, P.; Lee, E.; Kuhnert, F.; Olson, J.L. Reversible cell-cycle entry in adult kidney podocytes through regulated control of telomerase and Wnt signaling. Nat. Med. 2012, 18, 111. [CrossRef]

79. Diala, I.; Wagner, N.; Magdinier, F.; Shkreli, M.; Sirakov, M.; Bauwens, S.; Schluth-Bolard, C.; Simonet, T.; Renault, V.M.; Ye, J. Telomere protection and TRF2 expression are enhanced by the canonical Wnt signalling pathway. EMBO Rep. 2013, 14, 356-363. [CrossRef]

80. Ibata, M.; Takahashi, T.; Shimizu, T.; Inoue, Y.; Maeda, S.; Tashiro-Yamaji, J.; Okada, M.; Ueda, K.; Kubota, T.; Yoshida, R. Spontaneous rejection of intradermally transplanted non-engineered tumor cells by neutrophils and macrophages from syngeneic strains of mice. Microbiol. Immunol. 2011, 55, 726-735.

81. Musiani, P.; Allione, A.; Modica, A.; Lollini, P.L.; Giovarelli, M.; Cavallo, F.; Belardelli, F.; Forni, G.; Modesti, A. Role of neutrophils and lymphocytes in inhibition of a mouse mammary adenocarcinoma engineered to release IL-2, IL-4, IL-7, IL-10, IFN-alpha, IFN-gamma, and TNF-alpha. Lab. Investig. J. Tech. Methods Pathol. 1996, 74, 146-157.

82. Hoo, W.S.; Lundeen, K.A.; Kohrumel, J.R.; Pham, N.-L.; Brostoff, S.W.; Bartholomew, R.M.; Carlo, D.J. Tumor cell surface expression of granulocyte-macrophage colony-stimulating factor elicits antitumor immunity and protects from tumor challenge in the P815 mouse mastocytoma tumor model. J. Immunol. 1999, 162, $7343-7349$

83. Ibe, S.; Qin, Z.; Schuler, T.; Preiss, S.; Blankenstein, T. Tumor rejection by disturbing tumor stroma cell interactions. J. Exp. Med. 2001, 194, 1549-1559. [CrossRef]

84. Tsung, K.; Dolan, J.P.; Tsung, Y.L.; Norton, J.A. Macrophages as effector cells in interleukin 12-induced T cell-dependent tumor rejection. Cancer Res. 2002, 62, 5069-5075. [PubMed]

85. Inoue, Y.; Tashiro-Yamaji, J.; Hayashi, M.; Kiyonari, H.; Shimizu, T.; Ibata, M.; Yamana, H.; Kubota, T.; Tanigawa, N.; Yoshida, R. Transgene number-dependent, gene expression rate-independent rejection of Dd-, Kd-, or DdKd-transgened mouse skin or tumor cells from C57BL/6 (DbKb) mice. Microbiol. Immunol. 2011, 55, 446-453. [CrossRef] [PubMed]

86. Briesemeister, D.; Sommermeyer, D.; Loddenkemper, C.; Loew, R.; Uckert, W.; Blankenstein, T.; Kammertoens, T. Tumor rejection by local interferon gamma induction in established tumors is associated with blood vessel destruction and necrosis. Int. J. Cancer 2011, 128, 371-378. [CrossRef] [PubMed]

87. Guerin, M.V.; Regnier, F.; Feuillet, V.; Vimeux, L.; Weiss, J.M.; Bismuth, G.; Altan-Bonnet, G.; Guilbert, T.; Thoreau, M.; Finisguerra, V. TGF $\beta$ blocks IFN $\alpha / \beta$ release and tumor rejection in spontaneous mammary tumors. Nat. Commun. 2019, 10,1-12. [CrossRef] [PubMed]

88. Dunn, G.P.; Bruce, A.T.; Sheehan, K.C.; Shankaran, V.; Uppaluri, R.; Bui, J.D.; Diamond, M.S.; Koebel, C.M.; Arthur, C.; White, J.M. A critical function for type I interferons in cancer immunoediting. Nat. Immunol. 2005, 6, 722-729. [CrossRef] [PubMed]

89. Diamond, M.S.; Kinder, M.; Matsushita, H.; Mashayekhi, M.; Dunn, G.P.; Archambault, J.M.; Lee, H.; Arthur, C.D.; White, J.M.; Kalinke, U. Type I interferon is selectively required by dendritic cells for immune rejection of tumors. J. Exp. Med. 2011, 208, 1989-2003. [CrossRef]

90. Paludan, S.R.; Bowie, A.G. Immune sensing of DNA. Immunity 2013, 38, 870-880. [CrossRef]

91. Tatematsu, M.; Funami, K.; Seya, T.; Matsumoto, M. Extracellular RNA Sensing by Pattern Recognition Receptors. J. Innate Immun. 2018, 10, 398-406. [CrossRef] 
92. Corrales, L.; Glickman, L.H.; McWhirter, S.M.; Kanne, D.B.; Sivick, K.E.; Katibah, G.E.; Woo, S.-R.; Lemmens, E.; Banda, T.; Leong, J.J. Direct activation of STING in the tumor microenvironment leads to potent and systemic tumor regression and immunity. Cell Rep. 2015, 11, 1018-1030. [CrossRef]

93. Bek, S.; Stritzke, F.; Wintges, A.; Nedelko, T.; Bohmer, D.F.R.; Fischer, J.C.; Haas, T.; Poeck, H.; Heidegger, S. Targeting intrinsic RIG-I signaling turns melanoma cells into type I interferon-releasing cellular antitumor vaccines. Oncoimmunology 2019, 8, e1570779. [CrossRef]

94. Ruzicka, M.; Koenig, L.M.; Formisano, S.; Boehmer, D.F.; Vick, B.; Heuer, E.-M.; Meinl, H.; Kocheise, L.; Zeitlhöfler, M.; Ahlfeld, J. RIG-I-based immunotherapy enhances survival in preclinical AML models and sensitizes AML cells to checkpoint blockade. Leukemia 2020, 34, 1017-1026. [CrossRef] [PubMed]

95. Rigby, R.E.; Webb, L.M.; Mackenzie, K.J.; Li, Y.; Leitch, A.; Reijns, M.A.; Lundie, R.J.; Revuelta, A.; Davidson, D.J.; Diebold, S.; et al. RNA: DNA hybrids are a novel molecular pattern sensed by TLR9. EMBO J. 2014, 33, 542-558. [CrossRef] [PubMed]

96. Chen, Y.-A.; Shen, Y.-L.; Hsia, H.-Y.; Tiang, Y.-P.; Sung, T.-L.; Chen, L.-Y. Extrachromosomal telomere repeat DNA is linked to ALT development via cGAS-STING DNA sensing pathway. Nat. Struct. Mol. Biol. 2017, 24, 1124. [CrossRef] [PubMed]

97. Wang, Z.; Deng, Z.; Dahmane, N.; Tsai, K.; Wang, P.; Williams, D.R.; Kossenkov, A.V.; Showe, L.C.; Zhang, R.; Huang, Q. Telomeric repeat-containing RNA (TERRA) constitutes a nucleoprotein component of extracellular inflammatory exosomes. Proc. Natl. Acad. Sci. USA 2015, 112, E6293-E6300. [CrossRef] [PubMed]

98. Wang, Z.; Lieberman, P.M. The crosstalk of telomere dysfunction and inflammation through cell-free TERRA containing exosomes. RNA Biol. 2016, 13, 690-695. [CrossRef]

99. Toubiana, S.; Selig, S. DNA: RNA hybrids at telomeres-When it is better to be out of the (R) loop. FEBS J. 2018, 285, 2552-2566. [CrossRef]

100. Matsuo, M.; Wada, H.; Honda, S.; Tawara, I.; Uenaka, A.; Kanematsu, T.; Nakayama, E. Expression of multiple unique rejection antigens on murine leukemia BALB/c RLmale symbol1 and the role of dominant Akt antigen for tumor escape. J. Immunol. 1999, 162, 6420-6425.

101. Bremnes, R.M.; Al-Shibli, K.; Donnem, T.; Sirera, R.; Al-Saad, S.; Andersen, S.; Stenvold, H.; Camps, C.; Busund, L.T. The role of tumor-infiltrating immune cells and chronic inflammation at the tumor site on cancer development, progression, and prognosis: Emphasis on non-small cell lung cancer. J. Thorac. Oncol. 2011, 6, 824-833. [CrossRef]

102. Marshall, E.A.; Ng, K.W.; Kung, S.H.; Conway, E.M.; Martinez, V.D.; Halvorsen, E.C.; Rowbotham, D.A.; Vucic, E.A.; Plumb, A.W.; Becker-Santos, D.D.; et al. Emerging roles of T helper 17 and regulatory T cells in lung cancer progression and metastasis. Mol. Cancer 2016, 15, 67. [CrossRef]

103. Hobernik, D.; Bros, M. DNA Vaccines-How Far From Clinical Use? Int. J. Mol. Sci. 2018, 19, 3605. [CrossRef]

104. Jorritsma, S.; Gowans, E.; Grubor-Bauk, B.; Wijesundara, D. Delivery methods to increase cellular uptake and immunogenicity of DNA vaccines. Vaccine 2016, 34, 5488-5494. [CrossRef] [PubMed]

105. Thalmensi, J.; Pliquet, E.; Liard, C.; Chamel, G.; Kreuz, C.; Bestetti, T.; Escande, M.; Kostrzak, A.; Pailhes-Jimenez, A.S.; Bourges, E.; et al. A DNA telomerase vaccine for canine cancer immunotherapy. Oncotarget 2019, 10, 3361-3372. [CrossRef] [PubMed]

106. Choi, J.; Southworth, L.K.; Sarin, K.Y.; Venteicher, A.S.; Ma, W.; Chang, W.; Cheung, P.; Jun, S.; Artandi, M.K.; Shah, N.; et al. TERT promotes epithelial proliferation through transcriptional control of a Myc- and Wnt-related developmental program. PLoS Genet. 2008, 4, e10. [CrossRef] [PubMed]

107. Li, Y.; Tergaonkar, V. Noncanonical functions of telomerase: Implications in telomerase-targeted cancer therapies. Cancer Res. 2014, 74, 1639-1644. [CrossRef] [PubMed]

108. Wu, X.Q.; Huang, C.; He, X.; Tian, Y.Y.; Zhou, D.X.; He, Y.; Liu, X.H.; Li, J. Feedback regulation of telomerase reverse transcriptase: New insight into the evolving field of telomerase in cancer. Cell Signal. 2013, 25, 2462-2468. [CrossRef]

109. Ding, D.; Xi, P.; Zhou, J.; Wang, M.; Cong, Y.S. Human telomerase reverse transcriptase regulates MMP expression independently of telomerase activity via NF-kappaB-dependent transcription. FASEB J. 2013, 27, 4375-4383. [CrossRef] 
110. Ghosh, A.; Saginc, G.; Leow, S.C.; Khattar, E.; Shin, E.M.; Yan, T.D.; Wong, M.; Zhang, Z.; Li, G.; Sung, W.K.; et al. Telomerase directly regulates NF-kappaB-dependent transcription. Nat. Cell Biol. 2012, 14, 1270-1281. [CrossRef]

111. Koh, C.M.; Khattar, E.; Leow, S.C.; Liu, C.Y.; Muller, J.; Ang, W.X.; Li, Y.; Franzoso, G.; Li, S.; Guccione, E.; et al. Telomerase regulates MYC-driven oncogenesis independent of its reverse transcriptase activity. J. Clin. Investig. 2015, 125, 2109-2122. [CrossRef]

(C) 2020 by the authors. Licensee MDPI, Basel, Switzerland. This article is an open access article distributed under the terms and conditions of the Creative Commons Attribution (CC BY) license (http://creativecommons.org/licenses/by/4.0/). 